\title{
Biochemical Markers and Enzyme Assays for Herbicide Mode of Action and Resistance Studies
}

\author{
Franck E. Dayan, Daniel K. Owens, Natalia Corniani, Ferdinando Marcos Lima Silva, \\ Susan B. Watson, J'Lynn Howell, and Dale L. Shaner* \\ Key words: Acetolactate synthase, acetyl-CoA carboxylase, cellulose biosynthesis, deoxyxylulose-5- \\ phosphate synthase, dihydropteroate synthase, herbicide resistance, mitosis, mode of action, molecular probe, \\ photosystem I, photosystem II, $p$-hydroxyphenylpyruvate dioxygenase, phytoene desaturase, protoporphyr- \\ inogen oxidase, serine/threonine protein phosphatases, target site, very long chain fatty acid elongases.
}

Herbicides inhibit biochemical and physiological processes or both with lethal consequences. The target sites of these small molecules are usually enzymes involved in primary metabolic pathways or proteins carrying out essential physiological functions. Herbicides tend to be highly specific for their respective target sites and have served as tools to study these physiological and biochemical processes in plants (Dayan et al. 2010b).

A few reviews on the modes of action by herbicides have been published in recent years (Duke and Dayan 2011; Fedtke and Duke 2005), but the last comprehensive book on that topic was nearly 20 yrs old (Devine et al. 1993). Furthermore, no compendium of herbicide target-site assays has been available since the publication of the seminal book Target Assays for Modern Herbicides and Related Phytotoxic Compounds (Böger and Sandmann 1993), although new modes of action have been characterized since then (e.g., inhibition of $p$ hydroxyphenylpyruvate dioxygenase, very long fatty acid elongases, cellulose biosynthesis, serine/threonine protein phosphatases, and deoxyxylulose-5phosphate synthase). The aim of this chapter is to describe assay protocols for all current herbicide targets. Because of space constraints, this update will present the most common methods and, whenever applicable, will describe protocols that have been

\footnotetext{
DOI: $10.1614 / W S-D-13-00063.1$

* First, second, fifth, and sixth authors: Plant Physiologist, Plant Physiologist, Support Chemist, and Biological Science Laboratory Technician, Natural Products Utilization Research Unit, Agricultural Research Service, U.S. Department of Agriculture, University, MS 38677; third and fourth authors: Plant Physiologist and Agronomist, Faculty of Agronomic Sciences, São Paulo State University, Botucatu, Brazil 18610; seventh author: Plant Physiologist, Water Management Research Unit, Agricultural Research Service, U.S. Department of Agriculture, Fort Collins, CO 80526. Corresponding author's E-mail: franck.dayan@ars.usda.gov
}

used successfully in our laboratories. Readers interested in the specifics of each assay are referred to the literature for other examples that may be more suitable for their needs. However, we have taken the opportunity to mention key aspects that should be of help in successfully performing each assay. Additionally, the effects of herbicides can sometimes be detected before the onset of the visual symptoms by monitoring the accumulation of intermediates or measuring the integrity of the physiological processes they target. These will also be mentioned, where appropriate, as a means of rapid identification of certain herbicide modes of action (Table 1).

The sections in this chapter are organized according to the herbicide classification scheme established by the Herbicide Resistance Action Committee (HRAC) and adopted by the Weed Science Society of America as described in the Herbicide Handbook (Senseman 2007). That classification may need revision because the modes of action of several herbicides are either new or better understood than when the handbook was published. Those issues will be addressed as they arise in the text.

\section{General Considerations}

Equipment. Unless specifically indicated in the text, the following instruments were used for these experiments:

1. High-performance liquid chromatography (HPLC; Waters Corporation, Milford, MA) consisting of a model 600E pump, a model 717 autosampler, a Millennium 2010 controller, a model 996 photodiode detector, a model 2475 multi- $\lambda$-fluorescence detector, and the Empower software;

2. UV3101 PC spectrophotometer (Shimadzu Scientific Instruments, Columbia, MD);

3. RF-5301 PC spectrofluorophotometer (Shimadzu); 


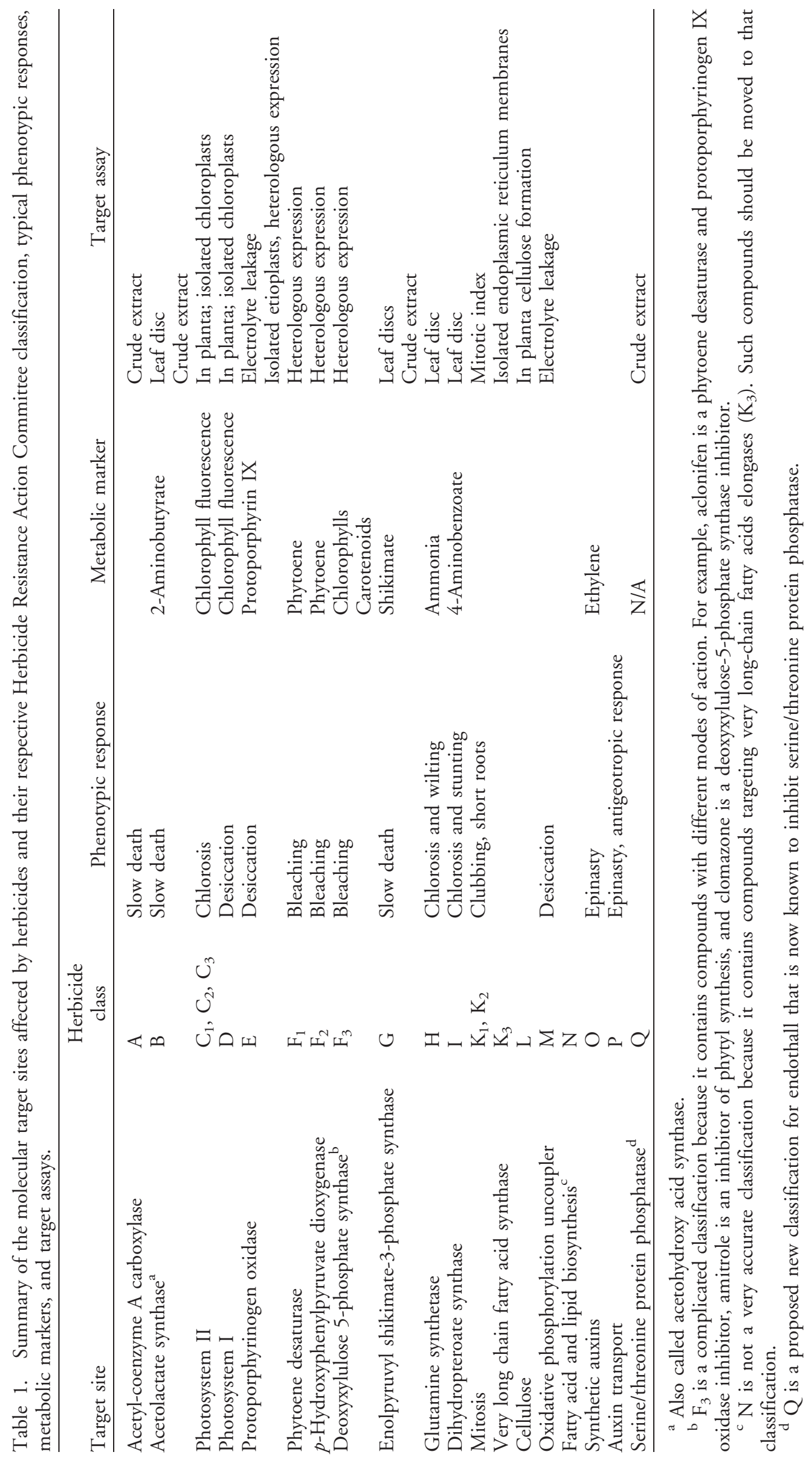

24 - Weed Science 63, Special Issue 2015 
4. Sorvall RC6 Plus centrifuge with SS34 rotor (Thermo Fisher Scientific Inc, Milford, MA);

5. Polytron PT-3100 homogenizer (Kinematica Inc., Bohemia, NY);

6. Model CU-36L5 incubator (Percival Scientific, Inc., Perry, IA);

7. Model OS5-FL pulse-modulated fluorometer (Opti-Science, Hudson, NH);

8. Model DW1 computer-controlled oxygen probe (Hansatech, PP Systems, Amesbury, MA) with a fiber-optic light source;

9. Tri-Carb 2100 scintillation counter (PerkinElmer, Waltham, MA);

10. PowerWave XS microplate reader (Bio-Tek Instruments, Inc., Winooski, VT);

11. French press (Thermo Spectronics Instrument from Thermo Fisher);

12. Electrical conductivity meter (model 1056, Amber Science Inc., Eugene, OR) equipped with a model 858 conductivity macro flow cell;

13. ThermoMixer-R (Brinkmann Instruments, Inc., Westbury, NY).

Buffers. Buffers are an important component of every assay, and readers are encouraged to learn more about how these molecules work. Calbiochem (Merck KGaA, Darmstadt, Germany) has an excellent, free, downloadable guidebook (Mohan 2003). Buffers are aqueous solutions that prevent changes in $\mathrm{pH}$, even when a small amount of strong acid or base is added to them. The optimum buffer capacity of a molecule is near its negative logarithm of the equilibrium constant for association $\left(\mathrm{p} K_{\mathrm{a}}\right)$, which allows for the selection of a buffer to maintain the optimum $\mathrm{pH}$ for the purpose of the experiment. However, published protocols generally provide little information regarding buffers, other than the chemical name or acronym and the concentration of the solution. Therefore, the following useful practical information on buffers is provided.

Buffer Tip 1. Prepare buffers in $\times 10$ concentrations and store in $50-\mathrm{ml}$ aliquots in a freezer until use. We use 50-ml BD Falcon tubes (BD Biosciences, San Jose, CA).

It is critical to consider under what condition the buffer will be used because the $\mathrm{pH}$ of a solution can be affected by temperature or by enzyme reactions. For example, if an extraction is performed at $4 \mathrm{C}$, it is important for the $\mathrm{pH}$ of the extraction buffer to be adjusted on ice instead of at room temperature (RT). Similarly, reactions known to generate significant amount of $\mathrm{H}^{+}$or $\mathrm{OH}^{-}$will require higher buffer concentrations to maintain the $\mathrm{pH}$.

Phosphate buffers are very common. The term phosphate buffer can describe either sodium phosphate or potassium phosphate buffers. Phosphate buffers are usually made by mixing different amounts of monobasic and dibasic stock solutions (see Table 2). For example, a 50-mM sodiumphosphate buffer of $\mathrm{pH} 6.5$ is made by mixing $68.5 \mathrm{ml}$ of $200 \mathrm{mM}$ sodium phosphate monobasic with $31.5 \mathrm{ml}$ of $200 \mathrm{mM}$ sodium phosphate dibasic and diluting with deionized water to a total volume of $400 \mathrm{ml}$. A similar principle is applied for potassium phosphate. Alternatively, a number of Web site tools and online tables can be used to simplify buffer calculations.

Although phosphate buffers are useful, their metal cations or phosphate components sometimes interfere with enzyme assays, so other buffers, such as Tris or Trizma (tris(hydroxymethyl)methylamine, pH 7.5-9.0), HEPES (4-(2-hydroxyethyl)1-piperazineethanesulfonic acid, $\mathrm{pH}$ 6.8-8.2), and MES (2-( $N$-morpholino)ethanesulfonic acid, $\mathrm{pH}$ 5.5-6.7) are often used.

Buffer Tip 2. Do not use sodium hydroxide to adjust the $\mathrm{pH}$ of the buffer if sodium interferes with an assay. Use potassium hydroxide instead; vice versa, if potassium is a problem for the assay.

Make sure the buffer selected is used within its buffer range ( $\mathrm{p} K_{\mathrm{a}} \pm 1 \mathrm{pH}$ unit as a rule of thumb). Methods should be checked carefully because it is not unusual to see published protocols using buffers at $\mathrm{pH}$ ranges outside their optimum buffer capacity.

Buffer Tip 3. Prepare Tris-HCl buffer by making up a solution of Tris-free base and adjusting its $\mathrm{pH}$ with $1 \mathrm{~N} \mathrm{HCl}$.

Ethylenediaminetetraacetic acid (EDTA) is often added to buffers because it prevents the deactivation of catalytic sites by removing traces of heavy metals known to interfere with the formation of disulfide bridges. However, EDTA interferes with the activity of enzymes with divalent metal cofactors (e.g., $\mathrm{Hg}^{2+}$ and $\left.\mathrm{Ag}^{2+}\right)$. Again, the judicious use of buffer components requires a good understanding of their functions. 
Table 2. Proportion table to obtain $100 \mathrm{ml}$ of $200 \mathrm{mM}$ sodium phosphate buffer at a specific $\mathrm{pH}^{{ }^{a}}$

\begin{tabular}{|c|c|c|c|c|c|}
\hline $\mathrm{pH}$ & $\mathrm{NaH}_{2} \mathrm{PO}_{4}$ & $\mathrm{Na}_{2} \mathrm{HPO}_{4}$ & $\mathrm{pH}$ & $\mathrm{NaH}_{2} \mathrm{PO}_{4}$ & $\mathrm{Na}_{2} \mathrm{HPO}_{4}$ \\
\hline & & & & & \\
\hline 5.7 & 93.5 & 6.5 & 6.9 & 45.0 & 55.0 \\
\hline 5.8 & 92.0 & 8.0 & 7.0 & 39.0 & 61.0 \\
\hline 5.9 & 90.0 & 10.0 & 7.1 & 33.0 & 67.0 \\
\hline 6.0 & 87.7 & 12.3 & 7.2 & 28.0 & 72.0 \\
\hline 6.1 & 85.0 & 15.0 & 7.3 & 23.0 & 77.0 \\
\hline 6.2 & 81.5 & 18.5 & 7.4 & 19.0 & 81.0 \\
\hline 6.3 & 77.5 & 22.5 & 7.5 & 16.0 & 84.0 \\
\hline 6.4 & 73.5 & 26.5 & 7.6 & 13.0 & 87.0 \\
\hline 6.5 & 68.5 & 31.5 & 7.7 & 10.5 & 89.5 \\
\hline 6.6 & 62.5 & 37.5 & 7.8 & 8.5 & 91.5 \\
\hline 6.7 & 56.5 & 43.5 & 7.9 & 7.0 & 93.0 \\
\hline 6.8 & 51.0 & 49.0 & 8.0 & 5.3 & 94.7 \\
\hline
\end{tabular}

${ }^{\text {a }}$ Prepare $500 \mathrm{ml}$ stocks of $200 \mathrm{mM}$ sodium phosphate monobasic monohydrate $\left(\mathrm{NaH}_{2} \mathrm{PO}_{4} \cdot \mathrm{H}_{2} \mathrm{O}\right)=2.75 \mathrm{~g} 100 \mathrm{ml}^{-1}$ water and $200 \mathrm{mM}$ sodium phosphate dibasic heptahydrate $\left(\mathrm{Na}_{2} \mathrm{HPO}_{4} \cdot 7 \mathrm{H}_{2} \mathrm{O}\right)=5.36 \mathrm{~g} 100 \mathrm{ml}^{-1}$ water, and mix different ratios to obtain a specific final $\mathrm{pH}$ of $200 \mathrm{mM}$ sodium phosphate buffer solution. This solution can then be diluted to lower concentrations with water, and the $\mathrm{pH}$ will remain the same.

Buffer Tip 4. Prepare $100 \mathrm{ml}$ of 500-mM EDTA stock by adding $18.6 \mathrm{~g}$ of $\mathrm{Na}_{2}$ EDTA $2 \mathrm{H}_{2} \mathrm{O}$ to $80 \mathrm{ml}$ of deionized water in a beaker on a stir plate and slowly add $1 \mathrm{~N} \mathrm{NaOH}$ a drop at a time to reach $\mathrm{pH}$ 8. When EDTA is solubilized, bring the volume to $100 \mathrm{ml}$ and store it refrigerated. It remains stable for a long time.

Finally, calibrate the $\mathrm{pH}$ meter in a range close to the $\mathrm{pH}$ of the solution being prepared. The use of color-coded, premade solutions at specific $\mathrm{pH}$ is very handy. Use the red ( $\mathrm{pH} 4$ standard) for solutions below $\mathrm{pH} 5.5$, the yellow ( $\mathrm{pH} 7$ standard) for solutions between 5.5 and 8.5 , and the blue $(\mathrm{pH}$ 10 standard) for solutions above 8.5.

Extinction Coefficients. Beer's law is commonly encountered in biochemical assays because it establishes the relationship between the absorbance of a compound and its concentration in a solution. A useful rule of thumb is that, when expressed in standard units, a 1-mM solution of a compound has an absorbance of $\varepsilon / 1,000$.

Beer's law. $A=\varepsilon C L$, where $A$ is the unitless absorbance, $\varepsilon$ is the molar extinction coefficient, $L \times \mathrm{mol}^{-1} \times \mathrm{cm}^{-1} ; C$ is the concentration, $\mathrm{mol}$ $\times \mathrm{L}^{-1}$; and $L$ is the cell length in centimeters. The simple and commonly used working form of the equation is $C=(A / \varepsilon)$.

In most modern spectrophotometers, the cell length is $1 \mathrm{~cm}$ and, therefore, does not contribute to the equation. The molar extinction coefficient is an experimentally determined constant of a specific substance at a particular wavelength, with known values often available from reference books or in the literature. It is common for extinction coefficients to be in units other than molar (millimolar or micromolar), so final calculated values are in more easily interpretable units. As shown in the phytoene desaturase section, other nonstandard units include percentage by weight or volume or grams per $100 \mathrm{ml}$.

\section{Common Protocols}

Protein Quantification. The most commonly used total-protein assay systems include direct measurement at absorbance $280 \mathrm{~nm}$ and colorimetric assays. Absorbance at $280 \mathrm{~nm}$ takes advantage of the fact that proteins have absorbance maxima at that wavelength, resulting primarily from the presence of aromatic amino acids. However, that method is subject to error because of the presence of many substances in plant extracts that absorb at $280 \mathrm{~nm}$.

Protein Tip 1. Use quartz cuvettes because plastic cuvettes interfere with readings in the ultraviolet (UV) range.

Colorimetric protein-determination methods are based on reactions between proteins and assay reagents that result in color production directly proportional to the amount of protein present in an extract. The amount of protein in the extract is calculated based on a standard curve, often produced 
using bovine serum albumin. The method of Bradford using Coomassie blue $\mathrm{G}$ is one of the most-common colorimetric protein assays (Bradford 1976).

Protein Tip 2. The Bradford system may not be compatible with all buffer components, particularly detergents and imidazole. Those interfering molecules must be removed by gel filtration, dialysis, or some other method before protein concentration can be determined accurately. In some cases, an alternate method or commercially available, specialized assays may be used to overcome this issue.

Chlorophyll Quantification. The method most often used for chlorophyll quantification is that of Arnon (Arnon 1949), which involves the homogenization of leaf tissues in acetone and centrifugation. However, we prefer the extraction method of Hiscox and Israelstam (Hiscox and Israelstam 1979) because it can be done with a smaller sample size (i.e., $5 \mathrm{mg}$ of tissue) without homogenization using dimethyl sulfoxide.

Chlorophylls extracted with dimethyl sulfoxide are stable for several more days than when they are extracted with acetone, and the analysis can be done using disposable cuvettes, whereas the Arnon method requires the use of glass or quartz cuvettes. In brief, place $5 \mathrm{mg}$ (or more) of leaf tissue in a glass tube with $2 \mathrm{ml}$ of dimethyl sulfoxide. Seal the tube, and place it in an oven at $65 \mathrm{C}$ for $2 \mathrm{~h}$. Vortex the samples every $30 \mathrm{~min}$. Transfer the dimethyl sulfoxide to clean tubes, and extract the tissue with another $1 \mathrm{ml}$ of dimethyl sulfoxide for an additional $1 \mathrm{~h}$ in the oven.

Chlorophyll Tip 1. Do not use parafilm to seal the tubes; it will melt in the oven. Instead, use the heat- and chemical-resistant Dura Seal film (PGC Scientific, Gaithersburg, MD) or tight-fitting culture tube caps.

Combine the extracts and determine the absorbance of 645 and $663 \mathrm{~nm}$ with a spectrophotometer using the equation developed by Arnon (Arnon 1949).

Carotenoid Quantification. The extraction process for carotenoids is more involved than it is for chlorophylls. Total carotenoids are extracted from
Chlorophyll Tip 2. The Arnon equation to quantify chlorophyll is as follows:

$$
\mathrm{mg}_{\text {chlorophyll }} \mathrm{L}^{-1}=\left(A_{645} \times 20.2\right)+\left(A_{663} \times 8.02\right)
$$

Make sure to dilute the extract if the absorption at $663 \mathrm{~nm}$ exceeds 0.7 units because that will be outside the linear range of the equation.

Chlorophyll Tip 3. Remember that some plants with thicker cuticle may require longer exposure to dimethyl sulfoxide for complete extraction of chlorophylls.

as little as $5 \mathrm{mg}$ of tissue, and total carotenoid concentrations are determined spectrophotometrically according to Sandmann and Böger (Sandmann and Böger 1983).

Place $5 \mathrm{mg}$ samples of fresh green tissue in $16 \times$ $100-\mathrm{mm}$ glass tubes containing $3 \mathrm{ml}$ of basic methanol $(6 \% \mathrm{KOH}$ in methanol w/v). All subsequent steps must be performed under dimgreen light. Homogenize the samples at full speed for $30 \mathrm{~s}$, and leave at RT for $15 \mathrm{~min}$. Centrifuge for 5 min at 2,000 $\times g$, and transfer the supernatant to clean, glass tubes. Extract the carotenoids by partitioning with $3 \mathrm{ml}$ of ether : petrol $(1: 9 \mathrm{v} / \mathrm{v})$. Mix the tubes vigorously, and wait for $5 \mathrm{~min}$. Add $1.5 \mathrm{ml}$ of saturated sodium chloride to the solution,

Carotenoid Tip 1. Be sure to use petrol (petroleum benzin) with a boiling point range between 90-110 C. Petrol with a higher boiling range does not work as well. The ether : petrol solution must be made immediately before use.

mix again, and centrifuge at 2,000 $\times g$ for $5 \mathrm{~min}$. Collect a 2-ml aliquot from the top organic layer, transfer to a clean tube, place the tube on a heat block set on low heat, and dry under gentle flow of nitrogen in the hood.

Carotenoid Tip 2. Do not use disposable cuvettes. They do not work because acetone reacts with the plastic.

Resuspend the carotenoids in $200 \mu$ l of acetone and quantify in quartz microcuvettes on a spectrophotometer at $445 \mathrm{~nm}$ with an extinction coefficient of $\varepsilon_{445}=2,500(\% \mathrm{w} / \mathrm{v})$. 
Carotenoid Tip 3. $\varepsilon_{445}=2,500(\% \mathrm{w} / \mathrm{v})$ means that a solution containing $1 \mathrm{~g}$ of carotenoid in $100 \mathrm{ml}$ would have an absorbance of 2,500 unit at $445 \mathrm{~nm}$. For the purpose of the Sandmann and Böger (Sandmann and Böger 1983) method, micrograms of carotenoids per grams of fresh weight $(\mathrm{FW})$ are obtained with the following equation:

$\mu \mathrm{g}_{\text {carotenoids }} \mathrm{g}_{\mathrm{FW}}^{-1}=\left[\left(A_{445} \times 0.000012\right) /\left(\mathrm{g}_{\mathrm{FW}} \times 10^{6}\right)\right]$

where $A_{445}$ is absorbance of the $3 \mathrm{ml}$ ether : petrol phase obtained at the end of the extraction. Make sure to convert the milligrams of tissue measured into the grams of FW for the equation.

Electrolyte Leakage. Cultivate plants in a growth chamber with a 16/8 h light/dark cycle for 7 to $10 \mathrm{~d}$ until cotyledons are fully expanded. Cucumber (Cucumis sativus L.) seedlings work well for screening most herbicidal compounds. Place 25 discs with 4-mm cotyledon on top of $5 \mathrm{ml}$ of bathing medium (2\% sucrose in $1 \mathrm{mM}$ MES] buffer that has been adjusted to $\mathrm{pH} 6.5$ at RT in $60 \times 15$ $\mathrm{mm}$ disposable petri dishes. Prepare test compounds in $\times 100$ stocks and add, as $50-\mu$ l aliquots, to the bathing medium. Expose the control samples to the same volume of solvent (acetone or methanol) in the absence of test compound. Incubate the plates in darkness for $16 \mathrm{~h}$ before exposure to high light intensity.

Leakage Tip 1. Expose the plants to high light intensity without heating the bathing medium for optimum detection of modes of action that might be light-dependent, such as the effect of compounds inhibiting protoporphyrinogen oxidase because the conductivity meter is sensitive to temperature change. We expose our discs to $1,000 \mu \mathrm{mol} \mathrm{m} \mathrm{s}^{-1}$ ) photosynthetically active radiation (PAR) in an incubator (model E-30-B, Percival Scientific).

Conductivity of the bathing medium can be measured with a conductivity meter at many time intervals during the periods of dark and light incubation(Figure 1, left panel) (Duke and Kenyon 1993). Alternatively, the experiment can be simplified by making measurements at only three specific time points, namely, at the beginning of the dark incubation period, after $16 \mathrm{~h}$ (overnight) dark

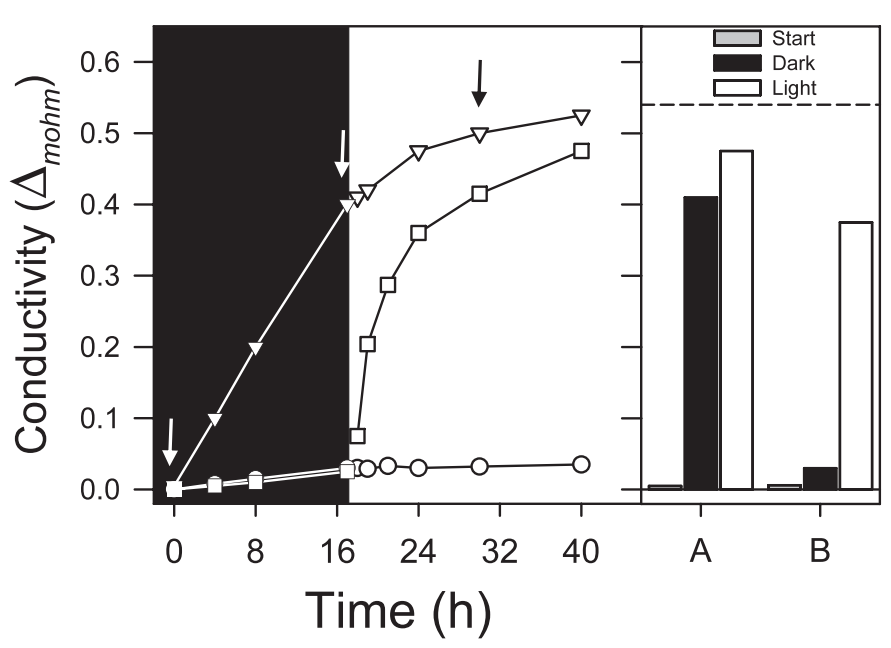

Figure 1. Left panel shows a time course experiment illustrating the light-independent $(\nabla)$ and light-dependent $(\square)$ loss of membrane integrity, compared to solvent control with no inhibitor $(\bigcirc)$. Arrows represents the 3 time measurements used in the simplified assay shown in panel B. The dotted line represents maximum change in conductivity (obtained after boiling the discs) from Dayan and Watson (2011).

incubation, and after $8 \mathrm{~h}$ of light exposure (Figure 1, right panel) (Dayan and Watson 2011).

Leakage Tip 2. Measure maximum conductivity by boiling three samples of each treatment for $20 \mathrm{~min}$. That value serves as an upper limit to gauge how much leakage is observed relative to total possible leakage.

Compounds with light-independent modes of action will cause leakage (increase in conductivity) during the period of dark incubation, whereas those with light-dependent modes of action will only cause leakage when the samples are exposed to light.

\section{Acetyl-Coenzyme A Carboxylase: Molecular Target of Herbicide Class A (WSSA Group 1)}

Acetyl-coenzyme A (acetyl-CoA) carboxylase (ACCase) catalyzes the adenosine triphosphate (ATP)-dependent carboxylation of acetyl-CoA to form malonyl-CoA, the first committed step in fatty acid biosynthesis (Figure 2A). There are two forms of ACCase: a prokaryote form consisting of three protein components-biotin carboxylase, carboxyltransferase, and biotin carboxylase carrier protein (Saski and Nagano 2004)_and a eukaryote form consisting of three functional domains on a single polypeptide (Saski and Nagano 2004). Most higher plants have the prokaryotic ACCase in the plastids, which are responsible for fatty acid biosynthesis, 

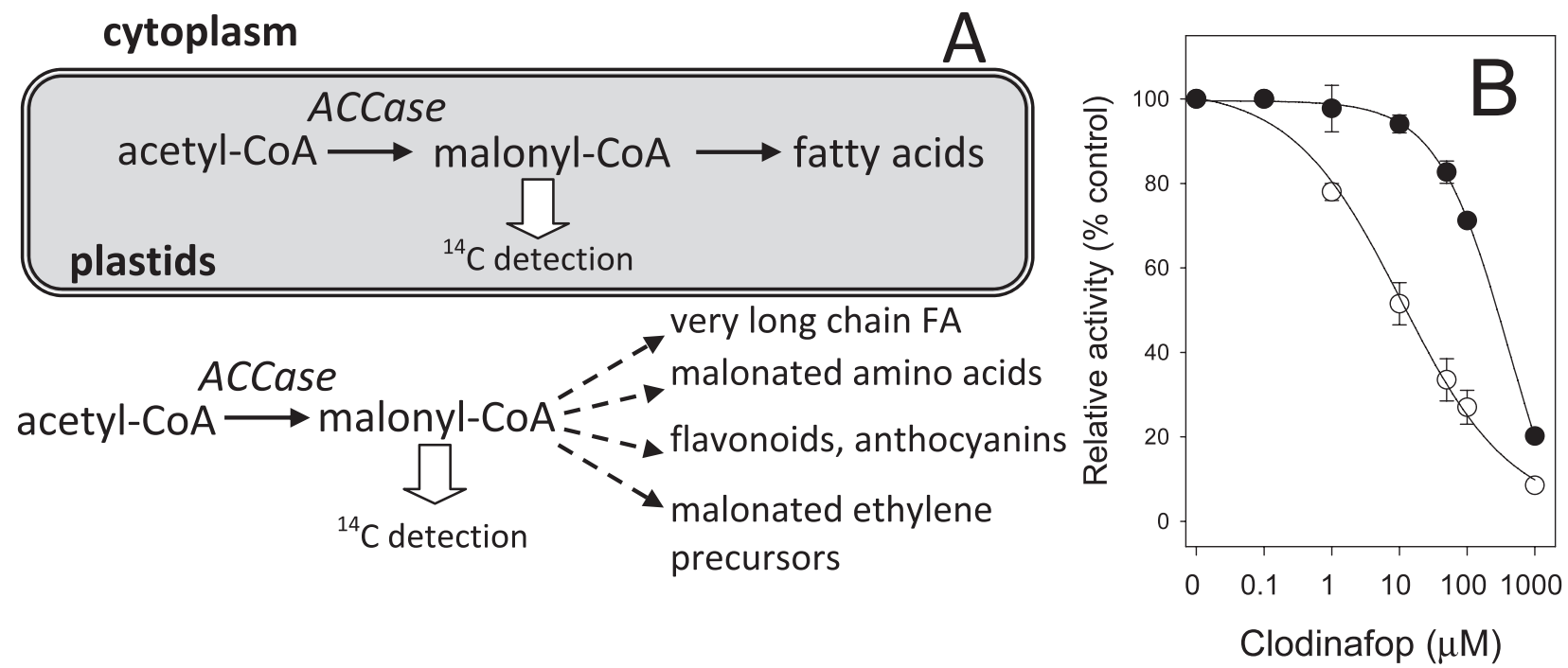

Figure 2. A) Acetyl-CoA carboxylase location and activity in Poaceae. B) Dose-response curve of clodinafop on ACCase activity from wild-type (○) and resistant (O) populations of Alopecurus myosuroides (data from Délye et al. 2003).

and the eukaryotic ACCase in the cytoplasm. However, members of the Poaceae (grasses) only have the eukaryotic form of ACCase in both the plastids and the cytoplasm (Saski and Nagano 2004). The eukaryotic ACCase, but not the prokaryotic ACCase, is inhibited by the cyclohexanediones and the aryloxyphenoxy propionates. Hence, the selectivity of those graminicides is due to the specific inhibition of the eukaryotic form of ACCase. The key component in measuring ACCase activity is the incorporation of ${ }^{14} \mathrm{C}$ from $\mathrm{CO}_{2}$ into a component that is stable in acid and heat. This enzyme assay can only be conducted in laboratories that have a license to use radiolabeled material.

ACCase Tip 1. Conduct this assay only within a fume hood or some type of protecting apparatus because the assay releases radioactive $\mathrm{CO}_{2}$, and the protective equipment will prevent the radioactive carbon from contaminating the immediate atmosphere.

Enzyme Extraction. The enzyme extraction procedure is adapted from Seefeldt et al. (1996) and Yu et al. (2003). Collect $3 \mathrm{~g}$ of plant material from the most actively growing shoot tissue, which has the highest level of ACCase. Conduct the protein extraction in a cold chamber at $3 \mathrm{C}$, or keep everything on ice during the extraction. Grind the tissue in liquid nitrogen and sterile-washed sea sand in a mortar and pestle with $5 \mathrm{ml}$ extraction buffer (100 mM Tris [pH 8], $1 \mathrm{mM}$ EDTA, 10\% glycerol, $2 \mathrm{mM}$ L-ascorbic acid, $1 \mathrm{mM}$ phenylmethanesulfonyl fluoride [PMSF], $20 \mathrm{mM}$ dithiothreitol [DTT], 0.5\% polyvinylpyrrolidone 40 [PVP40], $0.5 \%$ polyvinylpolypyrolidone [PVPP]). Filter the extract through four layers of cheesecloth into a centrifuge tube. Rinse the mortar and pestle with an additional $5 \mathrm{ml}$ of extraction buffer, and add to the original extract. Centrifuge the solution at 25,000 $\times \mathrm{g}$ for $15 \mathrm{~min}$, and discard the pellet. Add saturated ammonium sulfate drop-wise to the supernatant to a final concentration of $66 \%$ of the original supernatant volume. Stir the solution for $1 \mathrm{~h}$ on ice to allow the protein to precipitate.

ACCase Tip 2. Make saturated ammonium sulfate $(100 \%)$ by adding $761 \mathrm{~g}$ of $\left(\mathrm{NH}_{4}\right)_{2} \mathrm{SO}_{4}$ to $1,000 \mathrm{ml}$ distilled water $\left(\mathrm{dH}_{2} \mathrm{O}\right)$ at $25 \mathrm{C}$. Adjust $\mathrm{pH}$ to 6.8 to 7.0 with 5 or $10 \mathrm{M} \mathrm{NaOH}$.

Centrifuge the solution at $25,000 \times g$ for $30 \mathrm{~min}$. Discard the supernatant, and dissolve the pellet in $2.7 \mathrm{ml}$ elution buffer $(50 \mathrm{mM}$ Tricine $[\mathrm{pH}$ 8.0], $50 \mathrm{mM} \mathrm{KCl}$, and $2.5 \mathrm{mM} \mathrm{MgCl}_{2}$ ). Pipette the solution onto an equilibrated Sephadex G-25 column (GE Healthcare Life Sciences, Piscataway, $\mathrm{NJ}$ ), and elute with $2.8 \mathrm{ml}$ elution buffer. Samples can be stored in a final $25 \%$ glycerol concentration at $-80 \mathrm{C}$ until the assay is conducted.

ACCase Tip 3. Extract young tissue, which is critically important to maximize the amount of ACCase isolated. In grasses, that will either be from the base of the plant before tillering or from young tillers. 
Table 3. Solutions and reagents for extraction and enzyme assays to measure acetyl-coenzyme A carboxylase activity.

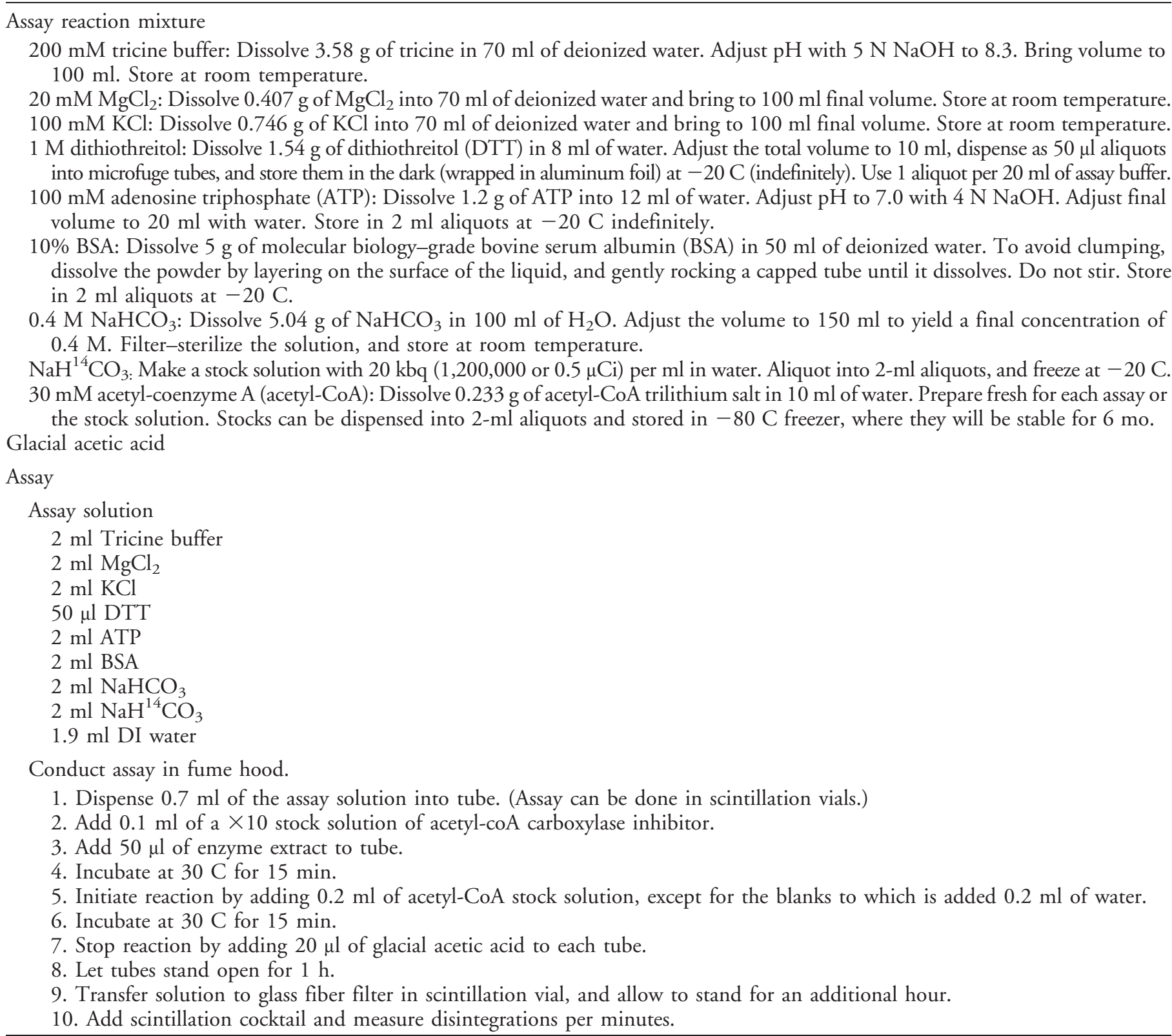

Enzyme Assay. Conduct this assay in a fume hood or in a container that will trap $\mathrm{CO}_{2}$. Add $50 \mu \mathrm{l}$ of enzyme extract to $950 \mu \mathrm{l}$ of reaction mixture (Table 3). Incubate the solution at $30 \mathrm{C}$ for $3 \mathrm{~min}$ before adding acetyl-CoA at $3 \mathrm{mM}$ final concentration. The blanks include all of the reagents, except the acetyl-CoA. Incubate the reaction at $30 \mathrm{C}$ for $15 \mathrm{~min}$, and stop the reaction by adding $20 \mu \mathrm{l}$ glacial acetic acid. Allow the samples to stand open for $1 \mathrm{~h}$ to allow the escape of ${ }^{14} \mathrm{CO}_{2}$. Transfer the assay solution to the surface of a glass fiber filter inside liquid scintillation vials, and allow the samples to dry before adding $10 \mathrm{ml}$ scintillation cocktail. Measure the radioactivity in the samples via liquid scintillation spectroscopy. See above for stock solutions and assay procedure.
For herbicide-sensitivity measurements, include at least four different concentrations of the ACCase inhibitor in the assay. A typical curve for inhibition of ACCase from the work of Délye et al. (2003) is shown in Figure 2B.

Leaf Disc Assay. To date, there is no leaf disc assay for this mechanism of action.

\section{Acetolactate Synthase: Molecular Target of Herbicide Class B (WSSA Group 2)}

Acetolactate synthase (ALS; also called acetohydroxyacid synthase or AHAS) is an enzyme in the pathway to the three branched-chain amino acids, 

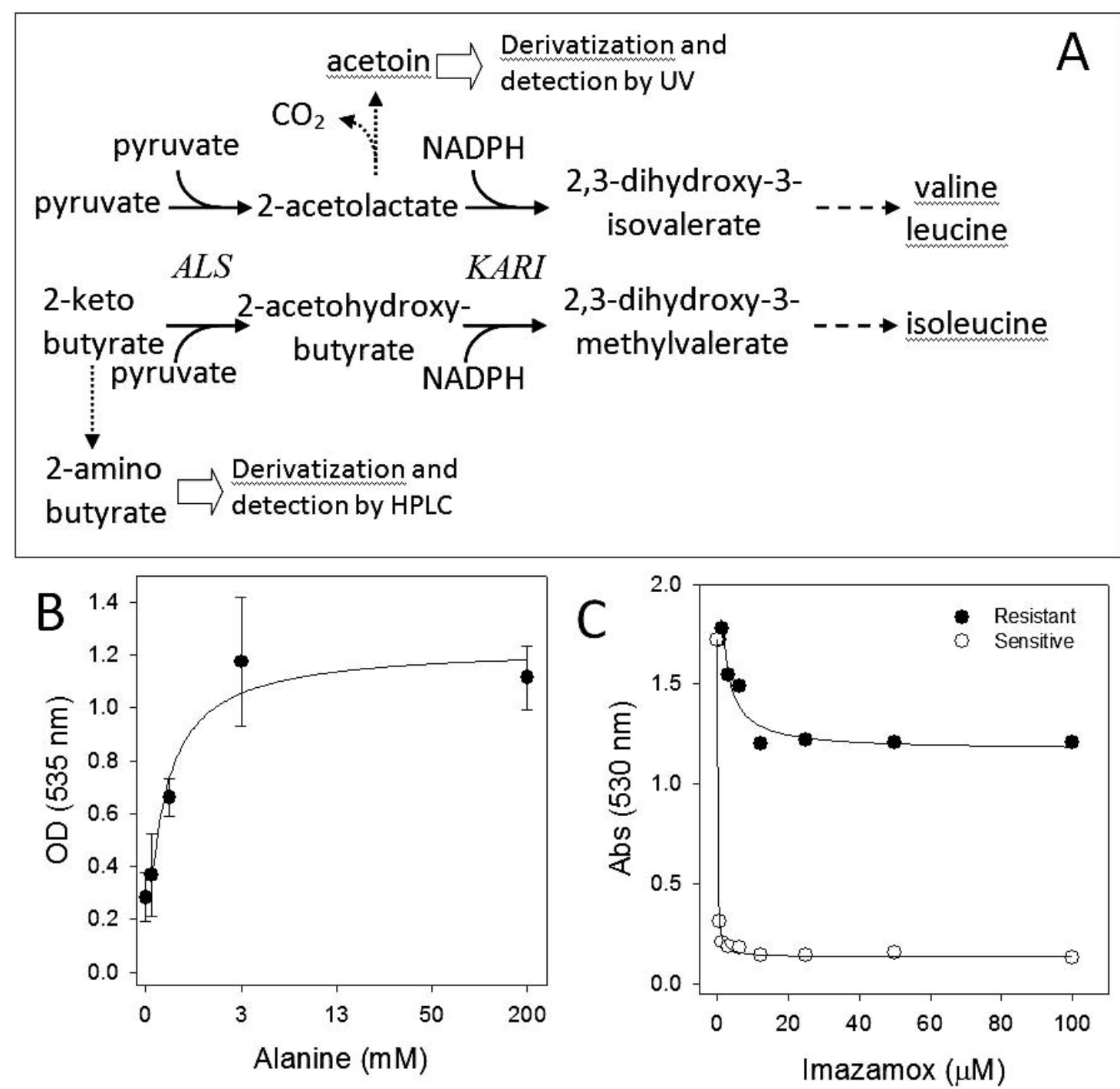

Figure 3. A) Acetolactate synthase (ALS) catalyzes an important step in the synthesis of branched chain amino acids via two parallel reactions. B) Effect of alanine on acetolactate accumulation in wheat leaf discs. C) Dose-response curve of ALS inhibitor imazamox on ALS activity from wild-type (black) and herbicide resistant (white) canola in leaf disc assays. KARI, ketoacid reductoisomerase is inhibited in order to cause 2-acetolactate accumulation.

leucine, isoleucine, and valine (Figure 3A). Plants treated with these inhibitors stop growing, eventually wilting, and turning red because of the accumulation of stress-induced anthocyanins. The inhibition of ALS causes accumulation of one of its precursors, 2-ketobutyrate, which is transaminated in situ to 2-aminobutyrate (Loper et al. 2002). At least part of the phytotoxicity appears to be due to the accumulation of those phytotoxic compounds.

Accumulation of 2-Aminobutyrate. The effects of ALS inhibitors can be measured by extracting and quantifying the accumulation of 2-aminobutyrate by HPLC. Grind fresh shoots $(250 \mathrm{mg})$ in an ice-cold mortar using liquid nitrogen, and homogenize in $900 \mu \mathrm{l}$ deionized water. Precipitate proteins by adding $50 \mu \mathrm{l}$ cold trichloroacetic acid to the extract, incubating for $15 \mathrm{~min}$ on ice and centrifugation at $45,000 \times g$ at $4 \mathrm{C}$ for $3 \mathrm{~min}$. Prepare the reagent solution by adding $5 \mu \mathrm{l}$ of undiluted $B$-mercaptoethanol to $1 \mathrm{ml} \mathrm{O}$-phthaldialdehyde. Derivatize 2aminobutyrate to a fluorescent form by mixing $100 \mu \mathrm{l}$ of the reagent solution with a $20 \mu \mathrm{l}$ aliquot of the supernatant within 2 min before analysis.

ALS Tip 1. Use $O$-phthaldialdehyde reagent to derivatize primary amines and amino acids. Detection of individual fluorescent derivatives requires reverse-phase HPLC separation. The presence of excess sulfhydryl (in the form of $\beta$ mercaptoethanol) is necessary. 
Analysis is done with a C18 reverse-phase column, with the following solvent system: (1) mobile phase A is $2.7 \mathrm{~g}$ sodium acetate trihydrate, $180 \mathrm{ml}$ triethylamine, and $3 \mathrm{ml}$ tetrahydrofuran in $1 \mathrm{~L}$ of deionized water at $\mathrm{pH} 7.2$; (2) mobile phase B is $2.7 \mathrm{~g}$ sodium acetate in $200 \mathrm{ml}$ deionized water at $\mathrm{pH} 7.2,400 \mathrm{ml}$ acetonitrile, and $400 \mathrm{ml}$ methanol. Start the gradient at $80 \% \mathrm{~A}$ and $20 \% \mathrm{~B}$ and reach $20 \% \mathrm{~A}$ and $80 \% \mathrm{~B}$ over $20 \mathrm{~min}$. Wash the column with $100 \%$ B for $7 \mathrm{~min}$, and reequilibrate to the initial conditions for

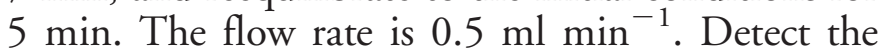
$O$-phthaldialdehyde derivatives with a fluorescence spectrophotometer with excitation and emission wavelength set at 340 and $450 \mathrm{~nm}$, respectively. Quantify 2-aminobutyrate based on a calibration curve obtained with technical standard (Li and Wang 2005).

Leaf Disc Assay. To measure ALS activity, it is first necessary to induce acetolactate accumulation (Figure 3B). This is achieved by floating leaf discs $(50 \mathrm{mg})$ from young leaves on $4 \mathrm{ml}$ of $25 \%$ Murashige and Skoog nutrient medium with $500 \mu \mathrm{M}$ 1,1-cyclopropanedicarboxylic acid (CPCA), an inhibitor of ketol-acid reductoisomerase (KARI), in $60 \times 15-\mathrm{mm}$ disposable Petri dishes (Gerwick et al. 1993) or 96 well microtiter plates. The effect of herbicides targeting ALS can then be evaluated by measuring the reduction in acetolactate levels (Figure 3C). Typical dose-response curves range from 0.001 and $1,000 \mu \mathrm{M}$.

ALS Tip 2. Be sure to prevent bacterial contamination. Use clean equipment, and wash any dirt off the leaves or plants to be tested before sampling. Use very sharp cork borers or cutting equipment. Do not crush leaf tissue during preparation. Handle the plant material as little as possible to prevent cell disruption. If any solutions are cloudy after the incubation period, discard the mixture. Bacteria will accumulate large amounts of acetolactate, but the ALS activity in bacteria is completely resistant to ALS inhibitors. Ampicillin (50 $\mathrm{U} \mathrm{ml}^{-1}$ ) can be added to the incubation solution to slow down bacterial growth.

ALS Tip 3. Take the discs from rapidly growing leaf tissue. For broadleaf species, that is the youngest leaf from which leaf discs can be taken. For seedling grasses, cut segments $\left(5 \mathrm{~mm}\right.$ segment $\left.{ }^{-1}\right)$ from the base of the plant, which contain the apical meristem. If grasses are tillering, sampling the tillers is better than using the main stem.
Incubate petri dishes with leaf samples in a growth chamber at $25 \mathrm{C}$ under fluorescent light $\left(250 \mu \mathrm{mol} \mathrm{m}{ }^{-2} \mathrm{~s}^{-1}\right.$ PAR $)$ for $24 \mathrm{~h}$. Dry leaf discs on paper towels, transfer into $1.5-\mathrm{ml}$ microcentrifuge tubes with $300-\mu$ l deionized water, and freeze at $-80 \mathrm{C}$ overnight (the samples are stable until analysis). For analysis, thaw samples, and allow acetolactate to diffuse into the solution by shaking the tubes on a thermomixer at $60 \mathrm{C}$ for $60 \mathrm{~min}$. Centrifuge for $5 \mathrm{~min}$ at $20,800 \times g$. Mix a $100-\mu \mathrm{l}$ aliquot with $10 \mu \mathrm{l}$ of $6 \mathrm{~N} \mathrm{H}_{2} \mathrm{SO}_{4}$. Incubate the mixture at $60 \mathrm{C}$ for $30 \mathrm{~min}$ to convert acetolactate to acetoin.

Microtiter Plates. Fill each well with $100 \mu \mathrm{l}$ assay buffer (Table 4). Place one to three 5-mm-diam leaf discs in each well. To maximize accumulation of acetolactate, $50 \mathrm{mM}$ alanine can be added to the incubation solution (Figure 3B). Wrap the plate in plastic wrap to prevent evaporation, and incubate under light as described above for 16 to $24 \mathrm{~h}$. Stop the reaction by adding $25 \mu \mathrm{l}$ of $5 \% \mathrm{H}_{2} \mathrm{SO}_{4}$ to each well, and place the plate at $-20 \mathrm{C}$, where it can remain until further analysis. After thawing the plate, the leaf discs should be a uniform greygreen, indicating that the acid has completely penetrated the discs. Transfer $75 \mu \mathrm{l}$ of the extract from each well to another microtiter plate, and add $125 \mu \mathrm{l}$ of the naphthol/creatine reagent described below. Incubate the plate at RT for $60 \mathrm{~min}$ or at $60 \mathrm{C}$ for $15 \mathrm{~min}$. If the solutions appear cloudy from precipitate, the plates can be centrifuged, and $150 \mu \mathrm{l}$ of the sample transferred to another plate.

Acetoin is quantified by a modified colorimetric assay (Westerfeld 1945) by derivatization with $\alpha$ naphthol to form a red complex. Add $50 \mu \mathrm{l}$ of $0.5 \%$ (w/v) creatine and $50 \mu \mathrm{l} \alpha$-naphthol reagents to each well, and heat the mixtures at $60 \mathrm{C}$ for $15 \mathrm{~min}$. After cooling, centrifuge the tubes for $5 \mathrm{~min}$ at $20,800 \times g$. Transfer $100 \mu \mathrm{l}$ to a microtiter plate, and record absorbance at $540 \mathrm{~nm}$ on a microplate reader (Figures 3B and 3C).

ALS Tip 4. Make fresh $\alpha$-naphthol reagent (5\% $\mathrm{w} / \mathrm{v}$ ) by adding $1 \mathrm{~g}$ of $\alpha$-naphthol to $20 \mathrm{ml}$ of 2.5 $\mathrm{N} \mathrm{NaOH} . \alpha-\mathrm{Naphthol}$ is readily oxidized, so the solution should be clear and should not be used if its color is more than faint yellow. Creatine is added to the reaction mixture to enhance the color development. 
Table 4. Solutions and reagents for extraction and enzyme assays to measure acetolactate synthase (ALS) activity.

\begin{tabular}{|c|c|}
\hline Components & Procedure \\
\hline \multicolumn{2}{|l|}{ ALS extraction buffer $(100 \mathrm{ml})$} \\
\hline $\begin{array}{l}100 \mathrm{mM} \text { potassium phosphate } \\
0.5 \mathrm{mM} \mathrm{MgCl}_{2}\left(33.5 \mu \mathrm{l} \text { of } 3 \mathrm{M} \mathrm{MCl}_{2}\right) \\
0.5 \mathrm{mM} \text { thiamine pyrophosphate } \\
0.01 \mathrm{mM} \text { flavine adenine dinucleotide } \\
1 \mathrm{mM} \text { diethyldithiocarbamate } \\
13.5 \% \text { glycerol }(\mathrm{v} / \mathrm{v})\end{array}$ & $\begin{array}{l}\text { Start with } 80 \mathrm{ml} \text { of water, add components, cool on ice, adjust } \mathrm{pH} \text { to } \\
7.5 \text {. and bring to a final volume of } 100 \mathrm{ml} \text {. }\end{array}$ \\
\hline \multicolumn{2}{|l|}{ Elution buffer $(200 \mathrm{ml})$} \\
\hline $\begin{array}{l}100 \mathrm{mM} \text { potassium phosphate } \\
20 \mathrm{mM} \text { sodium-pyruvate } \\
0.5 \mathrm{mM} \mathrm{MgCl}_{2}\left(33.5 \mu \mathrm{l} \text { of } 3 \mathrm{M} \mathrm{MgCl}_{2}\right)\end{array}$ & $\begin{array}{l}\text { Start with } 160 \mathrm{ml} \text { of water, add components, cool on ice, adjust } \mathrm{pH} \\
\text { to } 7.5 \text {, and bring to a final volume of } 200 \mathrm{ml} \text {. }\end{array}$ \\
\hline \multicolumn{2}{|l|}{ ALS assay buffer $(100 \mathrm{ml})$} \\
\hline
\end{tabular}

Crude Enzyme Extraction. It is very important to use young plants and to do all the extraction steps on ice. Grind $1 \mathrm{~g}$ of young plant tissue in liquid nitrogen, and sterile quartz sand using a mortar and pestle. Homogenize the sample after the addition of $3 \mathrm{ml}$ ALS extraction buffer (Table 4). Stir the homogenate for $2 \mathrm{~min}$, transfer to two $1.5-\mathrm{ml}$ microcentrifuge tubes, and centrifuge for $5 \mathrm{~min}$ at $20,800 \times g$ at 4 C. Combine the supernatants and apply $2.5 \mathrm{ml}$ of the extract to a Sephadex G25 column (PD-10, GE Healthcare Biosciences). This column has to be equilibrated with $25 \mathrm{ml}$ extraction buffer before loading the sample. Wash the column with $1 \mathrm{ml}$ of elution buffer, and discard the eluent because it contains very little ALS activity. Elute the ALS-containing fraction with an additional $2.5 \mathrm{ml}$ of elution buffer. Total soluble protein is quantified by the Bradford (1976) method.

ALS Tip 5. Enhance the ALS activity in the extract with ammonium sulfate precipitation, if it is very low. Although ALS activity is normally in the 30 to $50 \%$ fraction, that has to be determined for each species through preliminary experiments. It is critical that the extract never freeze and form ice crystals. If the extract forms ice crystals, all the ALS activity is lost.

ALS Assay. Add $70 \mu \mathrm{l}$ ALS assay buffer (Table 3), $20 \mu \mathrm{l}$ crude enzyme extract, and $10 \mu \mathrm{l}$ herbicide solution to $1.5 \mathrm{ml}$ microcentrifuge tubes. The blank consists of $100 \mu \mathrm{l}$ ALS assay buffer.
Incubate the assays for $1 \mathrm{~h}$ at $37 \mathrm{C}$, and stop the reaction by adding $10 \mu \mathrm{l}$ of $6 \mathrm{~N} \mathrm{H}_{2} \mathrm{SO}_{4}$. A positive control that estimates the baseline concentration of acetolactate consists of the complete assay performed with $10 \mu \mathrm{l}$ of $6 \mathrm{~N} \mathrm{H}_{2} \mathrm{SO}_{4}$ added at the beginning of the reaction. Convert acetolactate to acetoin by heating the acidified samples. Quantify acetoin as described earlier.

ALS Tip 6. Relative ALS activity is calculated as follows:

Relative ALS activity $=$

$$
\left\{\left[A_{\text {sample }}-\left(A_{\min }-\text { blank }\right)\right] /\left[A_{\max }-\left(A_{\min }-\text { blank }\right)\right]\right\}
$$$$
\times 100
$$

where $A_{\text {sample }}$ is absorbance of the sample at $540 \mathrm{~nm}, A_{\max }$ is absorbance of positive control, $A_{\text {min }}$ is absorbance of the sample incubated with $\mathrm{H}_{2} \mathrm{SO}_{4}$, and $A_{\text {blank }}$ is absorbance of reaction buffer.

Rapid Extraction and Assay. Another method that can be used to rapidly determine in vitro ALS activity to screen for resistance is to extract the tissue as described above, but the extraction buffer is $\times 2$ of the ALS analysis buffer. In this method, the tissue is first pulverized as described above. The pulverized tissue is extracted in $\times 2$ assay buffer as described above, and the extract is filtered through cheesecloth into a tube and centrifuged as described above. Use the supernatant directly for the ALS assay. Fill each 
well in a microtiter plate with $50 \mu$ l of either water or $\times 2$ the final concentration for the ALS inhibitor. Pipette $50 \mu \mathrm{l}$ of the supernatant into each well and incubate and analyze as previously described. This assay is rapid because it eliminates the ammonium sulfate precipitation, and the supernatant is used directly in the assay. This assay is suitable for screening for resistance.

ALS Tip 7. Determine whether there are artifacts in the in vitro ALS assay. Certain species, such as legumes, or ageing tissue have an ALS-like activity that is not related to the anabolic form of ALS. That activity produces acetoin directly from pyruvate and is not involved in the biosynthesis of the branched-chain amino acids. To determine whether that non-ALS assay is present, use two controls. The first control is to immediately stop the reaction, by adding acid to the medium right after adding the enzyme preparation. The second control is to stop the reaction, with $0.25 \mathrm{~N} \mathrm{NaOH}$ at the end of the reaction. Using $\mathrm{NaOH}$ prevents the conversion of acetolactate to acetoin, and the acetoin produced through the non-ALS enzyme can be subtracted from the total acetoin measured.

\section{Photosystem II: Molecular Target of Herbicide Class $\mathrm{C}_{1}, \mathrm{C}_{2}$, and $\mathrm{C}_{3}$ (WSSA Group 5,6,7)}

The paradigm underlying chlorophyll-fluorescence analysis is that the light energy absorbed by chlorophyll is used to drive photosynthesis (photochemical energy), and excess energy is released as nonphotochemical energy, such as heat and chlorophyll fluorescence (Figure 4A). Although chlorophyll fluorescence accounts for only 1 to $2 \%$ of the total light absorbed, it is easily measured and has been a powerful tool for investigating plant physiological processes (Figure 4B) (Dayan and Zaccaro 2012). The light reaction of photosynthesis can also be monitored by measuring the rate of $\mathrm{O}_{2}$ evolution (Figure 4C).

Chlorophyll Fluorescence. Chlorophyll fluorescence can be measured nondestructively on intact plants exposed to herbicides or on leaf discs floating on $5 \mathrm{ml}$ of bathing medium (Table 5) with known inhibitor concentrations in $60 \times 15-\mathrm{mm}$ disposable petri plates (Figure 4B). With the instrument set on kinetic mode, adjust so that the initial instantaneous fluorescence signal $(\mathrm{Ft})$ value in the control samples is approximately 210. Set the instrument detector gain between 75 and 85. Quantum yield is determined by the following light treatment: each cycle consisted of a 0.8 -s pulse of saturating light generated with a laser diode actinic source to saturate photosystem II (PSII), followed by a 4-s far-red light pulse, used to reoxidize PSII, and a 10-s delay to allow PSII to regain steady-state conditions. Seven cycles are performed for each sample. Electron transfer rate (ETR) values are expressed as percentages of the ETR average values observed in control treatments.

Fluorescence Tip 1. Make the opening of the clip holding the probe at the correct angle over the leaf surface smaller by taping a piece of nonreflective black paper with a smaller hole. The gain may have to be adjusted, but this technique works well with leaf discs.

Photosynthetic Oxygen Evolution. Oxygen evolution can be monitored from intact chloroplast preparation. Spinach (Spinacia oleracea L.) is used routinely in our laboratory because it yields excellent chloroplast preparations, but other plants can be used as well. Homogenize $50 \mathrm{~g}$ of tissue and $250 \mathrm{ml}$ of extraction buffer (Table 5) in a blender. Filter the homogenate through one layer of Miracloth (Merck) lined by two layers of cheesecloth, and collect it in a cold beaker. Centrifuge the filtrate for $20 \mathrm{~min}$ at $6,000 \times g$ at $4 \mathrm{C}$. Resuspend the pellet containing chloroplasts in $0.5 \mathrm{ml}$ of resuspension buffer. Rinse the tubes with $0.5 \mathrm{ml}$ of additional buffer through each tube in series, and combine with the chloroplast extract. This crude chloroplast extract can be used for oxygen evolution, but it contains broken chloroplasts and is contaminated with mitochondria.

$\mathrm{O}_{2}$ evolution can be measured polarographically using an oxygen probe. These experiments are performed under saturating light conditions $\left(2,400 \mu \mathrm{mol} \mathrm{m} \mathrm{m}^{-2} \mathrm{~s}^{-1}\right.$ PAR). We use a fiber-optic light with two sources and place one fiber optic over the top of the chamber and the other perpendicular to the chamber to maximize light exposure. All assays are performed at $30 \mathrm{C}$ using a recycling water heater. The half maximal inhibitory value $\left(\mathrm{IC}_{50}\right)$ of oxygen evolution can be obtained from doseresponse curves (Figure $4 \mathrm{C}$ ). 

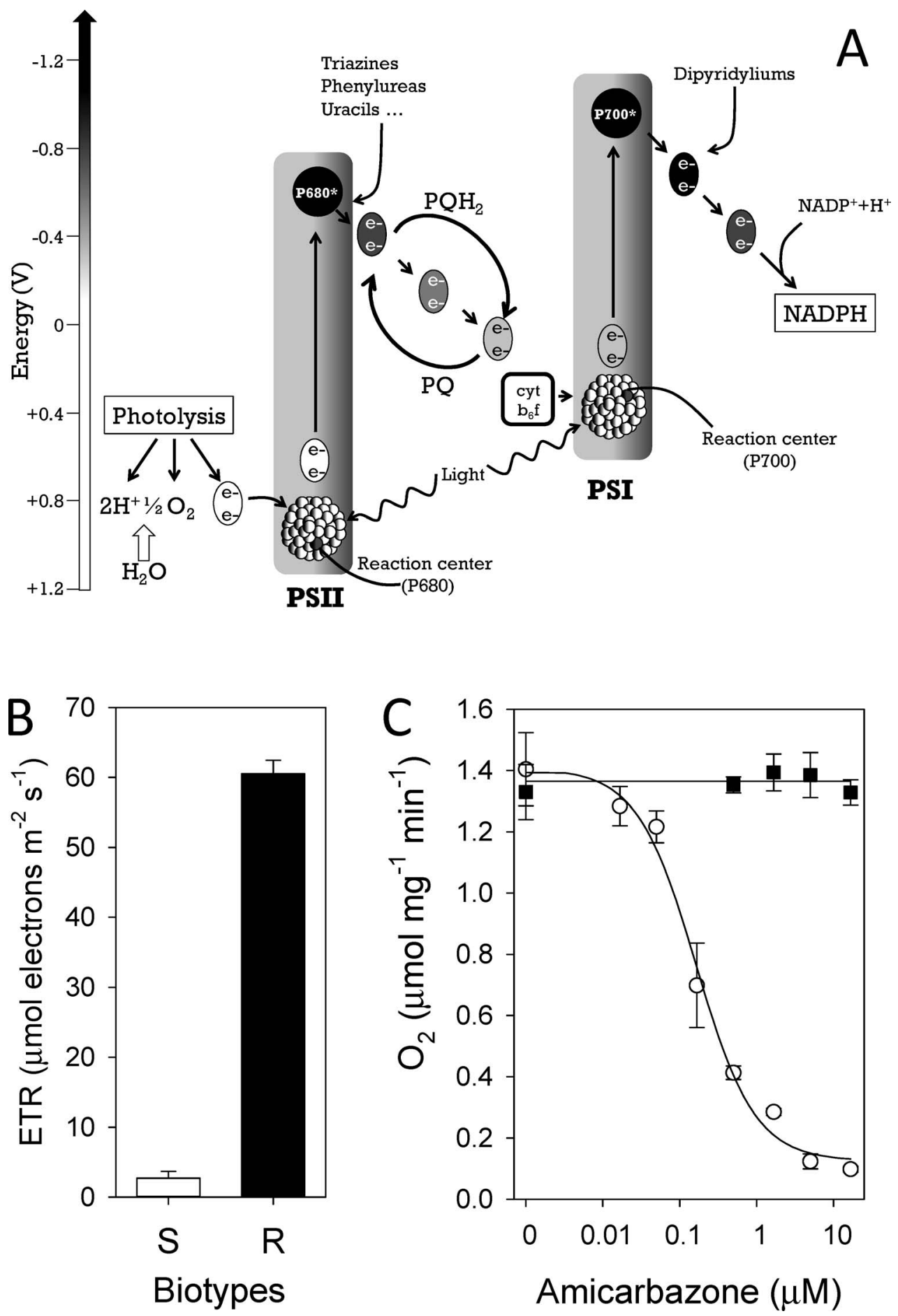

Figure 4. A) Diagram of the Z-scheme describing the hill reaction from Dayan et al. 2010. The sites of herbicide interactions are indicated with the red arrows. B) Effect of amicarbazone $(10 \mu \mathrm{M})$ on wild-type (white) and herbicide resistant pigweed (black) photosynthetic electron transport and C) oxygen evolution dose-response curve.

Oxygen Evolution Tip 1. Obtain intact chloroplasts by centrifuging the crude extract on a sucrose step gradient (30 to $52 \%$ ) for $60 \mathrm{~min}$ at $80,000 \times g$ at $4 \mathrm{C}$, which requires an ultracentrifuge and swinging buckets. Transfer the layer containing intact chloroplasts into a precooled tube containing about $3 \mathrm{ml}$ of resuspension buffer. Centrifuge for $15 \mathrm{~min}$ at $6,000 \times \mathrm{g}$. Resuspend the pellet in $3 \mathrm{ml}$ of resuspension buffer, and collect the clear chloroplasts as a soft pellet after centrifugation for $15 \mathrm{~min}$ at $6,000 \times g$. 
Table 5. Solutions and reagents to measure photosystem II activity. ${ }^{\text {a }}$

\begin{tabular}{|c|c|}
\hline Components & Procedure \\
\hline $\begin{array}{l}2 \% \text { sucrose } \\
1 \mathrm{mM} \mathrm{MES}\end{array}$ & $\begin{array}{l}\text { Start with } 160 \mathrm{ml} \text { of water, add components, and adjust } \mathrm{pH} \text { to } 6.5 \text { at } \\
\text { room temperature. }\end{array}$ \\
\hline \multicolumn{2}{|l|}{ Extraction buffer $(200 \mathrm{ml}$ of $\times 5)$} \\
\hline 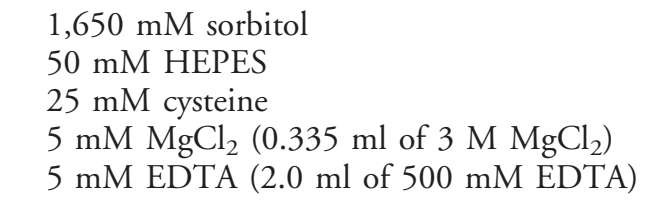 & $\begin{array}{l}\text { Start with } 160 \mathrm{ml} \text { of water, add components, cool on ice, adjust } \mathrm{pH} \\
\text { to } 7.7 \text {, and bring to a final volume of } 200 \mathrm{ml} \text {. Store at }-20 \mathrm{C} \text { in } \\
50-\mathrm{ml} \text { aliquots. Dilute } 50 \mathrm{ml} \text { of stock to } 250 \mathrm{ml} \text { final volume } \\
\text { before use. }\end{array}$ \\
\hline \multicolumn{2}{|l|}{ Resuspension buffer $(100 \mathrm{ml}$ of $\times 5)$} \\
\hline $\begin{array}{l}1,650 \mathrm{mM} \text { sorbitol } \\
50 \mathrm{mM} \text { HEPES } \\
5 \mathrm{mM} \text { dithiothreitol } \\
5 \mathrm{mM} \mathrm{MgCl}_{2}\left(0.167 \mathrm{ml} \text { of } 3 \mathrm{M} \mathrm{MgCl}_{2}\right) \\
5 \mathrm{mM} \mathrm{EDTA}(1.0 \mathrm{ml} \text { of } 500 \mathrm{mM} \mathrm{EDTA})\end{array}$ & $\begin{array}{l}\text { Start with } 80 \mathrm{ml} \text { of water, add components, cool on ice, adjust } \mathrm{pH} \text { to } \\
7.7 \text {, and bring to a final volume of } 100 \mathrm{ml} \text {. Store at }-20 \mathrm{C} \text { in } \\
25 \mathrm{ml} \text { aliquots. Dilute } 25 \mathrm{ml} \text { of stock to } 125 \mathrm{ml} \text { final volume } \\
\text { before use. }\end{array}$ \\
\hline $\begin{array}{l}800 \mathrm{mM} \text { sucrose } \\
50 \mathrm{mM} \mathrm{MES}-\mathrm{NaOH} \\
15 \mathrm{mM} \mathrm{CaCl}_{2} \\
1 \mathrm{mM} \mathrm{FeCN}^{\text {(potassium ferrocyanide) }}\end{array}$ & $\begin{array}{l}\text { Start with } 400 \mathrm{ml} \text { of water, add components, bring to } 30 \mathrm{C} \text {, adjust } \\
\mathrm{pH} \text { to } 6.2 \text {, and bring to a final volume of } 500 \mathrm{ml} \text {. Maintain at } \\
30 \mathrm{C} \text { in water bath during assay. Store in refrigerator for up to } \\
1 \mathrm{wk} \text {. }\end{array}$ \\
\hline
\end{tabular}

a Abbreviations: MES, 2-( $N$-morpholino)ethanesulfonic acid; HEPES, 4-(2-hydroxyethyl)-1-piperazineethanesulfonic acid; EDTA, ethylenediaminetetraacetic acid.

Oxygen Evolution Tip 2. Use spinach chloroplast extracts for crude extracts. Some methods recommend adding $300 \mu \mathrm{M}$ decyl-plastoquinone, but, in our experience, there is generally enough plastoquinone in spinach chloroplast extracts that decyl plastoquinone is not necessary when using crude extracts.

\section{Photosystem I Electron Diversion: Molecular Target of Herbicide Class D (WSSA Group 22)}

Photosystem I (PSI) is on the second part of the Z-scheme of photosynthetic electron transport. It provides the power to reduce nicotinamide adenine dinucleotide phosphate $\left(\mathrm{NADP}^{+}\right)$to its reduced form, NADPH, which is required for carbon fixation and other biochemical processes. In daylight, PSI has very strong reducing power, and PSII generates high levels of $\mathrm{O}_{2}$. Under those conditions, compounds with a redox potentials between -300 and $-700 \mathrm{mV}$ (e.g., paraquat $=$ $-446 \mathrm{mV}$ ) can be reduced by receiving electrons from PSI. This results in the production of large quantities of superoxide anion, which, in turn, generate other reactive radicals, including the highly toxic hydroxyl radical, ultimately leading to massive lipid peroxidation. In cell membranes, this process quickly causes membrane dysfunction and cell death.

There are no specific assays to monitor the mechanism of action of paraquat and other PSI inhibitors. However, the assays described to measure the effect of PSII inhibitors on chlorophyll fluorescence in leaves and on photosynthetic oxygen evolution from isolated chloroplasts can be useful, but PSI inhibitors induce different responses (see "Chlorophyll Fluorescence" in the "Photosystem II" section) (Dayan and Zaccaro 2012). The electrolyte leakage experiment described earlier can also provide some information on these types of inhibitors (see "Electrolyte Leakage" in the "Common Protocols section") (Dayan and Watson 2011).

\section{Protoporphyrinogen Oxidase Molecular Target of Herbicide Class E (WSSA Group 14)}

Protoporphyrinogen IX oxidase (PPO) catalyzes the last biochemical step in common between heme and chlorophyll synthesis (Dayan and Duke 2010). One of the key features of the inhibition of PPO is the rapid accumulation of the highly photodynamic tetrapyrrole protoporphyrin IX (Proto), the product of the reaction (Figure 5A) (Duke and Dayan 2011; 

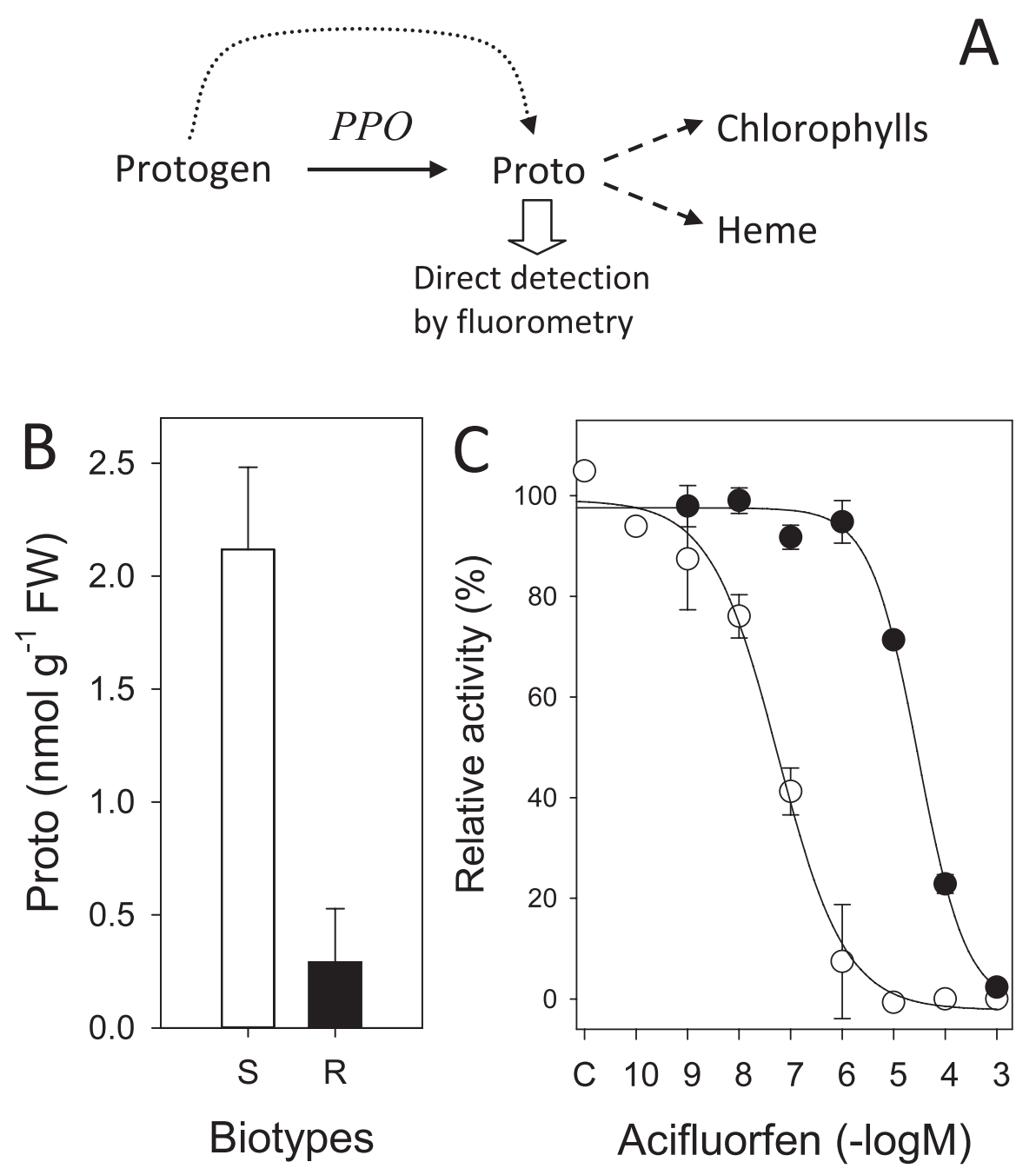

Figure 5. A) Protoporphyrinogen oxidase (PPO) catalyzes the conversion of the colorless protoporphyrinogen IX (Protogen) to the highly fluorescent protoporphyrin IX (Proto). The dotted arrow represents the non-enzymatic step leading to proto accumulation when PPO is inhibited. B) Effect of $10 \mu \mathrm{M}$ acifluorfen on wild-type (white) and herbicide resistant (black) Amaranthus tuberculatus and C) dose-response curves of acifluorfen on heterologously expressed PPO from wild-type ( $\bigcirc)$ and herbicide resistant $(\bigcirc)$ Amaranthus tuberculatus.

Matringe and Scalla 1988). A key aspect of the mechanism of action for class $\mathrm{E}$ inhibitors is the generation of reactive oxygen species in the presence of light. Therefore, the simple electrolyte leakage experiment can easily identify the light-dependent nature of these herbicides (see "Electrolyte Leakage" in the "Common Protocols" section) (Dayan and Watson 2011).

Analysis of Proto Levels. The effect of PPO inhibitors can be evaluated by measuring the accumulation of Proto in whole plants or in leaf disc (Figure 5B). A number of methods for the extraction and analysis of Proto from leaf tissues are available. The method presented here has been used successfully with a number of herbicides in our laboratory (Dayan et al. 1997a,b,c; Li et al. 2004).
PPO Tip 1. Prevent light exposure because Proto is highly photodynamic; therefore, all windows in the laboratory should be covered with aluminum foil, and several lamps can be mounted with green filters.

Homogenize approximately $100 \mathrm{mg}$ of leaf disks in $2 \mathrm{ml}$ of basic methanol (HPLC-grade methanol$0.1 \mathrm{~N}$ ammonium hydroxide $[9: 1 \mathrm{v} / \mathrm{v}]$ ) at full speed for $15 \mathrm{~s}$, and keep it in the dark for $10 \mathrm{~min}$. Collect the supernatant after centrifugation at 3,000 $\times g$ for $3 \mathrm{~min}$.

PPO Tip 2. Use Corex tubes (Corning Inc., Corning, NY) because regular, glass tubes tend to break in the centrifuge. 
Resuspend the pellet in $1 \mathrm{ml}$ of basic methanol, keep it in the dark for $10 \mathrm{~min}$, and collect the supernatant after centrifugation as above. Combine and filter the supernatants through a $0.2-\mu \mathrm{m}$ nylon syringe filter to remove particles, and store in lighttight glass vials at $-20 \mathrm{C}$ until analysis by HPLC.

PPO Tip 3. Use scintillation vials covered with aluminum foil, which work well.

Proto has a strong absorbance at $400 \mathrm{~nm}$, which is similar to chlorophyll and carotenoids; therefore, separation by HPLC is necessary to resolve Proto. Protocols must be adapted for individual HPLC/ column systems, but, as a general principle, a reverse-phase column (such as a 4.6 by $250-\mathrm{mm}$ Spherisorb 5-mm ODS-1 preceded by an ODS-5S guard column [Waters Corporation, Milford, MA]) works well. The solvent system consists of a gradient beginning at 60\% HPLC-grade methanol and 40\% deionized water. At $10 \mathrm{~min}$, the gradient used is $100 \%$ methanol to wash the column of lipophilic coextractants; then the solvent system is returned to the original settings after $30 \mathrm{~min}$.

PPO Tip 4. Use a fluorescence detector with excitation and emission wavelength settings at 400 and $630 \mathrm{~nm}$ to visualized Proto because, although it can be visualized with a photodiode array as a peak with a maximum near $400 \mathrm{~nm}$, the detection limit is not very good, and the fluorescence detector has much greater sensitivity.

PPO Tip 5. Set the photodiode array detector to scan from 300 to $700 \mathrm{~nm}$, so chlorophyll and carotenoids can easily be differentiated according to their respective spectra.

Quantify Proto levels in the extracts using a calibration curve obtained with a commercially available Proto standard.

Measuring PPO Activity. Assaying for PPO activity is a rather delicate process for several reasons. Synthesis of the substrate is complicated and dangerous. The assay also requires a spectrofluorophotometer, which is not common in most laboratories. The assay has traditionally been done in isolated etioplasts, but it can also be done by using plant PPO expressed heterologously in Escherichia coli, which makes it possible to perform additional biochemical experiments. The equipment necessary for this assay is the same as that used when working with etioplasts. The buffers, however, are different to maintain the enzyme and substrate in solution (Dayan et al. 2010a).

Etioplast Isolation. Germinate seeds in darkness within a growth chamber at $25 \mathrm{C}$ for $10 \mathrm{~d}$. Harvest etiolated tissue $(25 \mathrm{~g})$ in the dark, and homogenize in $125 \mathrm{ml}$ extraction buffer (Table 6) at full speed (three times for $30 \mathrm{~s}$ each). Filter the homogenate through a layer of Miracloth lined with two layers of cheesecloth, and centrifuge at $150 \times g$ for $5 \mathrm{~min}$ (4 C) to remove large debris. Transfer the supernatant to two clean tubes, and centrifuge at $9,000 \times g$ for $20 \mathrm{~min}(4 \mathrm{C})$ to collect the etioplasts. Resuspend and combine the pellets with $0.5 \mathrm{ml}$ of cold resuspension buffer per tube. Adjust the protein concentration to $5 \mathrm{mg}$ protein $\mathrm{ml}^{-1}$, and store at $-80 \mathrm{C}$ in $100-\mu \mathrm{l}$ aliquots in microfuge tubes. It is stable for several months.

PPO Tip 6. Etioplasts can be purified further by differential centrifugation on a Percoll gradient at $6,000 \times g$ for 6 min followed by ultracentrifugation on a sucrose step gradient (30 to $52 \%$ ) at $80,000 \times$ $g$ for $60 \mathrm{~min}$. Collect the yellow band-containing etioplasts, and centrifuge at $6,000 \times g$ for $15 \mathrm{~min}$.

Proto Preparation. Dissolve $4.23 \mathrm{mg}$ of Proto in $15 \mathrm{ml}$ of $10 \mathrm{mM} \mathrm{KOH} \mathrm{:} \mathrm{20 \%} \mathrm{ethanol} \mathrm{in} \mathrm{a} \mathrm{light-}$ proof, glass vial for $20 \mathrm{~min}$, which will yield approximately $500 \mu \mathrm{M}$ of Proto solution that can be stored in a fridge for up to 1 mo or until the solution becomes brownish.

PPO Tip 7. Determine the exact concentration on a spectrophotometer using the molar extinction coefficient $\varepsilon=13.5$ at $554 \mathrm{~nm}$. Add $50 \mu \mathrm{l}$ of solution to $950 \mu \mathrm{l} 2.7 \mathrm{~N} \mathrm{HCl}$, and measure absorbance. If absorbance $=0.327$, then $(0.327 / 13.5) \times 20$ (the dilution factor) $=0.484 \mathrm{mM}$ or $484 \mu \mathrm{M}$.

Sodium Amalgam Preparation. Protogen is prepared according to Jacobs and Jacobs (1987) by reducing Proto in the presence of sodium amalgam. This is the most important part of this assay, and it must be done under a chemical hood because it is highly exothermic and releases toxic fumes. Place a sidearm flask on a heating plate under low heat and constantly flush with nitrogen gas. Add $3.75 \mathrm{~g}$ of mercury to the flask. Do not let it get too hot or the 
Table 6. Solutions and reagents for extraction and enzyme assays to measure protoporphyrinogen IX oxidase (PPO) activity. ${ }^{\text {a }}$

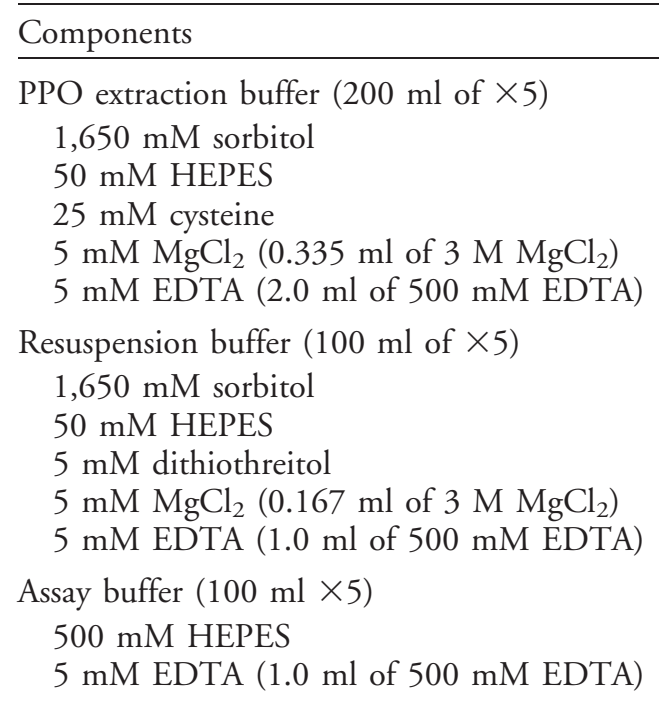

Procedure

Start with $160 \mathrm{ml}$ of water, add components, cool on ice, adjust $\mathrm{pH}$ to 7.7 , and bring to a final volume of $200 \mathrm{ml}$. Store at $-20 \mathrm{C}$ in $50-\mathrm{ml}$ aliquots. Dilute $50 \mathrm{ml}$ of stock to $250 \mathrm{ml}$ final volume before use.

Start with $80 \mathrm{ml}$ of water, add components, cool on ice, adjust $\mathrm{pH}$ to 7.7 , and bring to a final volume of $100 \mathrm{ml}$. Store at $-20 \mathrm{C}$ in $25 \mathrm{ml}$ aliquots. Dilute $25 \mathrm{ml}$ of stock to $125 \mathrm{ml}$ final volume before use.

Start with $80 \mathrm{ml}$ of water and add components. IMPORTANT: Adjust $\mathrm{pH}$ to 7.5 at room temperature, and bring to a final volume of $100 \mathrm{ml}$.

a Abbreviations: HEPES, 4-(2-hydroxyethyl)-1-piperazineethanesulfonic acid; EDTA, ethylenediaminetetraacetic acid.

next step will react too quickly. Remove the sodium metal block from the mineral oil it is typically stored in and cut a clean piece (remove any oxidized portions so that the metal has a shiny, silver appearance) weighing $0.18 \mathrm{~g}$. Blot oil away with a dry paper towel, and add the sodium to the flask, being careful to keep it separate from the mercury. The reaction between sodium and mercury will be instantaneous. Mix all the sodium at once into the warm mercury with a glass rod, and continue mashing with the glass rod until the reaction appears to be complete. This will produce a vigorous reaction, which will form an amalgam that will solidify upon cooling. The amalgam should be grey and brittle. Sodium amalgam is very hydroscopic and is no longer usable if it softens. It must be used quickly.

Grind the amalgam in a very dry mortar and pestle (one that has been dried and stored in an oven until used so that there is no moisture present) to yield approximately a $100 \mu \mathrm{l}$ volume of fine powder. Add that powder to $800 \mu$ l of Proto solution in a 3.6-ml screw-capped, polypropylene tube (Corning cryotubes work well). Pressure will build during the reduction reaction because hydrogen is produced. Vent the tube every $30 s$ to increase $\mathrm{H}_{2}$ partial pressure. It is better to maintain some slight head pressure, but extreme caution must be observed or the tube will explode. Let the reaction proceed until most of the color is gone from the solution (about 10 to $20 \mathrm{~min}$ ). Complete reduction is rarely achieved, but unreduced Proto will be removed in the next step. Transfer the solution with the Protogen by glass pipette from the sodium amalgam slurry to a 3 -cc $(3 \mathrm{ml})$ syringe equipped with a $0.2 \mu \mathrm{m} 13 \mathrm{~mm}$ nylon membrane filter (Gelman Acrodisc, Fisher Scientific, Pittsburgh, PA) containing $800 \mu \mathrm{l}$ of undiluted $\times 5$ direct assay buffer and $7.5 \mu \mathrm{l}$ of $1 \mathrm{M}$ dithiothreitol. Insert the plunger, gently mix the solution, and filter into a glass tube. Traces of Proto will stay in the filter, and Protogen will go through. The solution must be kept on ice and in darkness and used the same day. Dissolve any leftover amalgam, and the remaining solid in the reaction tube, into water to collect the mercury waste, which will collect at the bottom of the aqueous layer.

Enzyme Assay. The assay is done on a spectrofluorophotometer set at $30 \mathrm{C}$. Incubate $200 \mu \mathrm{l}$ of etioplasts with herbicides $(2-\mu l$ aliquots of $\times 100$ concentration) for at least $5 \mathrm{~min}$ on ice. Prepare the assay solution by combining $600 \mu \mathrm{l}$ of $\times 5$ assay buffer, $10 \mu \mathrm{l}$ dithiothreitol, and 2,080 $\mu$ l deionized water at $30 \mathrm{C}$. The assay reaction consists of $880 \mu \mathrm{l}$ of assay solution (Table 6), $20 \mu$ Protogen solution, and $100 \mu \mathrm{l}$ etioplast solution pipetted directly in a fluorescence-grade disposable cuvette (the disposable cuvettes must provide transparency from 220 to $900 \mathrm{~nm})$. Determine the $\mathrm{IC}_{50}$ values under saturated, substrate conditions ( $2 \mathrm{mM}$ Protogen) and in the presence of 0.01 to $1,000 \mu \mathrm{M}$ technicalgrade herbicide (Figure 5C).

Record fluorescence for $60 \mathrm{~s}$ using a spectrofluorophotometer with excitation and emission wavelengths set at 395 and $626 \mathrm{~nm}$, respectively. 
The excitation and emission bandwidths are set at 2.5 and $20 \mathrm{~nm}$, respectively, and an electronic emission filter with cutoff at $430 \mathrm{~nm}$ is used to reduce background noise.

PPO Tip 6. Select the smallest excitation slit and the largest emission slit, which reduces interference with scattered light from the light source, but this selection can result in high background noise because Proto is highly fluorescent.

\section{Phytoene Desaturase: Molecular Target of Herbicide Class $F_{1}$ (WSSA Group 12)}

Phytoene desaturase (PDS) participates in the carotenoid biosynthesis pathway (Dayan and Duke 2003). Key aspects of this mode of action are the bleaching (reduction of carotenoid and chlorophyll levels) in the newly emerging tissue and the accumulation of phytoene (Figure 6A). Please refer to the sections "Chlorophyll Quantification" and "Carotenoid Quantification."

Generally, the bleaching effect of a PDS inhibitor can be distinguished from that of an inhibitor of $p$ hydroxyphenylpyruvate dioxygenase (HPPD) by applying the herbicides to a leaf and observing where the bleaching occurs. PDS inhibitors are not phloem mobile because they are very lipophilic, so bleaching will occur on the new growth within the treated leaf. On the other hand, commercial HPPD inhibitors are less lipophilic and tend to translocate, causing bleaching of the meristematic tissue away from the treated leaf.

Phytoene Quantification. Phytoene is extracted and quantified by the method described by Sprecher et al. (1998), which is very similar to that described for carotenoid analysis. More tissue is required, however, and detection is done in petrol because the

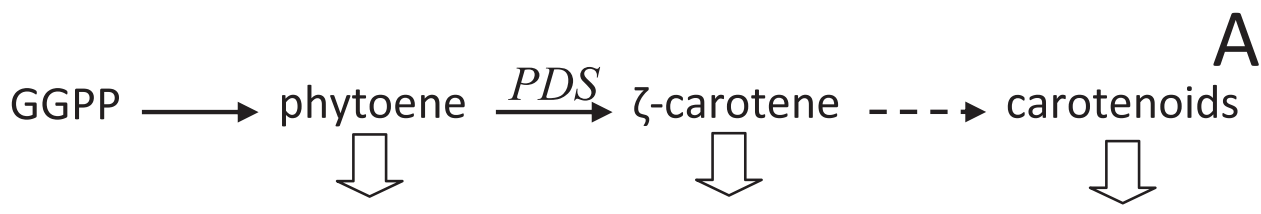

Direct detection by HPLC and UV

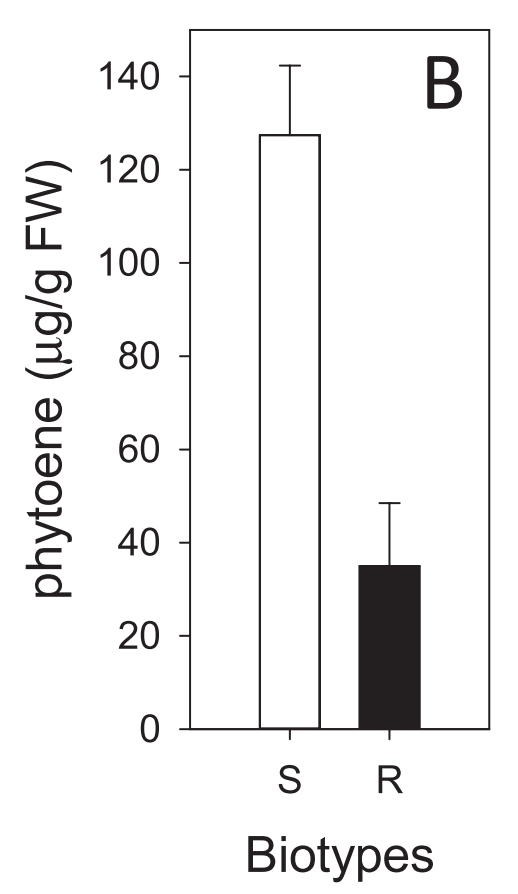

Biotypes
Direct detection by UV
Direct detection by HPLC and UV

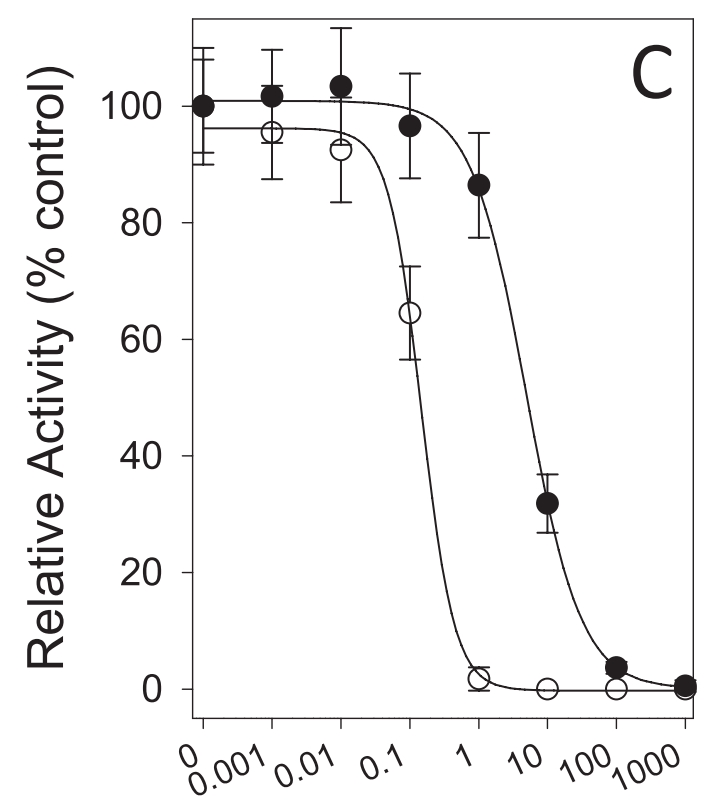

Fluridone $(\mu \mathrm{M})$

Figure 6. A) Phytoene desaturase (PDS) catalyzes the conversion of phytoene to $\zeta$-carotene in the biosynthesis of carotenoids. B) Effect of $12 \mathrm{nM}$ fluridone on phytoene accumulation in wild-type (white) and herbicide resistant (black) Hydrilla verticillata. C). Doseresponse curve of fluridone on heterologously expressed PDS from wild-type $(\bigcirc)$ and herbicide resistant $(\mathbf{O})$ Hydrilla verticillata. 
absorption spectrum of acetone interferes with that of phytoene. Measure between 100 and $250 \mathrm{mg}$ of fresh shoot tissue, and homogenize in $3 \mathrm{ml}$ of basic methanol $(6 \% \mathrm{KOH}$ in methanol w/v) in $16 \times$ $100-\mathrm{mm}$ glass tubes. Leave the samples at RT for $15 \mathrm{~min}$. Centrifuge for $5 \mathrm{~min}$ at $2,000 \times g$, and transfer the supernatant to clean glass tubes. Extract phytoene by partitioning with $3 \mathrm{ml}$ of petrol. Vortex the tubes and allow them to stand for $5 \mathrm{~min}$. Add a $1.5-\mathrm{ml}$ volume of saturated sodium chloride, and vortex the tubes again. Centrifuge at 2,000 $\times g$ for $5 \mathrm{~min}$. Collect and transfer a $1.25-\mathrm{ml}$ aliquot from the top organic layer of each tube to a $1.5-\mathrm{ml}$ methacrylate semimicro, disposable UV cuvette (Fisherbrand, Thermo Fisher). Quantify phytoene on a spectrophotometer at $287 \mathrm{~nm}$ with an extinction coefficient of $\varepsilon_{287}=1,108(\% \quad \mathrm{w} / \mathrm{v})$ (Figure 6B).

PDS Tip 1. Obtain the micrograms of phytoene per gram of FW with the following equation:

$$
\mu \mathrm{g}_{\text {phytoene }} \mathrm{g}_{\mathrm{FW}}^{-1}=\left(A_{287} \times 0.000027\right) /\left(\mathrm{g}_{\mathrm{FW}} \times 10^{6}\right)
$$

where $A_{287}$ is the absorbance of the $3-\mathrm{ml}$ petrol solution obtained at the end of the extraction. Make sure to convert the milligrams of tissue measured into grams of FW for the equation.

Enzyme Assay. There have been many attempts to assay phytoene desaturase activity in leaf crude extracts, but doing so is difficult because the substrate is a hydrocarbon chain with no chromophore and is not readily derivatized. However, it has been done by incorporating ${ }^{14} \mathrm{C}$-geranylgeranylpyrophosphate $\left({ }^{14} \mathrm{C}-\mathrm{GGPP}\right)$ in isolated thylakoid preparations (Sandmann 1993) and in isolated chromoplasts from red bell peppers (Capsicum annuum L.) (Camara 1993).

PDS Tip 2. Be aware that the problem with this approach is that more than $90 \%$ of the ${ }^{14} \mathrm{C}$ GGPP is incorporated into the phytyl tail of the chlorophyll, and only a small portion ends up in carotenoids (FE Dayan, personal experience).

Activity of plant PDS, however, can be expressed heterologously in E. coli using conventional molecular techniques (Michel et al. 2004). Pellet cells express PDS by centrifugation at $3,000 \times g$ for
20 min at $4 \mathrm{C}$. Wash the pellets with $0.9 \%$ sodium chloride, transfer them to 50-ml tubes, and centrifuge again. Discard the supernatant, and store the pellets at $-80 \mathrm{C}$. For extraction, thaw the pellets and lyse in $7.5 \mathrm{ml}$ PDS assay buffer (Table 7) using a French press at $140 \mathrm{MPa}$. Add $75 \mu \mathrm{l}$ of $100 \mathrm{mM}$ PMSF (in ethanol) to obtain $1 \mathrm{mM}$ protease inhibitor and 75 units of benzonase to degrade DNA, and wait $20 \mathrm{~min}$ at RT. Adding the benzonase is useful for liquefying the thick and sticky consistency of the extract and makes the centrifugation step more effective. Centrifuge the lysate at $16,000 \times g$ for 10 min at $4 \mathrm{C}$ and decant the supernatant into a clean tube on ice. Purify the his-tagged (Merck) PDS protein on a nickel-activated HiTrap Chelating HP column (GE Healthcare Biosciences, Pittsburgh, PA) according to the manufacturer's protocol and elute with $250 \mathrm{mM}$ imidazole.

PDS Tip 3. Determine the concentration of imidazole required to elute the his-tagged protein in preliminary experiments.

Desalt the sample by loading a 2.5-ml aliquot of the fraction containing PDS activity on a Sephadex G-25 size-exclusion column (GE Healthcare Biosciences), which has been equilibrated with assay buffer (200 mM sodium phosphate [pH 7.2]). Elute the protein with $3.5 \mathrm{ml}$ of assay buffer, adjust the protein concentration to $100 \mu \mathrm{g} \mathrm{ml}^{-1}$, and store at $-80 \mathrm{C}$.

Synthesis of Phytoene. Crude extracts containing phytoene are produced in E. coli JM101 (pACCRTEB) expressing GGPP synthase and phytoene synthase enzymes from Erwinia uredovora (EB) (Misawa et al. 1995). The EB extract is diluted to $10 \mathrm{mg}$ protein $\mathrm{ml}^{-1}$ and stored at $-80 \mathrm{C}$. This extract contains ample amounts of phytoene to assay PDS activity.

PDS Assay. Thaw one tube of purified PDS extract and one tube of EB extract. Keep on ice. For each sample, add $100 \mu \mathrm{l}$ of PDS $(10 \mu \mathrm{g}$ protein) to a microcentrifuge tube with $10 \mu \mathrm{l}$ of either solvent (acetone or methanol) or $\times 100$ herbicide solution, and mix thoroughly. Dose-response curves are obtained by testing technical-grade herbicides in concentrations ranging from $1 \mathrm{nM}$ to $1 \mathrm{mM}$ (Figure 6C). Incubate the enzyme with the herbicides on ice for $15 \mathrm{~min}$ before starting the reaction by adding $100 \mu \mathrm{l}$ of EB crude extract $(1 \mathrm{mg}$ total 
Table 7. Solutions and reagents for extraction and enzyme assays to measure phytoene desaturase (PDS) activity.

Components

Procedure

Saturated sodium chloride $(250 \mathrm{ml})$

$100 \mathrm{~g}$ sodium chloride

Add sodium chloride to $250 \mathrm{ml}$ of deionized water, and bring to a gentle boil while stirring on a hot plate. Add a very small amount of water gradually until salt is completely dissolved. Cool overnight, and store at room temperature. Some salt will crystallize, but the solution will be saturated.

PDS assay buffer $(100 \mathrm{ml})$

$200 \mathrm{mM}$ sodium phosphate

Add $28 \mathrm{ml}$ of $200 \mathrm{mM}$ sodium phosphate monobasic to $72 \mathrm{ml}$ of $200 \mathrm{mM}$ sodium phosphate dibasic to obtain $\mathrm{pH} 7.2$.

protein). The assay is carried out for $30 \mathrm{~min}$ at $30 \mathrm{C}$ with constant, gentle mixing on a thermomixer. Activity drops sharply at incubation times in excess of $30 \mathrm{~min}$.

Transfer the reaction mixtures to $12 \times 75-\mathrm{mm}$, disposable, glass culture tubes containing $1 \mathrm{ml}$ of basic methanol $(6 \% \mathrm{KOH}$ in methanol w/v). Rinse the microcentrifuge tube with $200 \mu \mathrm{l}$ of basic methanol and add to the glass tube. Mix the solutions thoroughly. Add $1 \mathrm{ml}$ of ether : petrol $(1: 9)$ to each tube, mix, and place on ice before adding $500 \mu \mathrm{l}$ of saturated sodium chloride. Centrifuge at $4 \mathrm{C}$ and $3,900 \times g$ for $10 \mathrm{~min}$. Transfer a $600-\mu \mathrm{l}$ aliquot of the supernatant to a fresh $12 \times 75-\mathrm{mm}$ disposable, glass culture tube, and dry in a heat block under a gentle flow of nitrogen. Cool the tube to RT, then add $125 \mu$ of acetone. Quantify $B$-carotene amounts by spectrophotometry at $425 \mathrm{~nm}$ in a quartz cuvette using a millimolar extinction coefficient of $\varepsilon_{425}=138$.

PDS Tip 4. Realize that millimolar $\varepsilon_{425}=138$ means that a $1 \mathrm{mM}$ solution of $\beta$-carotene has an absorbance of 138 unit at $425 \mathrm{~nm}$. For the PDS method described, obtain the nanomoles of $\beta$ carotene per milligram of protein per hour with the following equation:

$$
\mathrm{nmol}_{\beta \text {-carotene }} \mathrm{mg}^{-1} \mathrm{~h}^{-1}=A_{425} \times 45.29
$$

assuming that $10 \mu \mathrm{g}$ of protein is assayed for $30 \mathrm{~min}$ and that $\beta$-carotene is quantified in a $125-\mu \mathrm{l}$ final volume of acetone.

\section{p-Hydroxyphenylpyruvate Dioxygenase: Molecular Target of Herbicide Class $F_{2}$ (WSSA Group 27)}

$p$-Hydroxyphenylpyruvate dioxygenase (HPPD) converts $p$-hydroxyphenylpyruvate (HPP) to homogentisate (HGA), a step involved in the synthesis of prenyl quinones and tocopherol (Figure 7A). Because plastoquinone is an essential cofactor for PDS, the symptoms of HPPD inhibition are the same as those of PDS inhibitors (e.g., reduction in chlorophyll and carotenoids and accumulation of phytoene) (Figure 7C). There is no known case, to our knowledge, of naturally evolved resistance because of alteration of the enzyme target.

Bioassays. The simple tests measuring chlorophyll and carotenoid levels described at the beginning of this review work well with HPPD inhibitors. As a diagnostic tool, the bleaching pattern of HPPD inhibitors is different from that of the PDS inhibitors because of their differences in phloem mobility. HPPD inhibitors also reduce the cellular levels of plastoquinone, whereas PDS inhibitors do not have that effect.

Enzyme Assay. HPPD activity is not easily assayed in crude plant extracts but is easily tested by heterologous expression of the plant gene in $E$. coli (Dayan et al. 2007). Conventional molecular techniques are used to express the desired plant HPPD gene in E. coli.

Harvest the induced cells, and wash as described in the "Phytoene Desaturase" section. Store cells at $-80 \mathrm{C}$ until use. Resuspend cells in $7.5 \mathrm{ml}$ of extraction buffer and lyse with a French press. Add 6-aminohexanoic acid and benzamidine to final concentration of $1 \mathrm{mM}$ each, along with 750 unit of benzonase, to the lysed cells. Incubate for $20 \mathrm{~min}$ at RT. Obtain a cell-free supernatant by centrifugation at $35,000 \times \mathrm{g}$ for $30 \mathrm{~min}$ at $4 \mathrm{C}$.

HPPD Tip 1. Always apply protease inhibitors once the cells have been lysed. These compounds typically have very short half-lives in water and must interact with proteases very rapidly to deactivate them. 

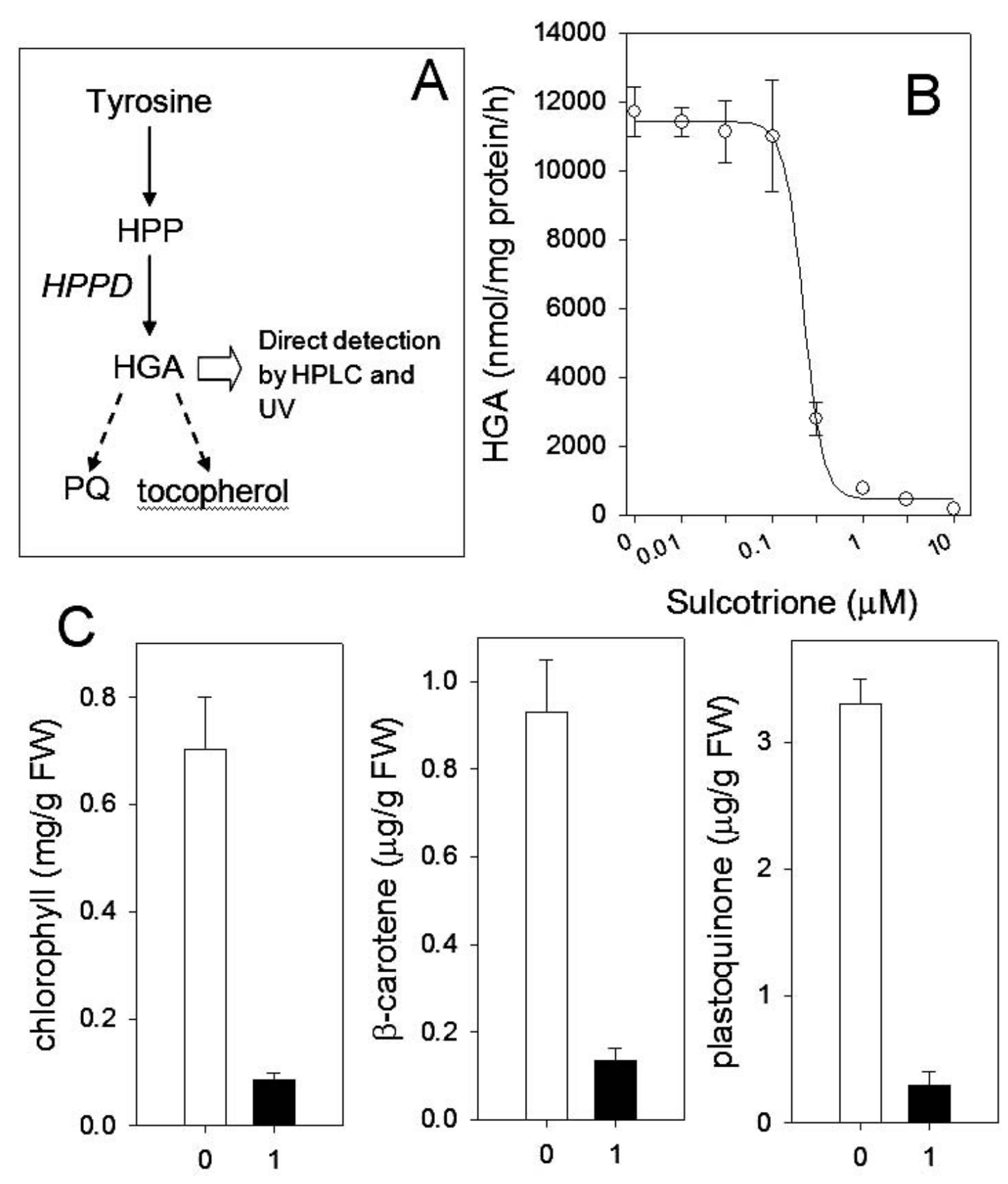

\section{Sulcotrione $(\mu \mathrm{M})$}

Figure 7. A) $p$-Hydroxyphenylpyruvate dioxygenase (HPPD) catalyzes the conversion of p-hydroxyphenylpyruvate (HPP) to homogentisate (HGA). Effect of sulcotrione on B) heterologously expressed Arabidopsis thaliana activity and C) chlorophylls, carotenoids and plastoquinone levels.

Adjust the total soluble protein concentration to $5 \mathrm{mg} \mathrm{ml}^{-1}$ using the Bradford (1976) method. The assay mixture consists of $50 \mu \mathrm{l}$ of extract $(250 \mu \mathrm{g}$ protein) in $140 \mu \mathrm{l}$ of assay buffer (Table 8). Add inhibitors to the assay mixture in a $5-\mu l$ volume to obtain final concentrations ranging from 0.01 to $100 \mu \mathrm{M}$ in half-log increments, and incubate for $15 \mathrm{~min}$ on ice. Start the reaction by adding $5 \mu \mathrm{l}$ of 4-HPP (from $10 \mathrm{mM}$ in methanol) for a final volume of $200 \mu \mathrm{l}$. Controls contain the same volume of solvent used to deliver the inhibitor. Incubate the assay at $30 \mathrm{C}$ for $15 \mathrm{~min}$. Add $70 \mu \mathrm{l}$ of $20 \%(\mathrm{v} / \mathrm{v})$ perchloric acid to stop the reaction. Centrifuge at $20,000 \times g$ for 5 min to remove the precipitate. Quantify HGA in the supernatant by HPLC (Figure 7B).

HPLC Analysis. A Nova-Pak C18 reversed-phase column (Waters), preceded by a Bio-Rad (Hercules, CA) ODS-5S guard column, is used for analysis. 
Table 8. Solutions and reagents for extraction and enzyme assays to measure $p$-hydroxyphenylpyruvate dioxygenase (HPPD) activity. ${ }^{\text {a }}$

Components
Extraction buffer $(100 \mathrm{ml})$
$20 \mathrm{mM}$ potassium phosphate
$1 \mathrm{mM}$ EDTA $(100 \mu \mathrm{l}$ of $1 \mathrm{M}$ stock $)$
HPPD assay buffer $(200 \mathrm{ml})$
$50 \mathrm{mM}$ sodium ascorbate
$100 \mathrm{mM}$ Tris- $\mathrm{HCl}$

Procedure

a Abbreviation: EDTA, ethylenediaminetetraacetic acid.

The solvent system consists of a linear gradient beginning at $0 \% \mathrm{~B}(100 \% \mathrm{~A})$ to $70 \% \mathrm{~B}$, from 0 to $7 \mathrm{~min} ; 70$ to $100 \% \mathrm{~B}$, from 7 to $9 \mathrm{~min} ; 100 \% \mathrm{~B}$, from 9 to $10 \mathrm{~min}$; 100 to $0 \% \mathrm{~B}$, from 10 to $12 \mathrm{~min}$; and $0 \% \mathrm{~B}$, from 12 to $22 \mathrm{~min}$. The flow rate is $1 \mathrm{ml} \mathrm{min}{ }^{-1}$, and the injection volume is $100 \mu \mathrm{l}$. Solvent $\mathrm{A}$ is deionized water containing $0.1 \%(\mathrm{v} / \mathrm{v})$ trifluoroacetic acid, and solvent $\mathrm{B}$ is a $4: 1$ ratio of HPLC-grade methanol : deionized water containing $0.07 \%(\mathrm{v} / \mathrm{v})$ trifluoroacetic acid. HGA is detected by UV absorbance at $288 \mathrm{~nm}$ (Garcia et al. 1999). A calibration curve is established by injecting known amounts of HGA.

\section{Deoxyxylulose-5-Phosphate Synthase: Molecular Target of Herbicide Class $\mathbf{F}_{3}$ (WSSA Group 13)}

$\mathrm{F}_{3}$ is a complicated classification because it contains compounds with modes of action other than deoxyxylulose-5-phosphate synthase (DXS). For example, aclonifen inhibits PDS $\left(\mathrm{F}_{1}\right)$ and PPO (E) (Kilinc et al. 2009). For the sake of this review, $\mathrm{F}_{3}$ will be strictly associated with DXS, the molecular target site involved in the mode of action for clomazone. We also suggest that this be formalized as a new category in the Herbicide Handbook. Additionally, compounds in this class that are known PPO inhibitors should be moved to class E.

DXS is the first committed step of the methylerythritol-4-phosphate (MEP) pathway leading to the synthesis of isopentenyl pyrophosphate (IPP) in the chloroplast (Fellermeier et al. 2003; Lichtenthaler 2010). It is a parallel pathway to IPP synthesis in the cytosol via the mevalonate pathway (Lichtenthaler et al. 1997). These two pathways serve different purposes, with the MEP pathway leading to carotenoids and phytyl (Figures 8A and 8B) and the mevalonate pathway being involved in the synthesis of sesquiterpenes and sterols (Dayan et al. 2010b).

Clomazone is the only herbicide known to interfere with DXS activity. Clomazone causes
Start with $80 \mathrm{ml}$ of deionized water, add EDTA and buffer, cool on ice, adjust $\mathrm{pH}$ to 6.8 , and bring to a final volume of $100 \mathrm{ml}$.

Start with $80 \mathrm{ml}$ of water, add sodium ascorbate and buffer, adjust $\mathrm{pH}$ to 7.5 at $30 \mathrm{C}$, and bring to a final volume of $200 \mathrm{ml}$.

bleaching of photosynthetic tissues by inhibiting carotenoid biosynthesis, but it does so indirectly. It must be metabolized to ketoclomazone to inhibit DXS (Mueller et al. 2000). The oxidation of clomazone to ketoclomazone is catalyzed by a P450 monooxygenase, and treatment of plants with phorate or other P450 monooxygenase inhibitors reduces the metabolism of clomazone and protects plants from bleaching (Ferhatoglu and Barrett 2006; Ferhatoglu et al. 2005).

Leaf Disc Assay. DXS activity cannot be easily measured directly in plant tissues. We have developed a simple assay evaluating the carbon flow through the MEP pathway by measuring phytoene accumulation, one of the downstream products of this pathway, in the presence of a PDS inhibitor (Figure 8A). This assay may be suitable, therefore, for measuring the inhibition of any of the early steps of the MEP pathway. Phytoene accumulation is achieved by floating $100 \mathrm{mg}$ of etiolated barley (Hordeum vulgare L.) leaf segments on $5 \mathrm{ml}$ of 5-mM MES buffer with $200 \mu \mathrm{M}$ norflurazon (an inhibitor of PDS) in a $60 \times$ 15-mm disposable petri dishes for $24 \mathrm{~h}$.

DXS Tip 1. Select barley because it is highly sensitive to clomazone (Anderson 1990), which is important because some plants do not metabolize clomazone to ketoclomazone (the active form) very rapidly, and their inhibitory effects may not be detected during the time span of the experiment.

The effect of clomazone, the only commercial herbicide targeting DXS, is evaluated by measuring the reduction in phytoene levels as described in the phytoene desaturase section (Figure 8B). Typical dose-response curves range from 0.1 to $100 \mu \mathrm{M}$.

Enzyme Assay. There are no simple assays to measure DXS activity, which is most easily achieved 
A

${ }^{14} \mathrm{C}$

Detection

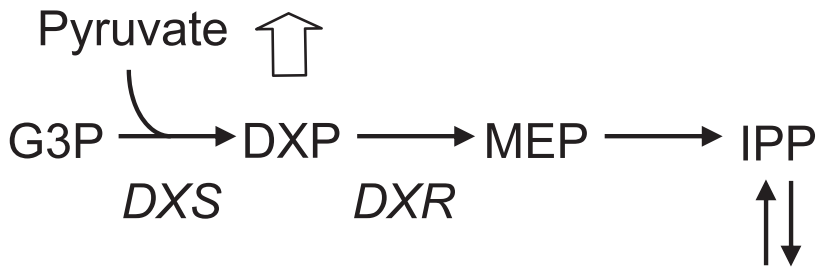

DMAPP

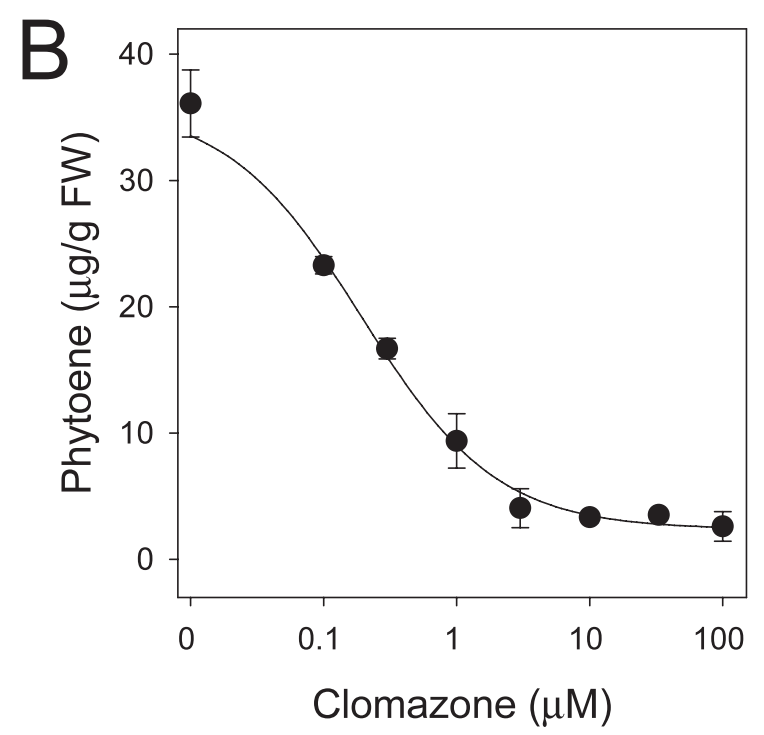

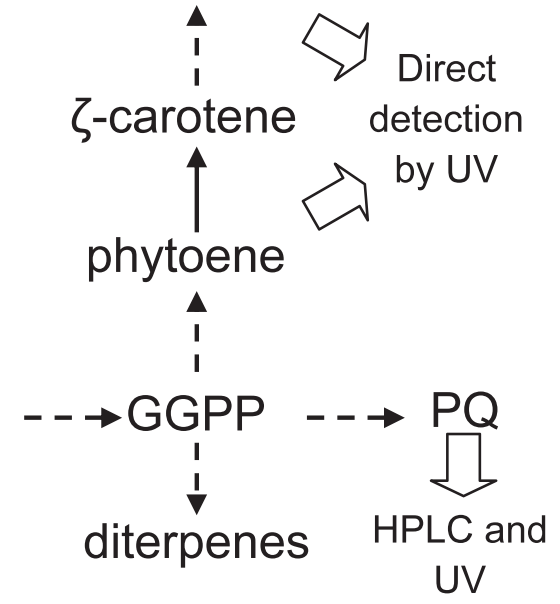

carotenoids

C

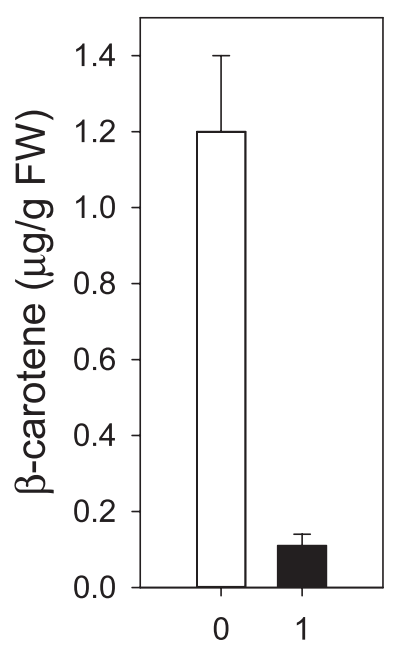

Clomazone $(\mu \mathrm{M})$

Figure 8. A) Deoxyxylulose-5-phosphate synthase (DXS) catalyzes the first step of the MEP pathway leading to IPP synthesis in plastids. B) Inhibition of $\beta$-carotene by clomazone. The curve is a reflection of the inhibition of carbon flow into the MEP. C) Effect of clomazone on accumulation of phytoene in barley leaf disc assay treated with $200 \mu \mathrm{M}$ norflurazone.

by heterologous expression of the plant gene in $E$. coli. Conventional molecular techniques are used to express and purify the desired plant DXS gene in $E$. coli (Chahed et al. 2000). The assay consists of incubating DXS with glyceraldehyde-3-phosphate and ${ }^{14} \mathrm{C}$-pyruvate and measuring the formation of ${ }^{14} \mathrm{C}$-deoxyxylulose after dephosphorylation with alkaline phosphatase (Schwender et al. 1999).

\section{5-Enolpyruvylshikimate-3-Phospate Synthase: Molecular Target of Herbicide Class G (WSSA Group 9)}

5-Enolpyruvylshikimate-3-phospate synthase (EPSPS), an enzyme in the shikimic acid pathway involved in the biosynthesis of all aromatic amino acids (phenylalanine, tyrosine, and tryptophan), is the target site of glyphosate (Figure 9A). The effect of glyphosate on plants can be easily measured by monitoring the accumulation of shikimate in young tissues (Figure 9B). Measuring the activity of EPSPS and its sensitivity to glyphosate is more involved and relatively expensive, but it can also be done in crude leaf extracts (Figure 9C).

Determination of Shikimate. A myriad of methods have been developed to quantify shikimate in leaf tissues. Most methods require 0.1 to $1 \mathrm{~g}$ of fresh tissue and require a homogenization or grinding step. In our laboratory, we selected the Shaner et al. (2005) method because of its relative simplicity and good sensitivity. It requires only single-leaf discs (i.e., 4 to $5 \mathrm{mg}$ tissue) and does not involve grinding or homogenization of the 


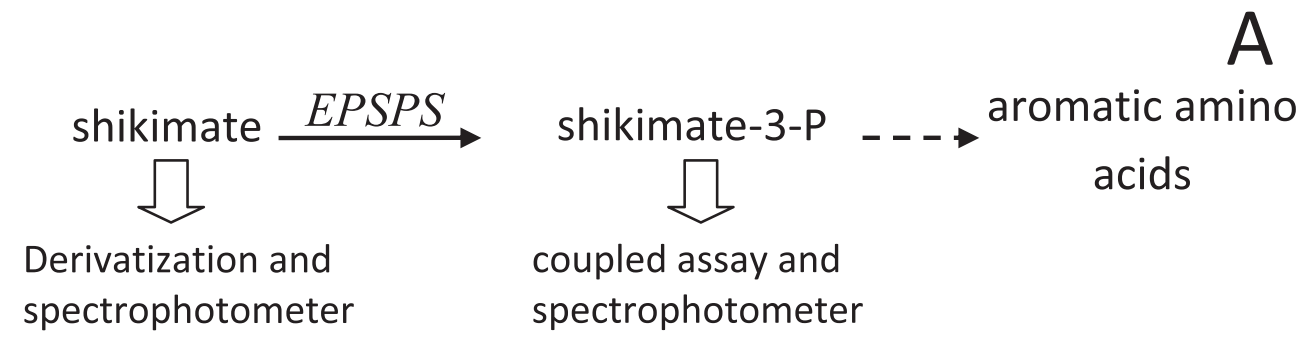

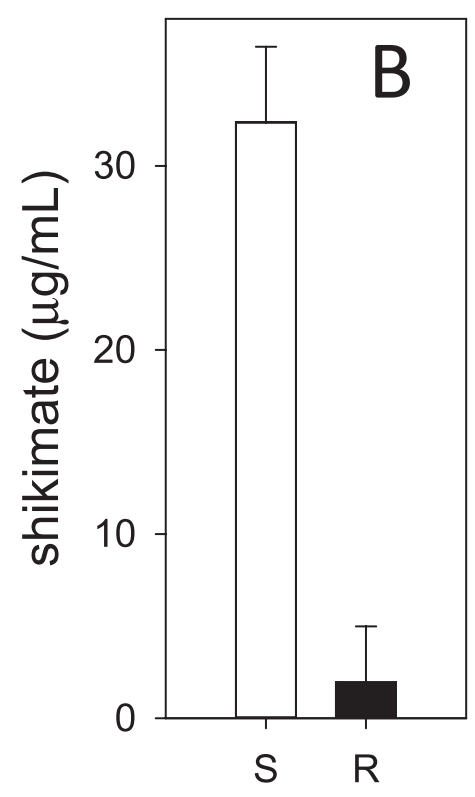

Biotypes

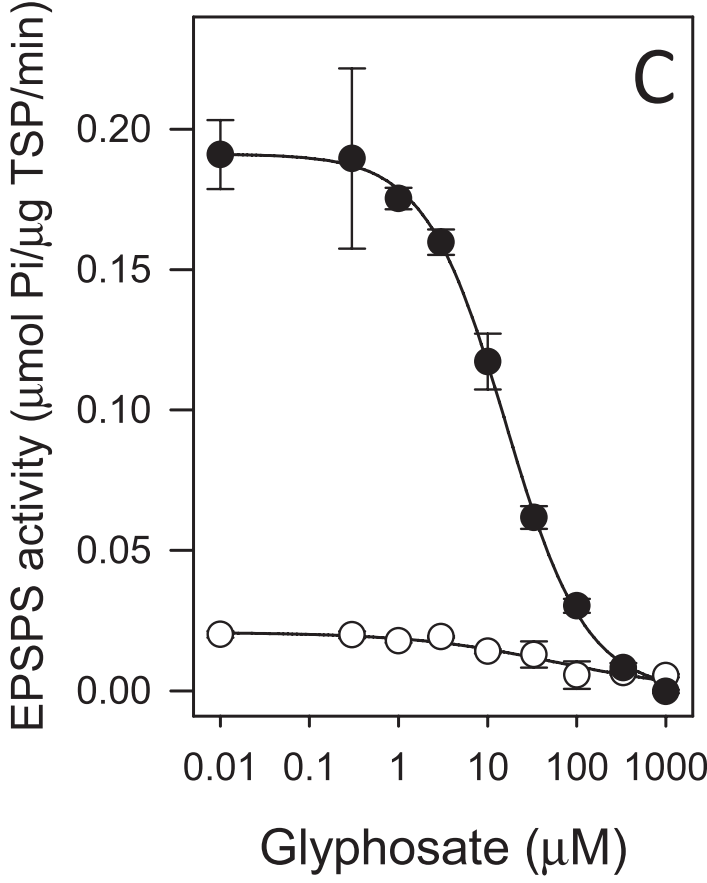

Figure 9. A) Enoylpyruvyl shikimate-3-phosphate synthase (EPSPS) catalyzes the conversion of shikimate-3-phosphate to enoylpyruvyl shikimate-3-phosphate in the biosynthesis of aromatic amino acids. B) Effect of $100 \mu \mathrm{M}$ glyphosate on shikimate accumulation in wild-type (white) and herbicide resistant (black) Amaranthus palmeri. C) Dose-response curve of glyphosate on EPSPS activity in crude extracts from wild-type (white) and herbicide resistant (black) Amaranthus palmeri. Notice the much higher activity in the resistant biotype, which is the result of gene amplification.

sample. For optimum results, excise discs $(4 \mathrm{~mm}$ in diameter) from young leaves, and place in separate wells of a microtiter plate each containing $100 \mu \mathrm{l}$ of 10 $\mathrm{mM}$ ammonium phosphate monobasic (adjust to $\mathrm{pH}$ 4.4 with either $0.1 \mathrm{~N} \mathrm{HCl}$ or $\mathrm{NaOH}$ ).

EPSPS Tip 1. Scale up the method developed for a microtiter plate format (which requires a microplate reader) for extractions in tubes and detection with a regular spectrophotometer.

A nonionic surfactant, such as $0.1 \%(\mathrm{v} / \mathrm{v})$ Tween 20 , can be added to reduce the surface tension, which improves both the penetration of glyphosate and the extraction of shikimate. Full dose-response curves (1 to $500 \mu \mathrm{M}$ glyphosate can be done directly in the microtiter plates. Seal and wrap plates with plastic to minimize evaporation, and incubate under fluorescent lights $\left(150 \mu \mathrm{M} \mathrm{m}^{-2} \mathrm{~s}^{-1}\right)$ at $25 \mathrm{C}$ for up to $24 \mathrm{~h}$. The format can be adapted if the desire is to determine the accumulation of shikimate over time. After incubation, place plates in a $-20 \mathrm{C}$ freezer until the solution is frozen. Alternatively, shikimate accumulating in tissue samples from whole plants treated with glyphosate can be extracted in the same way. The samples can be kept frozen until further analysis. At that time, thaw samples at $60 \mathrm{C}$ for $30 \mathrm{~min}$, add $25 \mu \mathrm{l}$ of 1.25 $\mathrm{N} \mathrm{HCl}$ into each well (final concentration of 0.25 $\mathrm{N} \mathrm{HCl}$ per well), and incubate the plates at $60 \mathrm{C}$ for $15 \mathrm{~min}$.

EPSPS Tip 2. Determine the final concentration of $\mathrm{HCl}$, which is very important for accurate shikimate quantification. 
Table 9. Solutions and reagents for extraction and enzyme assays to measure 5-enolpyruvylshikimate-3-phosphate synthase (EPSPS) activity. ${ }^{\mathrm{a}}$

\begin{tabular}{|c|c|}
\hline Components & Procedure \\
\hline $\begin{array}{l}100 \mathrm{mM} \mathrm{MOPS} \\
5 \mathrm{mM} \mathrm{EDTA} \\
10 \% \text { glycerol }(\mathrm{v} / \mathrm{v}) \\
50 \mathrm{mM} \mathrm{KCl} \\
0.5 \mathrm{mM} \text { benzamidine }\end{array}$ & $\begin{array}{l}\text { Start with } 80 \mathrm{ml} \text { of water, add components, adjust } \mathrm{pH} \text { to } 7.0 \text { on ice, } \\
\text { and bring to a final volume of } 100 \mathrm{ml} \text {. Just before using, add } 1 \% \\
\text { PVPP (which will not go into solution, so you'll end up with a } \\
\text { suspension) and } 70 \mu \mathrm{l} \text { of } \beta \text {-mercaptoethanol. }\end{array}$ \\
\hline $\begin{array}{l}100 \mathrm{mM} \text { MOPS } \\
5 \mathrm{mM} \text { EDTA (Final concentration } 10 \mathrm{mM} \text { MOPS, } \\
0.5 \mathrm{mM} \text { EDTA) }\end{array}$ & $\begin{array}{l}\text { Start with } 800 \mathrm{ml} \text { of water, add components, adjust } \mathrm{pH} \text { to } 7.0 \text { on } \\
\text { ice, and bring to a final volume of } 1 \mathrm{~L} \text {. Dilute } 1: 10 \text {, adding } \\
200 \mathrm{ml} \text { of buffer, } 200 \mathrm{ml} \text { of glycerol, and } 700 \mu \mathrm{l} \text { of } \beta \text { - } \\
\text { mercaptoethanol in a final volume of } 1 \mathrm{~L} \text {. }\end{array}$ \\
\hline \multicolumn{2}{|l|}{ Assay buffer $(100 \mathrm{ml}$ of $\times 2)$} \\
\hline
\end{tabular}

a Abbreviations: MOPS, 3-(N-morpholino)propanesulfonic acid; PVPP, polyvinylpolypyrrolidone; EDTA, ethylenediaminetetraacetic acid.

The tissues will become uniformly gray-green. Transfer $25-\mu \mathrm{l}$ aliquots to new wells, and oxidize shikimate with $100 \mu \mathrm{l}$ of a solution containing $0.25 \%$ $(\mathrm{w} / \mathrm{v})$ periodic acid and $0.25 \%(\mathrm{w} / \mathrm{v})$ sodium $m$ periodate at $25 \mathrm{C}$ for $90 \mathrm{~min}$. Then, add $100 \mu \mathrm{l}$ of 0.6 $\mathrm{N}$ sodium hydroxide in $0.22 \mathrm{M}$ sodium sulfite to the wells to neutralize the extract and to quench the oxidative reaction. Determine shikimate spectrophotometrically at $380 \mathrm{~nm}$ within $30 \mathrm{~min}$ using a microtiter plate reader. Background absorption values measured in wells containing discs not exposed to glyphosate are subtracted. Shikimate concentrations are calculated from a shikimate standard curve.

EPSPS Tip 3. Add known amounts of shikimate to wells containing untreated leaf discs (as 25- $\mu$ l aliquots) before placing the samples in the freezer. Extract shikimate as described. The amount of shikimate added to the wells ranges from 3.75 to $30 \mu \mathrm{g}$ to generate the concentrations ranging from 25 to $200 \mu \mathrm{g} \mathrm{ml}^{-1}$ usually observed in tissues treated with glyphosate.

Enzyme Assay. Protein extraction and the EPSPS assay described here generally follow the procedures developed by the Doug Sammons group at Monsanto (St. Louis, MO) (Salas et al. 2012). Grind young, newly developing leaf samples ( $5 \mathrm{~g} \mathrm{FW}$ ) in liquid nitrogen to fine powder in a chilled mortar, and transfer to $50-\mathrm{ml} \mathrm{BD}$ Falcon tubes containing $25 \mathrm{ml}$ of cold extraction buffer (Table 9). Homogenize the sample at full speed for about $5 \mathrm{~min}$ with constant stirring to minimize foaming. Centrifuge for $40 \mathrm{~min}$ at $18,000 \times g$ at 4 C. Decant the supernatant through cheesecloth into a cold beaker. Keep the solution on ice and stir continuously while slowly adding ammonium sulfate to obtain a $45 \%$ $(\mathrm{w} / \mathrm{v})$ solution. Continue stirring for at least $30 \mathrm{~min}$. Centrifuge at $30,000 \times g$ for $30 \mathrm{~min}$ at $4 \mathrm{C}$, and save the supernatant. Repeat this procedure to obtain a $70 \%(\mathrm{w} / \mathrm{v})$ solution, and precipitate the fraction containing EPSPS activity. Save the pellet following centrifugation, and dissolve it in a small volume (1 to $3 \mathrm{ml}$ ) of $\times 2$ assay buffer (Table 9). Dialyze the extract in Slide-A-Lyzer dialysis cassettes (Thermo Scientific, Meridian, IL) overnight in $2 \mathrm{~L}$ of dialysis buffer at $4 \mathrm{C}$ on a stir plate. Protein concentration of the solution in the cassette is quantified by the Bradford (1976) method.

Specific activities of EPSPS are measured in a continuous assay quantifying inorganic phosphate released from shikimate-3-phosphate with the EnzCheck phosphate assay kit (Invitrogen, Carlsbad, CA). Add reagents to a cuvette in the following manner: $600 \mu \mathrm{l}$ of $\times 2$ assay buffer, $300 \mu$ ldeionized water, $0.164 \mathrm{mM}$ of 2-amino-6-mercapto-7-methylpurine riboside (MESG), $1 \mathrm{U}$ purine-nucleoside phosphorylase, $1.02 \mathrm{mM}$ phosphoenolpyruvate (PEP), and $25 \mu \mathrm{l}$ EPSPS extract. MESG should be stored at $-80 \mathrm{C}$ and be freshly prepared for each 
assay. When the effect of glyphosate is tested, final concentrations ranging 0.1 and $1,000 \mu \mathrm{M}$ of the herbicide are added to the reaction mixture. Allow the mixture to react for $20 \mathrm{~min}$ to deplete any phosphate contaminants, and start the EPSPS reaction by adding $50 \mu \mathrm{l}$ of $10 \mathrm{mM}(0.41 \mathrm{mM})$ shikimate-3-phosphate. Monitor the change in absorption at $360 \mathrm{~nm}$ for $10 \mathrm{~min}$ in a spectrophotometer, and calculate the amount of phosphate (in micromoles) released per microgram of total soluble protein (TSP) per minute, based on the slope of the reaction and a calibration curve obtained with free phosphate as indicated in the EnzCheck phosphate assay kit. EPSPS activity is expressed as $\mu \mathrm{mol} \mathrm{Pi} \mu \mathrm{g}^{-1}$ TSP protein $\min ^{-1}$ ).

EPSPS Tip 4. Prepare the shikimate-3-phosphate and PEP stock solutions in $\times 2$ assay buffer, rather than in deionized water.

For the more-precise experiments necessary for kinetic studies, the slope is taken from the most linear portion of the initial rate curve greater than $5 \%$ reaction and less than $20 \%$ reaction. To do that, let the reaction go to completion once, and calculate the micromoles converted. Care must be taken that the initial rate be under conditions when the assay is proportional to the amount of EPSPS enzyme in the extract. As well, EnzCheck must be used in excess to be sure the coupled reaction is not limiting the rate of reaction measured.

\section{Glutamine Synthetase Assay: Molecular Target of Herbicide Class H (WSSA Group 10)}

Glutamine synthetase (GS) is a key enzyme in ammonia assimilation and recycling in plants (Figure 10A). There are two isozymes of GS in plants, a cytoplasmic form, and a chloroplastic form. The chloroplastic form of GS is primarily responsible for recycling ammonia during photorespiration as well as the synthesis of glutamine. The major isozyme of GS in leaves is the chloroplastic form, and its activity increases during development and with increases in photosynthesis and photorespiration (Ireland and Lea 1999). However, inhibitors of GS act on all forms of the enzyme. Glufosinate, the synthesized form of phosphinothricin (Lydon and Duke 1999), is the most widely used GS inhibitor. Glufosinate forms an irreversible complex with GS, causing a loss of extractable GS activity. Inhibition of GS results in a rapid decrease in the free pools of glutamine, glutamate, aspartate, alanine, serine, and glycine (Lydon and Duke 1999) and an accumulation of ammonia. This latter phenomenon is unique to GS inhibition and can be used to analyze inhibition of GS in leaf discs.

Leaf Disc Assay. The leaf disc assay measures the accumulation of ammonia caused by the inhibition of photorespiration by the GS inhibitor (Figure 10B). Hence, the assay needs to be conducted under light and photorespiration conditions (ambient $\mathrm{CO}_{2}$ ) and works primarily for C3 plants. This assay works well in a microtiter plate format. Each well contains $100 \mu \mathrm{l}$ of water. Add $100 \mu \mathrm{l}$ of a $200 \mu \mathrm{M}$ glufosinate solution to the top well (row A), and mix to make a $100 \mu \mathrm{M}$ solution. Transfer $100 \mu \mathrm{l}$ of that well into the well in row $\mathrm{B}$ to make a $50-\mu \mathrm{M}$ solution. Repeat that pattern down the plate to row $G$ to obtain the lowest concentration of glufosinate $(1.5625 \mu \mathrm{M})$. In that row, remove $100 \mu \mathrm{l}$ of solution and discard. The last row is the blank (water only).

GS Tip 1. Obtain a $200-\mu \mathrm{M}$ stock solution of glufosinate by using technical-grade material or by adding $13 \mu \mathrm{l}$ of commercial Rely 280 (Bayer CropScience, Monheim am Rhein, Germany) to $100 \mathrm{ml}$ of water. Rely 280 consists of a $280 \mathrm{~g} \mathrm{~L}^{-1}$ glufosinate solution.

Cut 5-mm-diam leaf discs from leaves of test plant (youngest fully expanded leaf gives the best GS reaction), and place 1 leaf disc per well. The plate is sealed with 2 layers of micropore tape and placed in a growth chamber under light at $150 \mu \mathrm{mol} \mathrm{m}{ }^{-2} \mathrm{~s}^{-1}$ PAR for 16 to $24 \mathrm{~h}$.

Stop the assay by placing the plate at $-80 \mathrm{C}$. Lyse the cell membranes completely by performing at least two freeze-thaw cycles. A 50- $\mu$ l aliquot of the bathing solution from each well is transferred to another plate. The amount of ammonium present in each well is determined using a modified Molin and Khan (1995) method by adding $150 \mu \mathrm{l}$ of water, $100 \mu \mathrm{l}$ of reagent $\mathrm{A}$, and $50 \mu \mathrm{l}$ of reagent $\mathrm{B}$ and mixing the solution. Keep the plates at RT for at least $30 \mathrm{~min}$ before reading on a microplate reader at $A_{630}$. The color development is stable for at least $4 \mathrm{~h}$. Reagent A consists of $6.25 \mathrm{~g}$ of phenol dissolved in $10 \mathrm{ml}$ of $\mathrm{MeOH}$, which is mixed with $56 \mathrm{ml}$ of $0.02 \%$ sodium nitroprusside dihydrate. Reagent B consists of $15 \mathrm{ml}$ of bleach $(6.15 \%$ sodium hypochlorite), $15 \mathrm{ml}$ of $27 \% \mathrm{NaOH}$, and 
<smiles>NC(CCC(=O)O)C(=O)O</smiles>
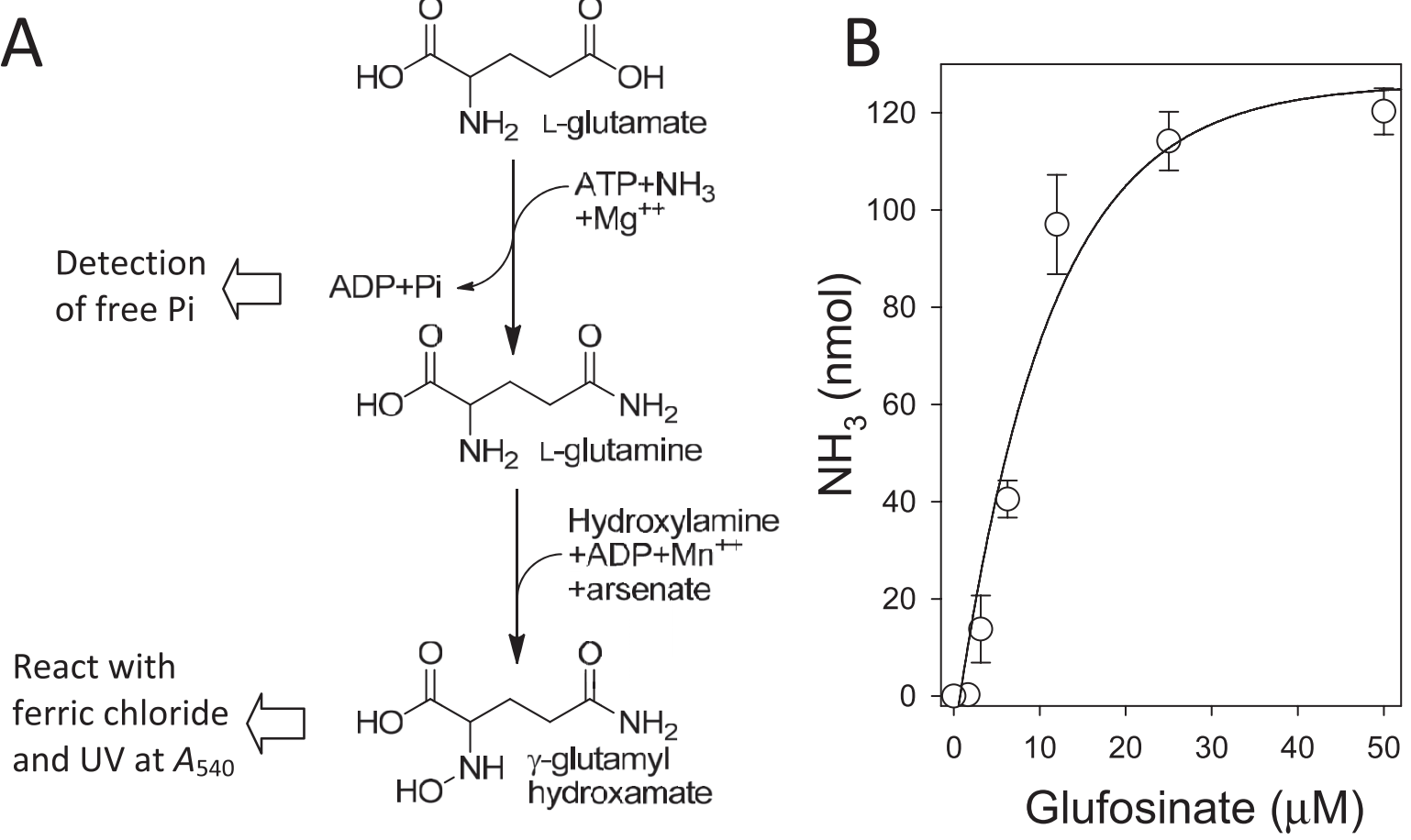

Figure 10. A) Reaction catalyzed by GS and various detection methods. B) Accumulation of ammonia in sunflower leaf discs after $16 \mathrm{~h}$ incubation under light in the presence of increasing amount of glufosinate.

$20 \mathrm{ml}$ of water. Reagents A and B are kept in the fridge in amber-colored glasses (or covered with aluminum foil), but they must be brought to RT before starting the reaction.

GS Tip 2. Alternatively, perform the assay using premixed phenol nitroprusside solution (P6994) and alkaline hypochlorite solution (A1727) from Sigma-Aldrich (St. Louis MO).

GS Tip 3. Use glufosinate technical grade or a commercial formulated product, which both have their glufosinate in its ammonium salt form; the contribution of the ammonium salt from the herbicide is, however, minimal in the color development of the assay.

Analysis of GS Activity In Vitro. Spray plants with solutions of glufosinate $\left(360 \mathrm{~g} \mathrm{~h}^{-1}\right.$ provides very strong inhibition of GS in planta), although the timing of the application can have a great effect on extractable GS activity (Sellers et al. 2004). After $4 \mathrm{~h}$ of light incubation, homogenize $2 \mathrm{~g}$ of leaf material in a chilled mortar and $3 \mathrm{ml}$ of extraction buffer (Table 10). PVP10 increases the extractable GS activity. Filter the extract through Miracloth layered on top of cheesecloth; wash the mortar with $1 \mathrm{ml}$ of extraction buffer, and add that to the Miracloth. Transfer the extract to microfuge tubes and centrifuge at $12,000 \times g$ for $10 \mathrm{~min}$ at $4 \mathrm{C}$. The crude supernatant contains GS activity and is used for the enzyme assay. GS activity can be measured by monitoring the release of inorganic phosphate from ATP. However, this method is sensitive to the presence of $\mathrm{Pi}$ from other reactions. Therefore, it is often more reliable to assay for the GS-dependent formation of $\gamma$-glutamyl hydroxamate, followed by colorimetric determination, by reacting this product with acidic ferric chloride reagent. This can be done by measuring the synthetase reaction as described by Manderscheid (1993). However, we prefer measuring the transferase activity (Forlani 2000).

GS Tip 3. Handle hydroxylamine hydrochloride with care because it is toxic. The glutamate and hydroxylamine should be freshly prepared with each assay.

The reaction consists of $0.9 \mathrm{ml}$ of assay buffer (Table 10) and $0.1 \mathrm{ml}$ crude enzyme extract. Incubate the reaction mixtures for $30 \mathrm{~min}$ at $30 \mathrm{C}$; add $0.5 \mathrm{ml}$ ferric chloride reagent to stop the 
Table 10. Solutions and reagents for extraction and enzyme assays to measure glutamine synthetase (GS) activity. ${ }^{\mathrm{a}}$

\begin{tabular}{l} 
Components \\
\hline GS extraction buffer $(100 \mathrm{ml})$ \\
$50 \mathrm{mM}$ Tris base \\
$1 \mathrm{mM}$ EDTA $(10 \mathrm{ml}$ of $10 \mathrm{mM}$ EDTA $)$ \\
$2 \mathrm{mM}$ DTT $(10 \mathrm{ml}$ of $20 \mathrm{mM} \mathrm{DTT})$ \\
$10 \mathrm{mM} \mathrm{MgCl} 2\left(1 \mathrm{ml}\right.$ of $\left.1 \mathrm{M} \mathrm{MgCl}_{2}\right)$ \\
$5 \mathrm{~g}$ PVP10 \\
GS assay buffer $(25 \mathrm{ml})$ \\
$25 \mathrm{mM}$ imidazole- $\mathrm{HCl}, \mathrm{pH} 7.5$ \\
$4 \mathrm{mM} \mathrm{MnCl}{ }_{2}$ \\
$5 \mathrm{mM}$ ADP \\
$50 \mathrm{mM}$ L-glutamine \\
$40 \mathrm{mM}$ sodium arsenate \\
$25 \mathrm{mM}$ hydroxylamine \\
Acidic ferric chloride reagent $(250 \mathrm{ml})$ \\
$10 \mathrm{~g}$ trichloroacetic acid \\
$8 \mathrm{~g}$ anhydrous ferric chloride \\
$250 \mathrm{ml} 0.5 \mathrm{M}$ HCl
\end{tabular}

Procedure

Make $1 \mathrm{M}$ Tris stock, and adjust to $\mathrm{pH}$ 8. Starting with $50 \mathrm{ml}$ of water, add $5 \mathrm{ml}$ Tris stock and other components, cool on ice, readjust $\mathrm{pH}$ to 8.0 , and bring to a final volume of $100 \mathrm{ml}$.

a Abbreviations: Tris, tris(hydroxymethyl)methylamine; EDTA, ethylenediaminetetraacetic acid; DTT, dithiothreitol; PVP10, polyvinylpyrrolidone 10; ADP, adenosine diphosphate.

reaction, and incubate for $10 \mathrm{~min}$ at RT. Centrifuge at $12,000 \times g$ for $10 \mathrm{~min}$ and determine the concentration of $\gamma$-glutamyl hydroxamate by measuring absorbance at $540 \mathrm{~nm}$ on a spectrophotometer. This assay can also be performed in a microtiter plate by reducing all of the volumes by a factor of 10 .

\section{7,8-Dihydropteroate Synthase: Molecular Target of Herbicide Class I (WSSA Group 18)}

Only one herbicide, asulam, acts by inhibiting folic acid synthesis (Figure 11) (Veerasekaran et al. $1981 \mathrm{a}, \mathrm{b})$. It is an analogue of 4-aminobenzoate ( $\mathrm{ABBA})$, one of the substrates of 7,8-dihydropteroate synthase (DHPS), an enzyme in the pathway to folic acid (Bedhomme et al. 2005). This target site was proven by both in vitro enzyme inhibition and resistance of a plant transformed with a resistant microbial form of DHPS.

The herbicidal symptoms are slowly developing chlorosis and stunted growth of new tissues and slow senescence of mature tissues. No weeds, to our knowledge, have evolved resistance to it, and no transgenic, asulam-resistant crops are available. Asulam is an analog of sulfanilamide, a well known inhibitor of DHPS (Bedhomme et al. 2005). There are no easy assays to measure the effect of asulam on DHPS. However, inhibition of DHPS can be followed in leaf discs or duckweed (Lemna spp.) assays by monitoring the accumulation of $p \mathrm{ABA}$, an intermediate in the synthesis of folic acid (Brain et al. 2008).

Determination of pABA Accumulation. This method is derived from a liquid chromatographytandem mass spectrometry (LC-MS/MS) protocol using cultures of Lemna sp. (Brain et al. 2008) and can be adapted to a spectrofluorometric detection (Huang and Gibson 1970). Place two or three duckweed [Lemna paucicostata (L.) Hegelm] fronds in nonpyrogenic, polystyrene, sterile, six-well plates (CoStar 3506, Corning) containing $5 \mathrm{ml}$ of sterile, full-strength Hoagland media, supplemented with Fe-EDTA. Only colonies with "Mickey Mouse" appearances, where the developing daughter fronds are significantly smaller and still attached to the maternal frond, are selected. Maintain the plates in an incubator (model CU-36L, Percival Scientific) under continuous white light $\left(94 \mu \mathrm{mol} \mathrm{m} \mathrm{m}^{-2} \mathrm{~s}^{-1}\right)$ (Bajsa et al. 2011a). Grow the colonies for $5 \mathrm{~d}$, and then, expose them to various concentrations of asulam in $50-\mu \mathrm{l}$ aliquots. The control receives $50 \mu \mathrm{l}$ of acetone. Incubate the fronds for $24 \mathrm{~h}$ under continuous light. After the incubation period, remove the growth medium, and wash the fronds three times with $4 \mathrm{ml}$ of water. Place samples in a $-80 \mathrm{C}$ freezer until the solution is frozen. The samples can be kept frozen until further analysis.

pABA Extraction. Place the plant samples (about $25 \mathrm{mg}$ ) in $15 \mathrm{ml} \mathrm{BD}$ Falcon tubes, and homogenize with $3 \mathrm{ml}$ of $100 \%$ methanol using a Polytron on 

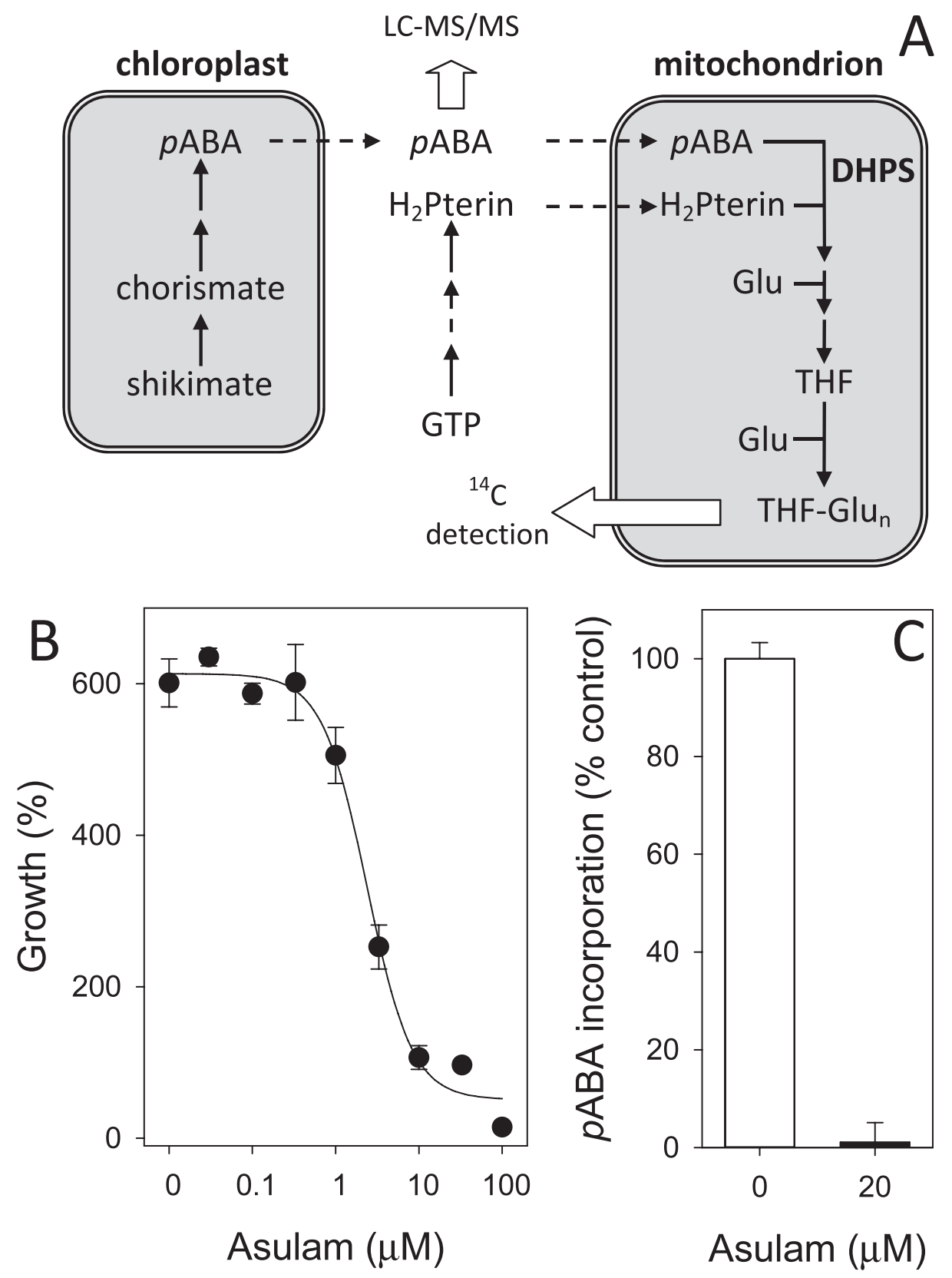

Figure 11. A) Dihydropteroate synthase (DHPS) is a key enzyme in the synthesis of folic acid. B) Dose-response curve of asulam on Lemna paucicostata growth (7 days after treatment). C). Effect of $200 \mu \mathrm{M}$ asulam on DHPS activity as measured by ${ }^{14} \mathrm{C}-p \mathrm{ABA}$ incorporation in folate in Lemna paucicostata.

maximum speed for 2 min. Extract $p \mathrm{ABA}$ at $25 \mathrm{C}$ for $1 \mathrm{~h}$. Centrifuge the homogenates at 5,000 $\times g$ for $5 \mathrm{~min}$. Save the supernatant. Repeat the homogenization of the pellet with an additional $3 \mathrm{ml}$ of methanol, and centrifuge again. Combine the supernatants, and evaporate under a stream of nitrogen at $30 \mathrm{C}$. Dissolve the residue in $0.8 \mathrm{ml}$ of methanol. Add $0.1 \mathrm{ml}$ of $2 \mathrm{M} \mathrm{HCl}$, and hydrolyze at $80 \mathrm{C}$ for $1 \mathrm{~h}$ in an oven.

DHPS Tip 1. Use hydrolysis, which is necessary to free the $p \mathrm{ABA}$ conjugated to the glucose.
Neutralize the solution with $0.1 \mathrm{ml}$ of $2 \mathrm{M}$ $\mathrm{NaOH}$ and mix thoroughly. Filter the solution through a $0.25-\mu \mathrm{m}$ nylon membrane filter (Gelman Acrodisc) before LC-MS/MS analyses.

LC-MS/MS Analysis of pABA. Analyze the extract using a Varian ProStar HPLC system coupled to a Varian model $1200 \mathrm{~L}$ triple quadrupole (Varian). Chromatographic separation of $p \mathrm{ABA}$ is achieved using a $15-\mathrm{cm} \times 2.1-\mathrm{mm}(5 \mu \mathrm{m}, 80 \AA)$ ExtendedC18 column (Agilent). The binary mobile-phase gradient consists of $0.1 \%(\mathrm{v} / \mathrm{v})$ formic acid in water (solvent A) and methanol (solvent B). The flow rate 
is set at $350 \mu \mathrm{lmin}^{-1}$, and the gradient for $p \mathrm{ABA}$ analysis starts at $97 \% \mathrm{~A}$ for $7 \mathrm{~min}$ and is then changed to $2 \% \mathrm{~A}$ in $1 \mathrm{~min}$, maintained at that level for $5 \mathrm{~min}$, and then returned back to the $97 \% \mathrm{~A}$ for reequilibration for $9 \mathrm{~min}$. Identify $p \mathrm{ABA}$ by injecting $10 \mu \mathrm{l}$ of the plant extract while the mass spectrometer is set in positive electrospray ionization mode, and the detector, needle, shield, and capillary voltages are set to $1.8,5.0,0.4$, and $-0.04 \mathrm{kV}$, respectively (Brain et al. 2008). Quantify $p$ ABA levels by monitoring the MS/MS transition mass : ratio $138>77$ at collision energies of $-18.5 \mathrm{~V}$ (Zhang et al. 2005).

Incorporation of ${ }^{14} \mathrm{C}-\mathrm{pABA}$ in Folate. Grow duckweed as described above for $5 \mathrm{~d}$, and then, expose it to different concentrations of asulam or equivalent volume of acetone (control) in the presence of $1 \mu \mathrm{Ci}$ of ${ }^{14} \mathrm{C}-p \mathrm{ABA}$ (American Radiolabeled Chemical, Inc, St. Louis, MO) for $24 \mathrm{~h}$ under continuous light. After the incubation period, remove the growth medium and wash the fronds three times with $3 \mathrm{ml}$ of water. Transfer the fronds to $15-\mathrm{ml}$ Falcon tubes, and homogenize in $2.5 \mathrm{ml}$ of sodium phosphate buffer $(\mathrm{pH} \mathrm{7.0)}$. Add pancreatin $(200 \mathrm{mg})$ and $300 \mu \mathrm{l}$ of $10 \%$ sodium ascorbate to the tubes, and mix thoroughly. Incubate for $2 \mathrm{~h}$ at $37 \mathrm{C}$, and then, heat to $100 \mathrm{C}$ for $20 \mathrm{~min}$. Cool the tubes on ice, and centrifuge at $3,300 \times g$ for 10 min with a SH-3000 rotor (Thermo Fisher Scientific). Save the supernatants in clean tubes. Resuspend the pellets with $2.2 \mathrm{ml}$ of sodium phosphate buffer ( $\mathrm{pH} 7.0$ ), and centrifuge again. Combine the supernatants, and filter through a $0.45-\mu \mathrm{m}$ nylon membrane filter using 5-ml syringes.

Equilibrate EASI-EXTRACT folic acid immunoaffinity columns (r-biopharm AG, Pfungstadt, Germany) with $10 \mathrm{ml}$ of $0.1 \%$ trifluoroacetic acid (TFA) in water by gravity. Load the $5-\mathrm{ml}$ extracts on the columns. Wash each column with $10 \mathrm{ml}$ of wash solution $(0.1 \%$ TFA in water) until no radioactivity elutes. Elute the labeled folate with $2.5 \mathrm{ml}$ of acetonitrile : water $(3: 7 \mathrm{v} / \mathrm{v})$ containing $0.2 \%$ TFA followed by $2.5 \mathrm{ml}$ of wash solution. This should elute all the ${ }^{14} \mathrm{C}$ bound to the affinity column. No other radioactivity elutes with subsequent washings. The radioactivity corresponds to a mixture of folic acid forms, but they are all derived from $p A B A$, so the effect of asulam on DHPS activity is measured as a decrease in radioactive incorporation.

\section{Mitosis: Molecular Target of Herbicide Class $K_{1}$ and $K_{2}$ (WSSA Group 3 and 23)}

Microtubules are dynamic structures composed of heterodimers of $\alpha$-tubulin and $\beta$-tubulin subunits that assemble on one end and disassemble on the other. Plant cell division, elongation, and cell wall formation require the proper functioning of microtubules. A number of structurally diverse herbicides (e.g., dinitroanilines trifluralin, pyridine thiazopyr, substituted amide dithiopyr, and phthalate dimethyl tetrachloroterephthalate) interfere with mitosis through their effects on the assembly of tubulin subunits into functioning microtubules by either binding tubulin directly or interfering with microtubule organizing centers (MTOCs) or microtubule-associated proteins (MAPS) that are involved in the proper assembly, disassembly, and functioning of microtubules (Figure 12A). Most of these herbicides are applied PRE and are often soil incorporated for control of grass weeds in dicotyledonous crops.

Mitotic Index. The most common assay to measure the effect of herbicides on mitosis is the by using the mitotic index. Onion (Allium cepa L.) is the best species for this assay because the root tips stain well and the tissues are easy to process. Germinate seeds for $7 \mathrm{~d}$ in petri dishes on wet filter paper in the presence of the inhibitor at $25 \mathrm{C}$ under a 14-h photoperiod. Prepare test compounds in $\times 100$ stock solutions $(10 \mathrm{mM})$ in acetone or other suitable solvents. Control samples receive the same amount of solvent as those receiving the test compounds.

We typically process our samples for mitotic analysis according to Armbruster et al. (1991). Fix 20 root ends (1-cm sections) in glacial acetic acidabsolute ethanol (1:3 v/v) for $30 \mathrm{~min}$. Hydrolyze the segments in $5 \mathrm{~N} \mathrm{HCl}$ at RT for $1 \mathrm{~h}$, and wash several times with distilled water. Stain the segments with Schiffs reagent for $45 \mathrm{~min}$ in the dark at RT.

The stained meristematic regions are easily identified as purple tips. Transfer the root segments to a drop of $45 \%$ acetic acid on top of a microscope slide using tweezers. Be sure to hold the root segments on the opposite side of the meristems, so that areas of interest aren't damaged. Once on the slide, use a razor blade to cut the tips and remove the rest of the root segments. Carefully place a cover slip over the tips and gently squash by applying slight and constant pressure directly over the tissues. 

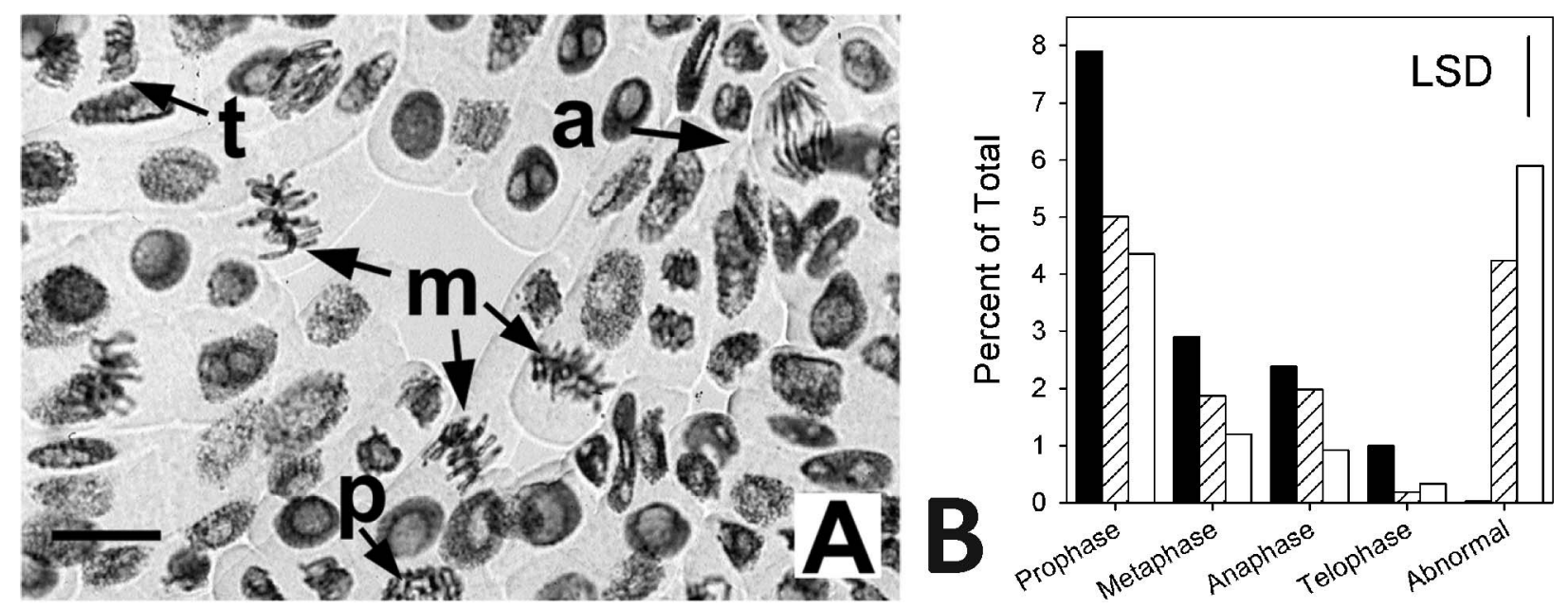

Figure 12. A) Light micrographs of untreated onion root tips. Cells at various stages of mitosis are indicated in $\mathrm{A}$ as $\mathrm{p}=\mathrm{prophase}, \mathrm{m}$ $=$ metaphase, $\mathrm{a}=$ anaphase, and $\mathrm{t}=$ telophase. Bars represent $100 \mu \mathrm{m} . \mathrm{B})$ Distribution of phases of mitosis in control $(\boldsymbol{\square})$, podophyllotoxin $(\equiv)$ and etoposide $(\square)$ treated onion root tips. Data is obtained by counting at least 3000 cells per treatment. Cells with chromosomal arrangements deviating from those associated with normal mitotic phases are classified as abnormal. LSD at $\mathrm{p}=$ 0.05. Images are from Oliva et al. (2002).

Mitosis Tip 1. Apply pressure vertically, directly over the prepared root tips, with no side-to-side or twisting movements to prevent smearing and tearing the cells. We use the eraser end of a pencil to push down.

Seal the edge of the cover slip with nail polish to retard the evaporation of acetic acid.

Calculate the mitotic index by tallying the cells in various stages of mitosis. At least 1,000 cells slide ${ }^{-1}$ and in triplicate $\left(3,000\right.$ cells treatment $\left.^{-1}\right)$ must be counted for the data to be statistically meaningful (Figure 12B). We use an Olympus BX60 microscope (Olympus, Center Valley, PA) and normally follow the description of the various mitotic phases described by Hess (1987) (Figure 12A). Count cells with abnormal mitotic configurations as a separate class.

\section{Very Long-Chain Fatty-Acid Elongases: Molecular Target of Herbicide Class $\mathrm{K}_{3}$ (WSSA Group 15)}

Very long-chain fatty acids (VLCFAs) are used by plants for synthesis of the waxes, cutins, and suberins that are necessary to keep moisture in plant cells and tissues while keeping other substances out. VLCFAs are also present at low concentrations in plasma membranes. A reduction in those compounds in cell membranes leads to both arrested cell division and growth. Symptoms of treatment with inhibitors of VLCFA elongases include decreased growth and leaf curling and twisting. Some crops and weeds are insensitive to this class of herbicides due to rapid detoxification. In some cases, chemicals that induce detoxification in crops (safeners) are applied to protect the crop from potential herbicide injury.

A number of herbicide chemical classes inhibit these enzymes. They include the chloroacetanilides (e.g., alachlor), the tetrazolinone compound fentrazamide, and the oxyacetamides (e.g., flufenacet). The thiocarbamates (e.g., EPTC) are found in the class $\mathrm{N}$ (fatty acid and lipid biosynthesis inhibitors) and should be moved to $\mathrm{K}_{3}$. Inhibitors of VLCFA elongases are generally high use rate, PRE herbicides that kill both broadleaf and grass weeds, but the activity on grasses is generally stronger. Some of the compounds listed under the $\mathrm{K}_{3}$ classification, such as the acetamides napropamide and diphenamid, do not inhibit VLCFA synthesis, and should be reclassified (Yang et al. 2010).

Enzyme Assay. Plant Material. Purchase leek (Allium porrum L.) plants from a local market. Cut off the leaves with a sharp blade, leaving $10 \mathrm{~cm}$ of leaf above each bulb. Plant the bulbs in commercial potting soil, such as Metro-mix 350 (Sun Gro Horticulture, Vancouver, Canada), and place in a growth chamber set at $23 \mathrm{C}$ with a $16-\mathrm{h}$ photoperiod and $300 \mu \mathrm{mol} \mathrm{m}{ }^{-2} \mathrm{~s}^{-1}$ PAR for $14 \mathrm{~d}$. This procedure greatly increases the VLCFA elongases activity recovered after extraction. Peel off the epidermis of the newly grown leaves, flash- 
Table 11. Solutions and reagents for extraction and enzyme assays to measure activity of very long-chain fatty acid elongases. ${ }^{a}$

\begin{tabular}{|c|c|}
\hline Components & Procedure \\
\hline \multicolumn{2}{|l|}{ Extraction buffer $(100 \mathrm{ml})$} \\
\hline $\begin{array}{l}80 \mathrm{mM} \text { HEPES-KOH } \\
2 \mathrm{mM} \text { EDTA }(200 \mu \mathrm{l} \text { of } 1 \mathrm{M} \text { stock }) \\
320 \mathrm{mM} \text { sucrose } \\
10 \mathrm{mM} \text { DTT } \\
0.3 \mathrm{mM} \text { PMSF }\end{array}$ & $\begin{array}{l}\text { Start with } 80 \mathrm{ml} \text { of deionized water; add EDTA, sucrose, DTT, and } \\
\text { buffer; cool on ice; adjust } \mathrm{pH} \text { to } 7.2 \text {; and bring to a final volume } \\
\text { of } 100 \mathrm{ml} \text {. Add PMSF to supernatant immediately before the first } \\
\text { centrifugation. }\end{array}$ \\
\hline \multicolumn{2}{|l|}{ Resuspension buffer $(100 \mathrm{ml})$} \\
\hline $\begin{array}{l}80 \mathrm{mM} \text { HEPES-KOH } \\
1 \mathrm{mM} \text { DTT } \\
15 \% \text { glycerol } \\
1 \mathrm{mM} \mathrm{MgCl}_{2}(33.3 \mu \mathrm{l} \text { of } 3 \mathrm{M} \text { stock })\end{array}$ & $\begin{array}{l}\text { Start with } 80 \mathrm{ml} \text { of water, add DTT and buffer, adjust } \mathrm{pH} \text { to } 7.2 \text { on } \\
\text { ice, and bring to a final volume of } 100 \mathrm{ml} \text {. }\end{array}$ \\
\hline \multicolumn{2}{|l|}{ Assay buffer $(100 \mathrm{ml}$ of $\times 5)$} \\
\hline $\begin{array}{l}400 \mathrm{mM} \text { HEPES-KOH } \\
5 \mathrm{mM} \mathrm{DTT} \\
5 \mathrm{mM} \mathrm{MgCl} 2(166.7 \mu \text { l of } 3 \mathrm{M} \text { stock }) \\
0.25 \% \text { Triton X-100 }\end{array}$ & $\begin{array}{l}\text { Start with } 80 \mathrm{ml} \text { of water; add DTT, } \mathrm{MgCl}_{2} \text {, Triton } \mathrm{X}-100 \text {, and } \\
\text { buffer; adjust } \mathrm{pH} \text { to } 7.2 \text { at } 30 \mathrm{C} \text {; and bring to a final volume of } \\
100 \mathrm{ml} \text {. Store in } 25-\mathrm{ml} \text { aliquot at }-80 \mathrm{C} \text {. }\end{array}$ \\
\hline
\end{tabular}

a Abbreviations: HEPES, 4-(2-hydroxyethyl)-1-piperazineethanesulfonic acid; EDTA, ethylenediaminetetraacetic acid; DTT, dithiothreitol; PMSF, phenylmethanesulfonyl fluoride.

freeze in liquid $\mathrm{N}_{2}$, and store at $-80 \mathrm{C}$ until used. The peels retain activity for more than 1 mo.

Microsomal Preparations. Grind the frozen leek epidermis $(2.5 \mathrm{~g})$ into powder with a cold mortar and pestle in liquid nitrogen, and transfer to a 50 $\mathrm{ml}$ BD Falcon tube. Thaw briefly before adding $30 \mathrm{ml}$ of extraction buffer (Table 11).

VLCFA Tip 1. Thaw the samples before adding the extraction buffer to avoid the formation of ice crystals, which would be detrimental to the isolation of microsomes.

Homogenize the sample with a Polytron (Thermo Fisher Scientific) for 1 to $2 \mathrm{~min}$, filter through two layers of Miracloth lined within two layers of cheesecloth, and centrifuge at $15,000 \times g$ for $20 \mathrm{~min}$ (SS34 rotor, Thermo Fisher Scientific). Collect the supernatant and centrifuge again in an ultracentrifuge at $106,000 \times g$ for $1 \mathrm{~h}(\mathrm{SW} 40 \mathrm{Ti}$ rotor, Beckman Coulter, Inc., Brea, CA). Resuspend the microsomal pellet in $0.5 \mathrm{ml}$ of resuspension buffer. Microsomes are either used immediately or frozen in 100- $\mu \mathrm{l}$ aliquots in liquid $\mathrm{N}_{2}$ and stored at $-80 \mathrm{C}$. The protein content is usually greater than $500 \mu \mathrm{g}$ protein $\mathrm{ml}^{-1}$.

Elongases Assays. Our assay is adapted from the methods of Evenson and Post-Beittenmiller (1995) and Schmalfuß et al. (2000). Mix a 100- $\mu$ l aliquot of microsomal preparation, $200 \mu \mathrm{l}$ of assay buffer
(Table 11), and $200 \mu \mathrm{l}$ of water. Incubate $50-\mu \mathrm{l}$ aliquots of this preparation at RT for $10 \mathrm{~min}$ with either $1 \mu \mathrm{l}$ of acetone or various $\times 100$ concentrations of inhibitors dissolved in acetone in a Teflonlined, screw-top microcentrifuge tube. Prepare the following reagents mixture in a separate microcentrifuge tube: $100 \mu \mathrm{l}$ of $20 \mathrm{mM}$ NADPH, $100 \mu \mathrm{l}$ of $20 \mathrm{mM} \mathrm{NADH}, 100 \mu \mathrm{l}$ of $10 \mathrm{mM}$ ATP, $100 \mu \mathrm{l}$ of $0.25 \mathrm{mM}$ C20-CoA substrate, and $100 \mu \mathrm{l}$ of $1 \mathrm{mM}$ $\left[{ }^{14} \mathrm{C}\right]$ malonyl-CoA. Start the assay by adding $50 \mu \mathrm{l}$ of reagent mixture to the $50 \mu \mathrm{l}$ of microsomal mixture. The assay is carried out at $30 \mathrm{C}$ for $1 \mathrm{~h}$ in a thermomixer set at $500 \mathrm{rpm}$.

VLCFA Tip 2. Use any of various acyl-CoA starter molecules (C16:0-CoA to C22:0-CoA), and determine independent inhibitory values for each step of the elongation.

These experiments can be used to test different concentrations of acyl-CoA. If $\left[{ }^{14} \mathrm{C}\right]$ acyl-CoA starter units are used, then different concentrations of malonyl-CoA can be tested. Finally, VLCFA elongases inhibitors are tested at concentrations ranging from 0.1 to $1,000 \mu \mathrm{M}$.

Stop the reactions with $50 \mu \mathrm{l}$ of $11 \mathrm{~N} \mathrm{KOH} \mathrm{(60} \mathrm{g}$ per $100 \mathrm{ml}$ ). Saponify for $1 \mathrm{~h}$ at $80 \mathrm{C}$ in a thermomixer set at $500 \mathrm{rpm}$ and subsequently place on ice. Acidify the assay mixture with $100 \mu \mathrm{l}$ cold $12 \mathrm{~N}$ $\mathrm{HCl}$. Extract twice with $1 \mathrm{ml}$ of cold acetone : $n$ hexane $(4: 3 \mathrm{v} / \mathrm{v})$. Collect the top $500 \mu \mathrm{l}$ of the organic 
phases, and combine in clean screw-cap tubes. Wash the pooled hexane fractions with $100 \mu \mathrm{l}$ of $4 \mathrm{~N} \mathrm{HCl}$. Transfer an 800- $\mu$ l aliquot of the hexane fraction to a clean glass test tube, and dry under $\mathrm{N}_{2}$ flow.

VLCFA Tip 3. Ensure the extract is very dry. Any water present in the tube will quench the methylation step and prevent the formation of methyl esters.

Dissolve the residue with dry hexane, transfer to a 12-ml screw-cap, Kimax, glass tube, and mix with 100 $\mu \mathrm{l}$ of dry methanol and $300 \mu \mathrm{l}$ of dry, $3 \mathrm{~N}$ methanolic $\mathrm{HCl}$. Seal the tube, and heat for $1 \mathrm{~h}$ at $80 \mathrm{C}$. Cool the tubes to RT, add $3 \mathrm{ml}$ of $0.88 \% \mathrm{NaCl}$ and $3 \mathrm{ml}$ of hexane, and vortex. Collect $2.5 \mathrm{ml}$ of the hexane layer containing the methylated fatty acids, transfer to a clean glass test tube, and dry under $\mathrm{N}_{2}$ flow.

Dissolve the methyl esters in $200 \mu \mathrm{l}$ of methanol, and apply to a C18 TLC plate (TLC Silica gel 60 RP18, EMD Bioscience). We routinely use a TLC plate spotter (Analtech, Inc. Newark, DE) to obtain uniform spots. Develop the plate in acetonitrile : tetrahydrofuran $(85: 15 \mathrm{v} / \mathrm{v})$. Quantify TLC products on a PhosphorImager (Molecular Dynamics, Sunnyvale, CA) (Figure 13C). Calculate the amount of VLCFA synthesized by adding an aliquot of the hexane to $6 \mathrm{ml}$ of Ultima Gold scintillation cocktail (Packard Instrument Co., Meriden, CT) and counting by liquid scintillation. The background radioactivity extracted in the blank is subtracted from the test samples.

VLCFA Tip 4. Perform dose-response curves carefully with identical incubation periods because herbicides inhibiting VLCFA elongases are irreversible inhibitors and inhibition increases over time. The concentration resulting in 50\% inhibition is time dependent, and must be reported as an apparent $\mathrm{IC}_{50}$ value ( $\mathrm{IC}_{50}$ app).

VLCFA Tip 5. Perform this assay with etiolated leek seedlings (Lessire et al. 1985a,b), if desired, but the overall activity is generally lower than it is when actively growing leek plants are used (Evenson and Post-Beittenmiller 1995). We have also used etiolated barley shoots successfully.

\section{Cellulose Biosynthesis: Molecular Target of Herbicide Class L (WSSA Group 20, 21, 28)}

A number of herbicides, such as isoxaben and dichlobenil, strongly inhibit incorporation of glucose into the cellulose-containing cell-wall fraction of plants causing a great reduction in plant growth (Figure 14A and B). Isoxaben and dichlobenil are inhibitors of cellulose biosynthesis, and their mechanism of action involves the incorporation of glucose into the cellulose-rich, acid-insoluble fraction of isolated cell walls (Corio-Costet et al. 1991; Heim et al. 1990) (Figure 14C). It was initially thought that isoxaben inhibited an early step in the pathway, whereas dichlobenil targeted cellulose synthase (Sabba and Vaughn 1999). It now appears that both herbicides have a direct action on cellulose synthase. Indeed, the Arabidopsis thaliana mutant IXR1, which encodes for $A t C E S A 3$, one of the isoforms of cellulose synthase, imparts resistance to isoxaben. This provides strong evidence that this herbicide also inhibits cellulose synthase (Scheible et al. 2001). Isoxaben is a much stronger inhibitor of glucose incorporation into cellulose than dichlobenil (Heim et al. 1990). Inhibition of cellulose synthase hinders in vivo formation of cellulose microfibrils. Lack of cellulose in young cells results in swelling of root tips and cessation of growth, as if they were treated with a tubulin-binding herbicide.

Assay. Cellulose biosynthesis is extremely complex, and there is no efficient protocol to measure the activity of cellulose synthase in vitro. However, both isoxaben and dichlobenil inhibit incorporation of glucose in the cellulose-rich, acid-insoluble fraction of plant tissues. Their activity can be measured using the same assay, realizing that the method is not specific for a single enzymatic step but a reflection of the over carbon flow into cellulose (Heim et al. 1990).

Place four duckweed fronds in nonpyrogenic, polystyrene, sterile, six-well plates (CoStar 3506, Corning Inc.) containing $5 \mathrm{ml}$ of sterile, fullstrength Hoagland media supplemented with FeEDTA (Table 12). Select only colonies with "Mickey Mouse" appearances: where the developing daughter fronds are significantly smaller and still attached to the maternal frond. Maintain the plates in an incubator (model CU-36L, Percival Scientific) under continuous white light $\left(94 \mu \mathrm{mol} \mathrm{m} \mathrm{m}^{-2} \mathrm{~s}^{-1}\right)$ (Bajsa et al. 2011a).

For the cellulose-labeling experiments, grow the colonies as described above for $3 \mathrm{~d}$. At that time, each well receives either $50 \mu \mathrm{l}$ of acetone (control) or the appropriate concentration of dichlobenil or isoxaben dissolved in acetone. Incubate the plates in the dark for $12 \mathrm{~h}$. Add $0.1 \mu \mathrm{Ci}$ of uniformly radiolabeled $\left[{ }^{14} \mathrm{C}\right]$ glucose $\left(1 \mathrm{mCi} \mathrm{ml}{ }^{-1}\right.$ in sterile 

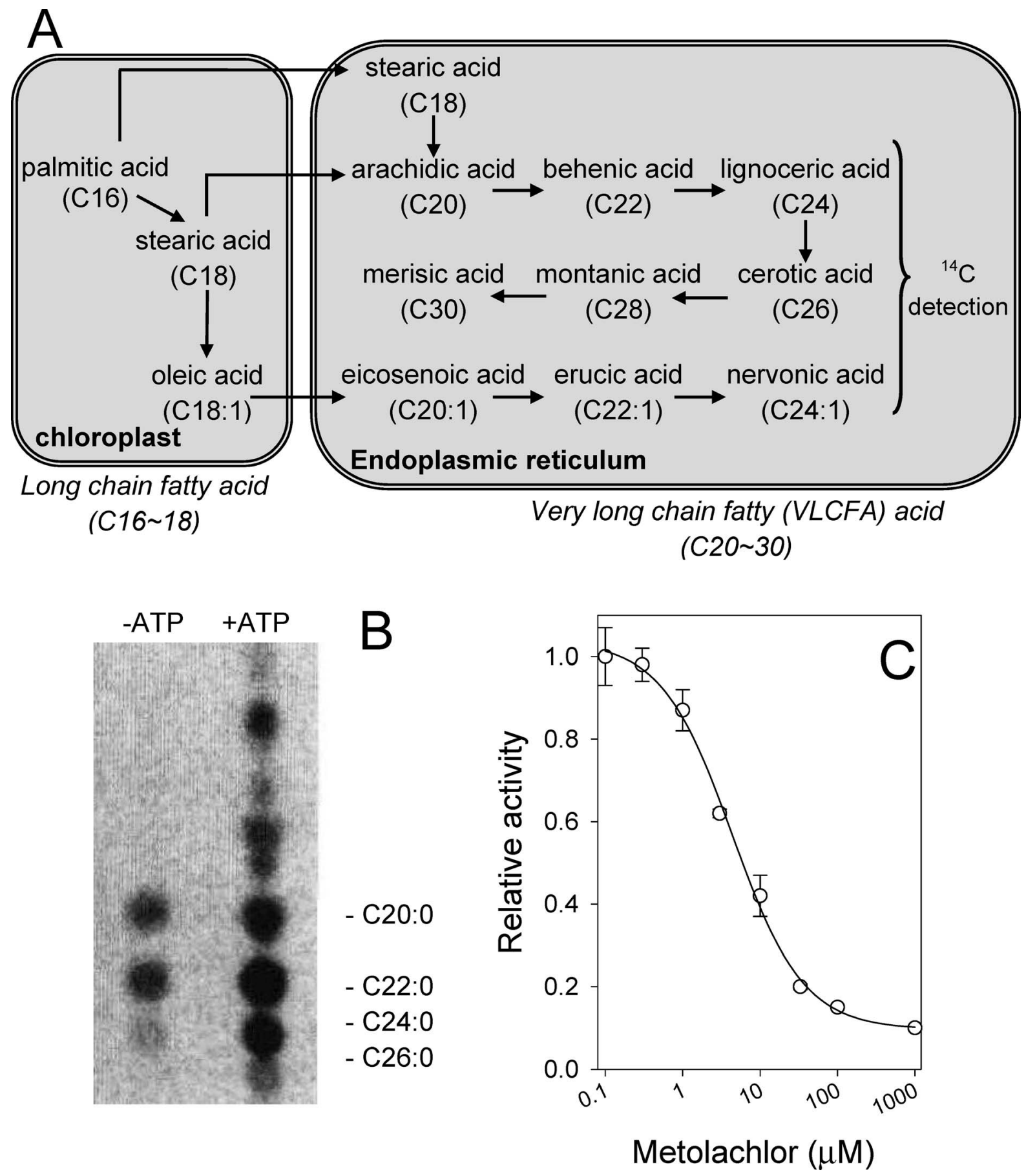

Figure 13. A) Very long chain fatty acid (VLCFA) elongases catalyze the elongation of acyl-CoA with 18 or more carbons. B) VLCFA profile obtained by incubating leek microsomal fraction with stearoyl-CoA and $\left[{ }^{14} \mathrm{C}\right]-\mathrm{malonyl}-\mathrm{CoA}$. C). Effect of $S$-metolachlor on VLCFA elongases activity in leek microsomal fraction.

water; American Radiolabeled Chemical) to each well. Incubate the fronds for $24 \mathrm{~h}$ under continuous light as before. After the incubation period, wash the fronds with $3 \mathrm{ml}$ water three times, remove from the plates using a spatula, and transfer to preweighed 12-ml, screw-cap, Kimax glass tubes. Estimate the FW of the sample by weighing the tubes after the fronds are transferred to the tubes. Add $0.5 \mathrm{ml}$ of water, $1 \mathrm{ml}$ of concentrated acetic acid, and $4 \mathrm{ml}$ of concentrated nitric acid to the tubes.

Cellulose Synthase Tip 1. Use glacial acetic acid : concentrated nitric acid : water in a ratio of $8: 1: 2 \mathrm{v} / \mathrm{v} / \mathrm{v}$ as the final hydrolysis acetic-nitric acid reagent (Crampton and Maynard 1938). 

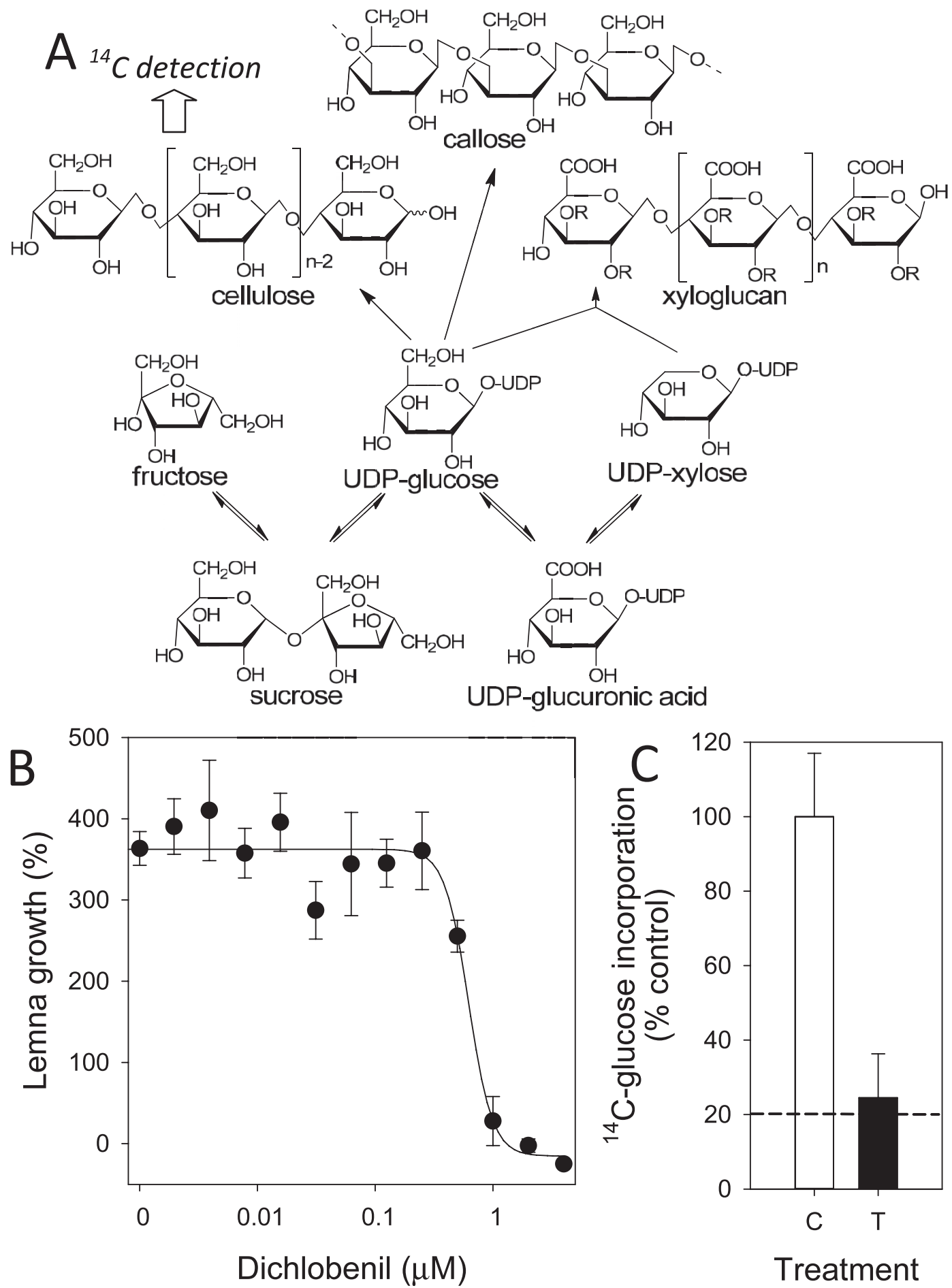

Figure 14. A) Simplified biochemical pathways involved in cell wall synthesis. The assay consists of incorporating ${ }^{14} \mathrm{C}$-glucose into cell wall and isolating the cellulose-rich acid-insoluble fraction and quantifying it following biological oxidation and liquid-scintillation counting. B) Typical dose-response curve of dichlobenil on the growth of Lemna paucicostata. C) Effect of dichlobenil on incorporation of ${ }^{14} \mathrm{C}$-glucose into cellulose-rich acid-insoluble fraction. $\mathrm{C}=$ control, $\mathrm{T}=10 \mu \mathrm{M}$ dichlobenil, dotted line marks the maximum inhibition measured.

Hydrolyze the samples for $2 \mathrm{~h}$ in a boiling-water bath. This creates a reflux inside the tubes that destroys lignin, hemicellulose, and xylosans, as well as all proteins, DNA, and lipids. Be sure to maintain the water level in the bath to match the level of the reagent in the tubes. Afterward, let cool to RT. Collect the remaining acid-insoluble cell wall material by vacuum filtration using a 25-ml, disposable filter funnel fitted with 25-mm removable Whatman GF/C glass microfiber filters (GE Healthcare Life Sciences).

$$
\text { Dayan et al.: Biochemical markers and enzyme assays }
$$


Table 12. Preparation of growth medium and ${ }^{14} \mathrm{C}$-glucose label. ${ }^{\mathrm{a}}$

Components

Procedure

Lemna growth medium (1 L)

Hoagland modified basal salts mixture

(PhytoTechnology Laboratories, Shawnee Mission, KS)

Fe-EDTA stock $\left(18.355 \mathrm{~g}^{-1}\right)$ filter-sterilized

${ }^{14}$ C-glucose

$\left[{ }^{14} \mathrm{C}(\mathrm{U})\right]$-D-glucose, 250 to $360 \mathrm{mCi} \mathrm{mmol}^{-1}$

(ARC-0122G). Solution consists of $1 \mathrm{mCi} \mathrm{ml}^{-1}$

in sterile water (American Radiolabeled Chemicals)

Add $1.63 \mathrm{~g}$ of Hoagland salts to $1 \mathrm{~L}$ of deionized water, and supplement with $1 \mathrm{ml}$ of Fe-EDTA stock. Adjust $\mathrm{pH}$ to 5.5 at room temperature with $1 \mathrm{~N} \mathrm{NaOH}$. Filter-sterilize with $0.22-\mu \mathrm{m}$ PES filters (Corning) by vacuum filtration.

a Abbreviation: EDTA, ethylenediaminetetraacetic acid; PES, polyethersulfone.

Cellulose Tip 2. Use a disposable filter funnel fitted with a removable, glass, microfiber filter to simplify the handling of the radioactive material. Other filters can be used (Heim et al. 1990).

Add $10 \mathrm{ml}$ of water to the funnel, and as the vacuum is initiated, transfer the hydrolysis mixture from the glass tube to the funnel. Wash the tube with $10 \mathrm{ml}$ of water, four times, adding the liquid to the funnel to remove any remaining soluble radiolabeled products. Instead of relying on a biological oxidizer to release the ${ }^{14} \mathrm{C}$ trapped in the cellulose, we transfer the filters directly into glass scintillation vials and measure the radioactivity with a liquid scintillation counter.

Moreover, it is usually not possible to completely inhibit glucose incorporation into the residue extracted by this method. It is not known whether the extract contains cellulosic polymers derived from herbicideinsensitive pathways or is contaminated with acidstable noncellulosic components (Heim et al. 1990).

Cellulose Tip 3. Know that, clearly, this assay is limited in its specificity for cellulose synthesis inhibitors. It is likely that many toxins that are either generally cytotoxic or that disrupt carbon metabolism may have an effect on this assay.

\section{Oxidative Phosphorylation Uncoupler: Molecular Target of Herbicide Class M (WSSA Group 24)}

Compounds that uncouple oxidative phosphorylation (e.g., dinoterb) cause very rapid membrane disruption (Senseman 2007). However, those types of inhibitors are no longer used commercially, so little attention will be paid to assays used to study those herbicides. Dinoterb has multifaceted mechanisms of action that involve the inhibition of photosynthesis, uncoupling oxidative phosphorylations, and interference with respiratory oxygen consumption (Belbachir et al. 1980). Therefore, the electrolyte leakage and chlorophyll fluorescence assays described under general protocols are good diagnostic tools for such compounds (Dayan and Watson 2011; Dayan and Zaccaro 2012).

\section{Fatty Acid and Lipid Biosynthesis: Molecular Target of Herbicide Class $\mathbf{N}$ (WSSA Group 8, 16)}

Many of the herbicides classified in this category (e.g., ethofumesate, EPTC, diallate, and triallate) are oxidized in planta to sulfoxides and act as inhibitors of VLCFA (molecular target of herbicide class $\mathrm{K}_{3}$ ) (Abulnaja et al. 1992; Matthes et al. 1998). Assays relevant to this mode of action have been discussed above. However, the modes of action of all the compounds in the $N$ class are not known. A number of physiological responses have been reported, such as effects on the biosynthesis of fatty acid, proteins, isoprenoids (e.g., gibberellins), and flavonoids (e.g., anthocyanins)(Senseman 2007). No assays are described in this review for the modes of action of these inhibitors.

\section{Synthetic Auxins and Auxin Transport Inhibitors: Molecular Target of Herbicide Classes $O$ and P (WSSA Group 4, 19)}

These classes of inhibitors include some important herbicides, such as 2,4-D and dicamba. The first synthetic herbicides were compounds that mimicked high doses of auxin (indole acetic acid), a natural plant hormone required for cell elongation and plant growth and development. There are no 

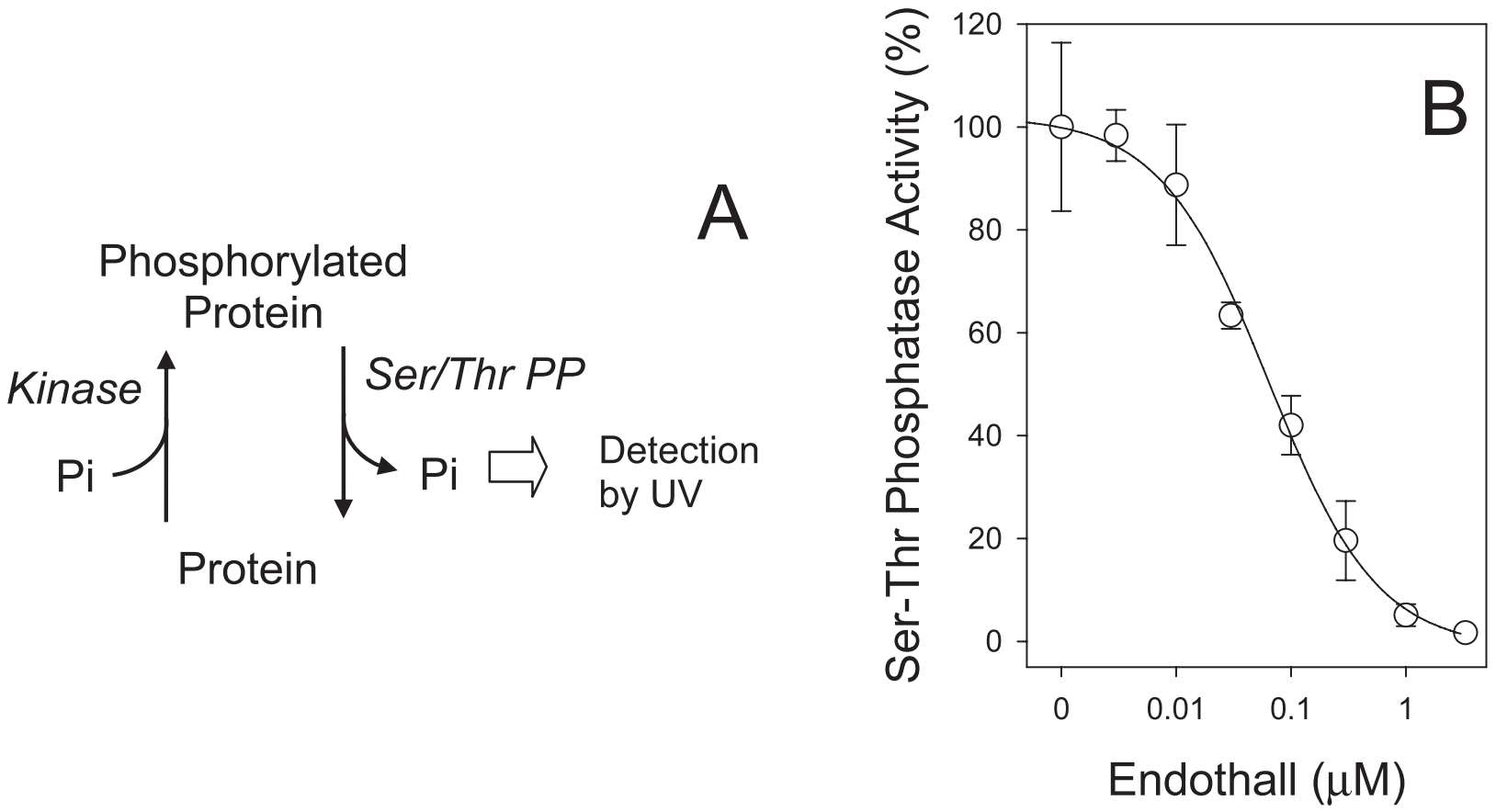

Figure 15. A) Regulation of protein activity by phosphorylation/dephosphorylation by protein kinases and phosphatases. B) Inhibition of Ser-Thr protein phosphatases by endothall in Lemna paucicostata crude extract.

known bioassays that easily measure their biochemical effects on their respective target sites. So, no methods are described in this review for herbicides of the molecular target of herbicide classes $\mathrm{O}$ and $\mathrm{P}$.

\section{Serine/Threonine Protein Phosphatases: Molecular Target of Herbicide Class Q}

We propose to create a new herbicide target site classification called $\mathrm{Q}$ to encompass the modes of action of endothall. Serine/threonine protein phosphatases (Ser/Thr PPs) and their kinases counterpart regulate many plant cellular processes, including cell division, fertilization, and general metabolism (Shenolikar 1994), by altering the phosphorylation/dephosphorylation of regulatory proteins (Figure 15A) (Goda et al. 2004; Holmberg and Lee 1976; MacDonald et al. 2002; Skogerboe and Getsinger 2002; Tresch et al. 2011). Although the activity of protein kinases is relatively easily assayed by measuring the incorporation of radioactive phosphate into proteins or specific peptide substrates, the activity of protein phosphatases is more difficult to measure. Protein phosphatases are generally classified into two main groups: (1) the tyrosine protein phosphatases cleave phosphates from proteins containing phosphotyrosine, whereas (2) the serine/threonine protein phosphatates remove phosphate groups from proteins containing phosphoserine or phosphothreonine.
Ser/Thr PPs are the herbicidal target site of endothall and its natural structural analog, cantharidin (Bajsa et al. 2011a,b). The herbicidal activity of endothall was discovered in 1951. However, the elucidation of the mechanism of action took many years, in part, because inhibition of Ser/Thr PPs has such profound and wideranging physiological effects on plants.

Ser/Thr PP Enzyme Assay. There is no quick diagnostic marker for inhibition of Ser/Thr PP, but the activity of this enzyme is measured relatively easily in crude plant extracts as described below (Figure 15B). Ser/Thr PP activity is measured using a Ser/Thr PP assay system kit (V2460, Promega, Madison, WI) in half-area, 96-well plates (included with the kit, or Costar 3690, Corning Inc.). This assay is based on a sensitive coupled assay to measure the amount of pyrophosphate cleaved from the enzyme-specific synthesized phosphopeptide substrate, Arg-Arg-Alap-Thr-Val-Ala. This peptide is suitable for measuring the activity of several Ser/Thr phosphatases (i.e., 2A, 2B, and 2C) while not reacting with protein phosphatase 1 .

Grind $1 \mathrm{~g}$ of frozen plant material in a mortar and pestle with liquid $\mathrm{N}_{2}$, and homogenize in $3 \mathrm{ml}$ of cold extraction buffer (Table 13). Add $30 \mu \mathrm{l}$ of a plant protease inhibitor cocktail (P9599 SigmaAldrich) to the suspension, and centrifuge at 17,500 $\times g$ for $30 \mathrm{~min}$. Load $250 \mu \mathrm{l}$ of cell-free extract over a prepared Sephadex G25 desalting spin column 
Table 13. Solutions and reagents for extraction and enzyme assays to measure serine/threonine protein phosphatase (PP) activity. ${ }^{a}$

Components Procedure

Ser/Thr PP extraction buffer $(200 \mathrm{ml}$ of $\times 5)$

125 mM Tris-HCl, $\mathrm{pH} 7.5$

$5 \mathrm{mM}$ benzamidine

$0.25 \%$ Tween 20

$0.5 \% \beta$-mercaptoethanol

$5 \mathrm{mM}$ EDTA (2.0 $\mathrm{ml}$ of $500 \mathrm{mM}$ EDTA)

Assay buffer $(100 \mathrm{ml}$ of $\times 5)$

$250 \mathrm{mM}$ imidazole. $\mathrm{pH} 7.2$

$1 \mathrm{mM}$ EGTA

$0.1 \% \beta$-mercaptoethanol

$0.5 \mathrm{mg} / \mathrm{ml}$ bovine serum albumin
Start with $160 \mathrm{ml}$ of water, add components, cool on ice, adjust $\mathrm{pH}$ to 7.5 , and bring to a final volume of $200 \mathrm{ml}$. Store at $-20 \mathrm{C}$ in $50 \mathrm{ml}$ aliquots. Dilute $50 \mathrm{ml}$ of stock to $250 \mathrm{ml}$ final volume before use.

Start with $80 \mathrm{ml}$ of water, add components, cool on ice, adjust $\mathrm{pH}$ to 7.7 , and bring to a final volume of $100 \mathrm{ml}$. Store at $-20 \mathrm{C}$ in $25-$ $\mathrm{ml}$ aliquots. Dilute $25 \mathrm{ml}$ of stock to $125 \mathrm{ml}$ final volume before use.

${ }^{\text {a }}$ Abbreviation: Tris, tris(hydroxymethyl)methylamine; EDTA, ethylenediaminetetraacetic acid; EGTA, ethylene glycol tetraacetic acid.

$(10 \mathrm{ml}$ of the slurry included in the kit, as per kit directions) and centrifuge for $5 \mathrm{~min}$ at $600 \times g$ to remove contaminating free phosphate. Determine the total soluble protein concentration by the Bradford method (BioRad 500-0006).

Add the following, in order, to the well plate: protein extract, $10 \mu \mathrm{l}$ of $\times 5$ assay buffer, and phosphate-free water (supplied with the kit), so that the final reaction volume is $50 \mu \mathrm{l}$ with $5 \mu \mathrm{l}$ of inhibitor. Mix the components by briefly centrifuging the plate. Incubate the mixtures with predetermined concentrations of inhibitors at RT for $15 \mathrm{~min}$. Reaction is started with the addition of the phosphopeptide substrate. Incubate for $30 \mathrm{~min}$, then stop the reaction by adding an equal volume $(50 \mu \mathrm{l})$ of molybdate dye/additive mixture (supplied with the kit) Incubate at RT for an additional $15 \mathrm{~min}$ for color development. Measure the absorbance of a molybdate : malachite green phosphate complex with a microplate reader at $600 \mathrm{~nm}$.

\section{Parting Comments}

Measuring the activity of herbicide target sites is a broad topic, and our aim has been to provide practical information to perform those assays based on our collective personal experiences. We hope these protocols will also be useful for anyone interested in studying herbicide-resistance mechanisms, such as those that involve point mutations, deletions, or overexpression that affect the behavior of these proteins and enzymes.

In contrast to the large number of primary metabolic pathways whose inhibition is lethal, there is a surprisingly small number (about 20) of molecular target sites for commercial herbicides. In many cases (e.g., inhibitors of nucleic acid synthesis or glycolysis), the potential for mammalian toxicity may be too high. In other cases, plants may overcome inhibition of a particular enzyme by having redundant enzymes (isozymes) or alternate pathways that circumvent the effect of the herbicide. Therefore, this review highlights the uniqueness of certain target sites within each pathway affected by commercial herbicides. We would like to point out that, in many cases (e.g., GS, PPO, and ALS inhibitors), the effectiveness of the herbicides is not necessarily due to a reduction of carbon flow in the inhibited pathway, but rather to the catastrophic consequences of the accumulation of toxic products (ammonia, Proto, and 2-ketobutyrate, respectively).

Although molecular biology and chemical genetic approaches are powerful tools for discovery of molecular target sites of new herbicides and for determination of whether a particular target site is viable, none of the target sites identified by these techniques have resulted in the discovery of a new commercial herbicide mode of action.

Finally, this comprehensive review revealed HRAC herbicide classifications that need to be updated. Classification $\mathrm{F}_{3}$ should be limited to clomazone and its target site deoxyxylulose-5-phosphate synthase. Aclonifen should be moved to E because it is a PPO inhibitor. Amitrole inhibits phytyl synthesis and should be classified in a new category $\mathrm{F}_{4}$. Many of the compounds in $\mathrm{N}$ are known inhibitors of VLCFA elongases and should be moved to $K_{3}$. We also propose that endothall be moved to a new classification Q for its inhibition of Ser/Thr PPs.

\section{Literature Cited}

Abulnaja KO, Tighe CR, Harwood JL (1992) Inhibition of fatty acid elongation provides a basis for the action of the herbicide, 
ethofumesate, on surface wax formation. Phytochemistry 3:1155-1159

Anderson RL (1990) Tolerance of safflower (Carthamus tinctorius), corn (Zea mays), and proso millet (Panicum miliaceum) to clomazone. Weed Technol 4:606-611

Armbruster BL, Molin WT, Bugg MW (1991) Effects of the herbicide dithiopyr on cell division in wheat root tips. Pestic. Biochem. Physiol 39:110-120

Arnon DI (1949) Copper enzymes in isolated chloroplasts: polyphenoloxidase in Beta vulgaris. Plant Physiol 24:1-15

Bajsa J, Pan Z, Dayan FE, Owens DK, Duke SO (2011a) Validation of serine-threonine protein phosphatase as the herbicide target site of endothall. Pestic Biochem Physiol 102:38-44

Bajsa J, Pan Z, Duke SO (2011b) Transcriptional responses to cantharidin, a protein phosphatase inhibitor, in Arabidopsis thaliana reveal the involvement of multiple signal transduction pathways. Physiol Plant 143:188-205

Bedhomme M, Hoffmann M, McCarthy EA, Gambonnet B, Moran RG, Rébeillé F, Ravanel S (2005) Folate metabolism in plants. J Biol Chem 280:34823-34831

Belbachir O, Matringe M, Tissut M, Chevallier D (1980) Physiological actions of dinoterb, a phenol derivative, 1: physiological effects on the whole plant and on tissue fragments of pea. Pestic Biochem Physiol 14:303-308

Böger P, Sandmann G (1993) Target Assays for Modern Herbicides and Related Phytotoxic Compounds. Boca Raton, FL: Lewis. Pp. 320

Bradford MM (1976) A rapid and sensitive method for the quantitation of microgram quantities of protein utilizing the principle of protein dye binding. Anal Biochem 72:248-254

Brain RA, Ramirez AJ, Fulton BA, Chambliss CK, Brooks BW (2008) Herbicidal effects of sulfamethoxazole in Lemna gibba: using $p$-aminobenzoic acid as a biomarker of effect. Environ Sci Technol 42:8968-8970

Camara B (1993) Plant phytoene synthase complex: component enzymes, immunology, and biogenesis. Pages 352-365 in Packer L, ed. Methods in Enzymology. Volume 214: Carotenoids Part B: Metabolism, Genetics, and Biosynthesis. San Diego: Academic

Chahed K, Oudin A, Guivarc'h N, Hamdi S, Chénieux J-C, Rideau M, Clastre M (2000) 1-Deoxy-D-xylulose 5-phosphate synthase from periwinkle: cDNA identification and induced gene expression in terpenoid indole alkaloid-producing cells. Plant Physiol Biochem 38:559-566

Corio-Costet M-F, Agnese MD, Scalla R (1991) Effects of isoxaben on sensitive and tolerant plant cell cultures, II: cellular alterations and inhibition of the synthesis of acidinsoluble cell wall material. Pestic Biochem Physiol 40:246254

Crampton EW, Maynard LA (1938) The relationship of cellulose and lignin content to the nutritive value of animal feeds. J Nutr 15:383-395

Dayan FE, Duke SO (2003) Herbicides: Carotenoid biosynthesis inhibitors. Pages 744-749 in Plimmer JR, Gammon DW, Ragsdale NN, eds. Encyclopedia of Agrochemicals. New York: J. Wiley

Dayan FE, Duke SO (2010) Protoporphyrinogen oxidaseinhibiting herbicides. Pages 1733-1751 in Krieger R, Doull J, Hodgson E, Maibach H, Reiter L, Ritter L, Ross J, Slikker WJ, Van Hemmen J, eds. Haye's Handbook of Pesticide Toxicology. San Diego: Academic
Dayan FE, Watson SB (2011) Plant cell membrane as a marker for light-dependent and light-independent herbicide mechanisms of action. Pestic Biochem Physiol 101:182-190

Dayan FE, Daga PR, Duke SO, Lee RM, Tranel PJ, Doerksen RJ (2010a) Biochemical and structural consequences of a glycine deletion in the $\alpha-8$ helix of protoporphyrinogen oxidase. Biochim Biophys Acta 1804:1548-1556

Dayan FE, Duke SO, Grossmann K (2010b) Herbicides as probes in plant biology. Weed Sci 58:340-350

Dayan FE, Duke SO, Reddy KN, Hamper BC, Leschinsky KL (1997a) Effects of isoxazole herbicides on protoporphyrinogen oxidase and porphyrin physiology. J Agric Food Chem 45:967-975

Dayan FE, Duke SO, Sauldubois A, Singh N, McCurdy C, Cantrell CL (2007) p-Hydroxyphenylpyruvate dioxygenase is a herbicidal target site for B-triketones from Leptospermum scoparium. Phytochemistry 68:2004-2014

Dayan FE, Duke SO, Weete JD, Hancock HG (1997b) Selectivity and mode of action of carfentrazone-ethyl, a novel phenyl triazolinone herbicide. Pestic Sci 51:65-73

Dayan FE, Weete JD, Duke SO, Hancock HG (1997c) Soybean (Glycine max) cultivar differences in response to sulfentrazone. Weed Sci 45:634-641

Dayan FE, Zaccaro MLdM (2012) Chlorophyll fluorescence as a marker for herbicide mechanisms of action. Pestic Biochem Physiol 102:189-197

Délye C, Zhang X-Q, Chalopin C, Michel S, Powles SB (2003) An isoleucine residue within the carboxyl-transferase domain of multidomain acetyl-coenzyme A carboxylase is a major determinant of sensitivity to aryloxyphenoxypropionate but not to cyclohexanedione inhibitors. Plant Physiol 132: $1716-1723$

Devine MD, Duke SO, Fedtke C (1993) Physiology of Herbicide Action. Englewood Cliffs, NJ: Prentice-Hall, $441 \mathrm{p}$ Duke SO, Dayan FE (2011) Bioactivity of herbicides. Pages 23-35 in Murray MY, ed. Comprehensive Biotechnology. Amsterdam: Elsevier

Duke SO, Kenyon WH (1993) Peroxidizing activity determined by cellular leakage. Pages 61-66 in Böger P, Sandmann G, eds. Target Assays for Modern Herbicides and Related Compounds. Boca Raton, FL: Lewis

Evenson KJ, Post-Beittenmiller D (1995) Fatty acid-elongating activity in rapidly expanding leek epidermis. Plant Physiol 109:707-716

Fedtke C, Duke SO (2005) Herbicides. Pages 247-330 in Hock B, Elstner EF, eds. Plant Toxicology. New York: Marcel Dekker

Fellermeier M, Sagner S, Spiteller P, Spiteller M, Zenk MH (2003) Early steps of deoxyxylulose phosphate pathway in chromoplasts of higher plants. Phytochemistry 64:199-207

Ferhatoglu Y, Barrett M (2006) Studies of clomazone mode of action. Pestic Biochem Physiol 85:7-14

Ferhatoglu Y, Avdiushko S, Barrett M (2005) The basis for the safening of clomazone by phorate insecticide in cotton and inhibitors of cytochrome P450s. Pestic Biochem Physiol 81:59-70

Forlani G (2000) Purification and properties of a cytosolic glutamine synthetase expressed in Nicotiana plumbaginifolia cultured cells. Plant Physiol Biochem 38:201-207

Garcia I, Rodgers M, Pepin R, Hsieh T-Z, Matringe M (1999) Characterization and subcellular compartmentation of recombinant 4-hydroxyphenylpyruvate dioxygenase from Arabidopsis in transgenic tobacco. Plant Physiol 119:1507-1516 
Gerwick BC, Mireles LC Eilers RJ (1993) Rapid diagnosis of ALS/AHAS-resistant weeds. Weed Technol 7:519-524

Goda H, Sawa S, Asami T, Fujioka S, Shimada Y, Yoshida S (2004) Comprehensive comparison of auxin-regulated and brassinosteroid-regulated genes in Arabidopsis. Plant Physiol 134:1555-1573

Heim DR, Skomp FR, Tschabold ED, Larrinua IM (1990) Isoxaben inhibits the synthesis of acid insoluble cell wall materials In Arabidopsis thaliana Plant Physiol, 93:695-700

Hess FD (1987) Herbicide effects on the cell cycle of meristematic plant cells. Rev Weed Sci 3:183-203

Hiscox JD, Israelstam GF (1979) A method for the extraction of chlorophyll from leaf tissue without maceration. Can J Bot 57:1332-1334

Holmberg DJ, Lee GF (1976) Effects and persistence of endothall in the aquatic environment. J Water Pollut Control Fed 48:2738-2746

Huang M, Gibson F (1970) Biosynthesis of 4-aminobenzoate in Escherichia coli. J Bacteriol 102:767-773

Ireland RJ, Lea PJ (1999) The enzymes of glutamine, glutamate, asparagine, and aspartate metabolism. Pages 49-110 in Singh BK, ed. Plant Amino Acids. New York: Marcel Dekker

Jacobs JM, Jacobs NJ (1987) Oxidation of protoporphyrinogen to protoporphyrin, a step in chlorophyll and haem synthesis. Biochem J 244:219-224

Kilinc Ö, Reynaud S, Perez L, Tissut M, Ravanel P (2009) Physiological and biochemical modes of action of the diphenylether aclonifen. Pestic Biochem Physiol 93:65-71

Lessire R, Juguelin H, Moreau P, Cassagne C (1985a) Elongation of acyl-CoAs by microsomes from etiolated leek seedlings. Phytochemistry 24:1187-1192

Lessire R, Juguelin H, Moreau P, Cassagne C (1985b) Nature of the reaction product of $\left[1-{ }^{14} \mathrm{C}\right]$ stearoyl-CoA elongation by etiolated leek seedlings microsomes. Arch Biochem Biophys 239:260-269

Li J, Smeda RJ, Dayan FE (2004) Physiological basis for resistance to diphenyl ether herbicides in common waterhemp (Amaranthus rudis). Weed Sci 52:333-338

Li Y-Z, Wang C-Y (2005) 2-Aminobutyric acid as a chemical marker for the detection of sulfonylurea herbicides. Weed Technol 19:176-182

Lichtenthaler HK (2010) The non-mevalonate DOXP/MEP (deoxyxylulose 5-phosphate/methylerythritol 4-phosphate) pathway of chloroplast isoprenoid and pigment biosynthesis. Pages 95-118 in Rebeiz CA, Benning C, Bohnert HJ, Daniell H, Hoober JK, Lichtenthaler HK, Portis AR, Tripathy BC, eds. The Chloroplast: Basics and Applications. Advances in Photosynthesis and Respiration. Volume 31. Dordrecht, the Netherlands: Springer Science+Business

Lichtenthaler HK, Rohmer M, Schwender J (1997) Two independent biochemical pathways for isopentenyl diphosphate and isoprenoid biosynthesis in higher plants. Physiol Plant 101:643-652

Loper BR, Cobb WT, Anderson KA (2002) Chemical marker for ALS-inhibitor herbicides: 2-aminobutyric acid proportional in sub-lethal applications. J Agric Food Chem 50:26012606

Lydon J, Duke SO (1999) Inhibitors of glutamine synthesis. Pages 445-464 in Singh BK, ed. Plant Amino Acids. New York: Marcel Dekker

MacDonald GE, Querns R, Shilling DG, McDonald SK, Bewick TA (2002) Activity of endothall on hydrilla. J Aquat Plant Manag 40:68-71
Manderscheid R (1993) Irreversible inhibition of glutamine synthetase from higher plants by the herbicide phosphinothricin. Pages 103-107 in Böger P, Sandmann G, eds. Target Assays for Modern Herbicides and Related Phytotoxic Compounds. Boca Raton, FL: Lewis.

Matringe M, Scalla R (1988) Effects of acifluorfen-methyl on cucumber cotyledons: porphyrin accumulation. Pestic Biochem Physiol 32:164-172

Matthes B, Schmalfuß J, Böger P (1998) Chloroacetamide mode of action, II: Inhibition of very long chain fatty acid synthesis in higher plants. Z Naturforsch 53c:1004-1011

Michel A, Arias RS, Scheffler BE, Duke SO, Netherland M, Dayan FE (2004) Somatic mutation-mediated evolution of herbicide resistance in the nonindigenous invasive plant hydrilla (Hydrilla verticillata). Mol Ecol 13:3229-3237

Misawa N, Satomi Y, Kondo K, Yokoyama A, Kajiwara S, Saito T, Ohtani T, Miki W (1995) Structure and functional analysis of a marine bacterial carotenoid biosynthesis gene cluster and astaxanthin biosynthetic pathway proposed at the gene level. J Bacteriol 177:6575-6584

Mohan C (2003) Buffers: A Guide for the Preparation and Use of Buffers in Biological Systems. Darmstadt, Germany: EMD Biosciences, Merck. 32 p www.emdmillipore.com/ showBrochure/200708.063.ProNet.pdf. Accessed July 152013

Molin WT, Khan RA (1995) Microbioassays to determine the activity of membrane disrupter herbicides. Pestic Biochem Physiol 53:172-179

Mueller C, Schwender J, Zeidler J, Lichtenthaler HK (2000) Properties and inhibition of the first two enzymes of the nonmevalonate pathway of isoprenoid biosynthesis. Biochem Soc Trans 28:792-793

Oliva A, Moraes RM, Watson SB, Duke SO, Dayan FE (2002) Aryltetralin lignans inhibit plant growth by affecting the formation of mitotic microtubular organizing centers. Pestic Biochem Physiol 72:45-54

Sabba RP, Vaughn KC (1999) Herbicides that inhibit cellulose biosynthesis. Weed Sci 47:757-763

Salas RA, Dayan FE, Pan Z, Watson SB, Dickson JW, Scott RC, Burgos NR (2012) EPSPS gene amplification in glyphosateresistant Italian ryegrass (Lolium perenne ssp. multiflorum) from Arkansas. Pest Manag Sci 68:1223-1230

Sandmann G (1993) In vitro assay system for phytoene desaturase inhibitors with isolated thylakoids. Pages 15-20 in Böger P, Sandmann G, eds. Target Assays for Modern Herbicides and Related Phytotoxic Compounds. Boca Raton, FL: Lewis

Sandmann G, Böger P (1983) Comparison of the bleaching activity of norflurazon and oxyfluorfen. Weed Sci 31:338-341

Saski Y, Nagano Y (2004) Plant acetyl-CoA carboxylase: structure, biosynthesis, regulation, and gene manipulation for plant breeding. Biosci Biotechnol Biochem 68:1175-1184

Scheible WR, Eshed R, Richmond T, Delmer D, Somerville C (2001) Modifications of cellulose synthase confer resistance to isoxaben and thiazolidinone herbicides in Arabidopsis Ixr1 mutants. Proc Nat Acad Sci U S A 98:10079-10084

Schmalfuß J, Matthes B, Knuth K, Böger P (2000) Inhibition of acyl-CoA elongation by chloroacetamide herbicides in microsomes from leek seedlings. Pestic Biochem Physiol 67:2535

Schwender J, Mueller C, Zeidler J, Lichtenthaler HK (1999) Cloning and heterologous expression of a cDNA encoding 1deoxy-D-xylulose-5-phosphate reductoisomerase of Arabidopsis thaliana. FEBS Lett 455:140-144 
Seefeldt SS, Fuerst EP, Gealy DR, Shukla A, Irzyk GP, Devine MD (1996) Mechanisms of resistance to diclofop of two wild oat (Avena fatua) biotypes from the Willamette Valley of Oregon. Weed Sci 44:776-781

Sellers BA, Smeda RJ, Li J (2004) Glutamine synthetase activity and ammonium accumulation is influenced by time of glufosinate application. Pestic Biochem Physiol 78:9-20

Senseman SA (2007) Herbicide Handbook. 9th ed. Lawrence, KS: Weed Science Society of America. 458 p

Shaner DL, Nadler-Hassar T, Henry WB, Koger CH (2005) A rapid in vivo shikimate accumulation assay with excised leaf discs. Weed Sci 53:769-774

Shenolikar S (1994) Protein serine/threonine phosphatasesnew avenues for cell regulation. Ann Rev Cell Biol 10:55-86

Skogerboe JG, Getsinger KD (2002) Endothall species selectivity evaluation: northern latitude aquatic plant community. J Aquat Plant Manag 40:1-5

Sprecher SL, Netherland MD, Stewart AB (1998) Phytoene and carotene response of aquatic plants to fluridone under laboratory conditions. J Aquat Plant Manag 36:111-120

Tresch S, Schmotz J, Grossmann K (2011) Probing mode of action in plant cell cycle by the herbicide endothall, a protein phosphatase inhibitor. Pestic Biochem Physiol 99:86-95

Veerasekaran P, Kirkwood RC, Parnell EW (1981a) Studies of the mechanism of action of asulam in plants, part I: antagonistic interaction of asulam and 4-aminobenzoic acid. Pestic Sci 12:325-329

Veerasekaran P, Kirkwood RC, Parnell EW (1981b) Studies of the mechanism of action of asulam in plants, part II: effect of asulam on the biosynthesis of folic acid. Pestic Sci 12:330-338

Westerfeld WW (1945) A colorimetric determination of blood acetoin. J Biol Chem 161:495-502

Yang X, Guschina IA, Hurst S, Wood S, Langford M, Hawkes T, Harwood JL (2010) The action of herbicides on fatty acid biosynthesis and elongation in barley and cucumber. Pest Manag Sci 66:794-800

Yu Q, Friesen LJS, Zhang X-Q, Powles SB (2003) Tolerance to acetolactate synthase and acetyl-coenzyme A carboxylase inhibiting herbicides in Vulpia bromoides is conferred by two co-existing resistance mechanisms. Pestic Biochem Physiol 78:21-30

Zhang G-F, Mortier KA, Storozhenko S, De Steene J, Van Der Straeten D, Lambert WE (2005) Free and total paraaminobenzoic acid analysis in plants with high-performance liquid chromatography/tandem mass spectrometry. Rapid Commun Mass Spectrom 19:963-969

Received April 22, 2013, and approved September 20, 2013. 